\title{
Habituelle Dispositionen von Lehrkräften zur Unterstützung sozial benachteiligter Schüler*innen: Ergebnisse der Einzelfallanalysen
}

In diesem Kapitel wird zunächst der Auswahlprozess von vier Einzelfällen aus dem Gesamtsample (Abschnitt 3.1) und die Darstellungsweise der empirischen Ergebnisse (Abschnitt 3.2) beschrieben, um anschließend zu dem Hauptteil dieser Arbeit zu gelangen: In detaillierter Weise werden die unterschiedlichen Perspektiven vorgestellt, die die befragten Lehrkräfte auf ihre Schüler*innen- und Elternschaft einnehmen (Abschnitt 3.3. bis Abschnitt 3.6). Dieses Kapitel zielt auf die Entschlüsselung handlungsleitender Orientierungen hinsichtlich der Unterstützung sozial benachteiligter Schüler*innen. Hierbei wird der Einzelfall entlang der zuvor umrissenen modifizierten Analysedimensionen betrachtet.

\subsection{Auswahl der Eckfälle}

Im Sinne des minimalen Kontrastes beschränkt sich die Auswahl der Eckfälle zunächst auf Lehrkräfte, die am Anfang ihrer beruflichen Laufbahn stehen und zum ersten Mal die alleinige Verantwortung für ihr pädagogisches Handeln übernehmen. Der Berufseinstieg ist Lamy (2015) zufolge eine Zeit, in der sich die neuen Lehrkräfte erstmals eigenständig mit beruflichen Anforderungen wie z. B. die Planung und Durchführung des Unterrichts, die Klassenführung und die Gestaltung von Lehrer*innen-Schüler*innen-Beziehungen befassen. Grundsätzlich müssen sie auf Basis der ihnen zur Verfügung stehenden Ressourcen und im Kontext der spezifischen schulischen Rahmenbedingungen versuchen, ihren Bildungs- und Erziehungsauftrag so gut wie möglich zu bewältigen und die eigene berufliche Entwicklung zu gestalten. Die neuen beruflichen Anforderungen ergeben sich ebenso im erweiterten schulischen Umfeld und in der Interaktion mit den neuen Arbeitskolleg*innen, Eltern und Vorgesetzten. Im Grundsatz treffen die Lehrkräfte auf eine Schulkultur mit mehr oder weniger bereits existenten

S. Rutter, Sozioanalyse in der pädagogischen Arbeit, Bildung und Gesellschaft, https://doi.org/10.1007/978-3-658-32065-2_3 
sozialen Normen und Regeln und stehen zum Interviewzeitpunkt vor der Herausforderung, ihren Platz in diesem Umfeld zu finden. Die Berufseinstiegsphase wird demnach als Handlungs- und Möglichkeitsraum für die Herausbildung einer beruflichen Identität verstanden. Vor diesem Hintergrund scheint die Berufseinstiegsphase besonders aufschlussreich für die vorliegende Untersuchung $\mathrm{zu}$ sein, da sich die befragten Lehrkräfte wahrscheinlich zum Interviewzeitpunkt vergleichsweise intensiv mit ihrer Rolle als Lehrperson auseinandersetzen und dabei relativ wenige schulische und unterrichtliche Handlungsroutinen entwickelt haben. So können habituelle Orientierungen bezüglich der Unterstützung sozial benachteiligter Schüler*innen analysiert werden, die noch verhältnismäßig wenig von berufsbiografischen Prozessen beeinflusst sind.

Der theoretische Zweck der vorliegenden Untersuchung besteht darin, die Bedeutung von Habitus und Milieu für die pädagogische Arbeit aufzuzeigen und dadurch Passungsverhältnisse zwischen Lehrkräften und Schüler*innen zu konkretisieren. Dabei ließen die Auswertungen in der SKILL-Studie bereits habitusund milieuspezifische Orientierungen annehmen. Wie in den folgenden Kapiteln noch ausführlich dargelegt wird, zeigen Frau Akay, Frau Antonova, Frau Kamper und Herrn Jansen besonders kontrastive Grundmuster bezüglich der Unterstützung sozial benachteiligter und bisher im Bildungssystem ausgegrenzter Schüler*innen, sodass sie für eine intensivere Analyse ausgewählt wurden. Diese vier Eckfälle können im Hinblick auf die forschungsleitenden Fragestellungen ein breites Spektrum an Sensibilität für die unterschiedlichen Lernvoraussetzungen, Potenziale und Bedürfnisse der Schüler*innen abbilden. So eröffnen die vier Lehrkräfte auf unterschiedliche Art und Weise Anknüpfungsmöglichkeiten und Bezüge für ganz bestimmte sozial benachteiligte Schüler*innengruppen.

Hinzu kommt, dass diese vier Lehrkräfte an unterschiedlichen Schulstandorten tätig sind. Wenngleich der Schulstandort kein Hauptkriterium sein sollte, um sich mit der Vielfalt der Schüler*innen und Bildungsungleichheit eingehend zu beschäftigen, stellt die Schulumgebung eine wichtige Einflussgröße für die Auseinandersetzung mit Differenzmerkmalen dar (vgl. Fölker \& Hertel, 2015; Jäger, 2014).

\subsection{Darstellungsweise der empirischen Ergebnisse}

Die Fallrekonstruktionen wurden ausführlich und in Abfolge an die zuvor dargelegten Interpretationsschritte analysiert: Zuerst wurden für jedes Interview thematische Verläufe erstellt, im Rahmen dessen Ober- und Unterthemen identifiziert wurden. Anschließend wurden die gruppierten Interviewpassagen in eigene 
Worte gefasst. Als nächstes wurde jedes Interview als einzelner Fall reflektierend interpretiert. Innerhalb dieses Auswertungsschrittes wurden zu Beginn die Textsorten differenziert. In die reflektierende Interpretation wurden auch Argumentationen und Bewertungen einbezogen, da die Rekonstruktion von Dispositionen zur Unterstützung sozial benachteiligter Schüler*innen auch durch nicht narrative Textteile sinnvoll erscheint. Wie bereits in den methodologischen Grundlagen der dokumentarischen Methode bemerkt wurde, erscheint es gerade, wenn es um die Institution Schule geht, bedeutsam, das handlungsleitende implizite Wissen in einem systematischen Bezug zu den normativen Erwartungsstrukturen und institutionalisierten Wissensbestände zu setzen (Bohnsack, 2014b). So wurden für jede Fallanalyse die Orientierungsschemata und Orientierungsrahmen herausgearbeitet. Die reflektierende Interpretation geht dabei von Anfang an vergleichend vor, um die Regelhaftigkeit von Erfahrungen und den in dieser Regelhaftigkeit liegenden dokumentarischen Sinngehalt herauszuarbeiten (Nohl, 2017). Diese aufwändige Vorgehensweise kann bei der Darstellung der Ergebnisse nicht abgebildet werden, sodass in diesem Kapitel die formulierenden, reflektierenden und komparativen Analysen in einem Text verarbeitet werden. Die folgenden Fallanalysen beinhalten demnach interpretative Verdichtungen, die einen Gesamteindruck von der jeweiligen Lehrperson vermitteln.

\subsection{Frau Akay}

Das Gespräch mit Frau Akay fand ungestört in den Räumlichkeiten der offenen Ganztagsgrundschule statt und dauerte knapp 50 Minuten. Die Grundschule liegt im urbanen Zentrum des westlichen Ruhrgebiets, das als strukturschwache Region gilt. So ist die Gesamtarbeitslosenquote des regionalen Großraums eine der höchsten der westdeutschen Bundesländer. Insgesamt ist die wirtschaftliche Lage der Kommune, die für die Grundschule verantwortlich ist, angespannt. Hinzu kommt eine relativ hohe Bevölkerungsdichte, wobei das Privathaushaltseinkommen eher niedrig ist und überdurchschnittlich viele Einwohner*innen öffentliche Sozialleistungen beziehen. Typisch für Großstädte in Nordrhein-Westfalen ist der hohe und wachsende Anteil an Einwohner*innen mit Migrationshintergrund mit auffallend schwachen sozioökonomischen Indikatoren. So übersteigt auch in der zuständigen Kommune die Arbeitslosenquote unter den Einwohner*innen mit Migrationshintergrund deutlich die der Einwohner*innen ohne Migrationshintergrund. Zudem beziehen die Einwohner*innen mit Migrationshintergrund im Vergleich zu den 
Einwohner*innen ohne Migrationshintergrund häufiger Leistungen zur Grundsicherung ${ }^{1}$.

Die Grundschule umfasst insgesamt ca. 300 Schüler*innen sowie ein Team von annähernd 35 Lehrkräften, Sonderpädagog*innen, Sozialpädagog*innen und Heilpädagog*innen. Frau Akay ist zum Zeitpunkt des Interviews Mitte 30 Jahre alt und seit ungefähr einem Jahr als Sonderpädagogin an der Grundschule tätig. Sie verfügt über eine abgeschlossene Ausbildung im medizinischen Bereich sowie ein Studium der Heilpädagogik. Vor ihrer Beschäftigung an der Grundschule arbeitete sie mehrere Jahre in der Kinder- und Jugendpsychiatrie.

\title{
3.3.1 Konstruktion der Schüler*innen- und Elternklientel
}

Frau Akay legt im Kontext ihres Selbstverständnisses von besonderen Lebenslagen am Beispiel von geflüchteten Schüler*innen dar, dass die persönliche Lebenssituation auch die Lernvoraussetzungen beeinflusst:

\begin{abstract}
zum Beispiel äh mit den-die Flüchtlingskinder die haben ja auch diese Sprachbarbarriere wir nennen sie dann auch äh Seiteneinsteiger die kommen dann an die Schule und äh haben natürlich Startschwierigkeiten erst mal weil sie die Sprache nicht verstehen und äh diese Kinder bekommen dann besonderen ähm (.) Förderunterricht (.) Deutsch DaZ ne-nennt sich das (.) Deutsch als Zweitsprache ähm (.) ja (.) die profitieren natürlich sehr davon die Kinder ne die lernen innerhalb von wenigen Wochen Monaten Deutsch (Fallstudie 1, Interview Frau Akay, Z. 54-75)
\end{abstract}

An den Ausführungen zu geflüchteten Kindern wird zunächst ersichtlich, dass deutschsprachliche Kompetenzen in der Wahrnehmung von Frau Akay von zentraler Bedeutung für die pädagogische Arbeit sind. So beschreibt sie eingangs, dass geflüchtete Kinder „Sprachbarrieren“ (Z. 55) und „natürlich Startschwierigkeiten“ (Z. 63) aufgrund geringer bzw. nicht vorhandener Deutschkenntnisse aufweisen. Der von Frau Akay angeführte Begriff „Seiteneinsteiger“ (Z. 59) dokumentiert hierbei eine schulische Unterscheidungspraxis einer scheinbar spezifischen Schüler*innengruppe, die mit Bewertungen und Problemzuschreibungen (,,haben natürlich Startschwierigkeiten erstmal weil sie die Sprache nicht verstehen“, Z. 63 f.) einhergeht. Keine bzw. geringe deutsche Sprachkompetenzen zu

\footnotetext{
${ }^{1}$ Um die Anonymität der befragten Lehrkräfte zu wahren, werden die Ausführungen zur regionalen Struktur des Schulstandortes nicht mit konkreten Zahlen belegt, sondern lediglich in groben Zügen beschrieben.
} 
Beginn der Aufnahme in das deutsche Schulsystem sind somit Frau Akays negativer Gegenhorizont von optimalen Lernvoraussetzungen. Unmittelbar anschließend schildert Frau Akay, dass nicht vorhandene oder geringe deutschsprachliche Kompetenzen durch den speziellen Förderunterricht „Deutsch als Zweitsprache“ (Z. 72) zügig kompensiert werden können und die Kinder innerhalb kurzer Zeit Deutsch lernen. DaZ-Unterricht als Deutschförderungsmaßnahme stellt entsprechend das Enaktierungspotenzial dar, um die nicht vorhandenen oder geringen Deutschkenntnisse der geflüchteten Kinder in der Schule auszugleichen. Kern der Orientierung ist, dass keine oder geringe Deutschkenntnisse von geflüchteten Kindern durch schulische Interventionen bearbeitbar und handhabbar sind.

Die Gruppe der geflüchteten Kinder ohne bzw. mit geringen Deutschkenntnissen grenzt Frau Akay von der Gruppe der Schüler*innen mit Migrationshintergrund ab:

dann haben wir auch die Kinder mit Migrationshintergrund ähm (.) die sprechen sehr gut Deutsch die sind-die meisten sind hier geboren und aufgewachsen ähm die Eltern sind glaube ich schon die zweite Generation müssten die zweite und dritte Generation sein ähm sind auch gut integriert hier (.) führen sich gut ein (.) ich habe auch den Eindruck dass sie sich sehr wohl fühlen hier an der Schule weil sie äh weil die-der Migrationshintergrund auch mit aufgegriffen wird (.) lesen zum Beispiel auch Bücher in-in mehreren Sprachen in zwei Sprachen bei den türkischen Kindern sind es dann tü-Bücher in Deutsch (.) und schr-Deutsch und Türkisch ähm das sind halt so Sachen die stärken die Kinder glaube ich auch die freuen sich dann auch ähm dass es so aufgegriffen wird und so positiv wertgeschätzt wird (Fallstudie 1, Interview Frau Akay, Z. 80-100)

Zunächst gibt Frau Akay an, dass Kinder mit Migrationshintergrund über ,sehr gut[e]“ (Z. 82) Deutschkenntnisse verfügen, da sie überwiegend in Deutschland geboren und aufgewachsen seien und die Eltern bereits in der zweiten oder dritten Generation in Deutschland leben. Die Konstruktion der Gruppe der Schüler*innen mit Migrationshintergrund erfolgt demnach anhand der Merkmale Sprachstand in der deutschen Sprache sowie eigene Migrationserfahrung. So verfügen Frau Akay zufolge Kinder mit Migrationshintergrund im Gegensatz zu geflüchteten Kindern über ausreichend deutschsprachliche Kompetenzen und haben keine eigene Migrationserfahrung. Aus der Perspektive von Frau Akay sind diese Kinder aufgrund ihrer Lebenssituation ,auch gut integriert hier (.) führen sich gut ein“ (Z. 83). Die Formulierungen ,integrieren' und ,sich einführen' implizieren hierbei eine An- bzw. Einpassungsleistung der Kinder durch und in die Schule. Vergleichbar mit der Sichtweise auf geflüchtete Schüler*innen erscheinen die deutschsprachlichen Kompetenzen als Voraussetzung für schulische Integration 
und stellen somit Frau Akays positiven Horizont des Schüler*innenbildes von Kindern mit Migrationshintergrund dar. Nach ihrer Ansicht gelingen die schulische Integration und das Stärken des schulischen Wohlbefindens von Kindern mit Migrationshintergrund - ebenso wie die Förderung der deutschen Sprache von geflüchteten Schüler*innen - durch pädagogisches Handeln. Hierbei betont sie die Mehr- bzw. Zweisprachigkeit der Kinder und die entsprechende Ressourcenorientierung der Schule. Das Eingehen auf den Migrationshintergrund, beispielsweise durch Lesen von Büchern in mehreren Sprachen, stellt das Enaktierungspotenzial für die schulische Integration dieser Kinder dar. In der Wortwahl ,so Sachen die stärken die Kinder“ (Z. 99), dokumentiert sich darüber hinaus das Erfordernis bzw. die Motivation, die Ressourcen von Kindern mit Migrationshintergrund zu steigern. Die pädagogische Unterstützung erfolgt hierbei auf einer Beziehungsebene (,die freuen sich dann auch ähm dass es so aufgegriffen wird und so positiv wertgeschätzt wird“, Z. 99 f.). Kern der Orientierung im Hinblick auf Kinder mit Migrationshintergrund ist demzufolge die potenzielle pädagogische Einflussnahme auf die schulische Integration und das Wohlbefinden von Kindern mit Migrationshintergrund.

Der übergeordnete Orientierungsrahmen beider Passagen zu den besonderen Lebenssituationen von Kindern mit Fluchterfahrung und Kindern mit Migrationshintergrund und deren Auswirkungen auf das Lernen ist davon geprägt, dass mit der Migration verbundene Herausforderungen, wie die Förderung deutschsprachlicher Kompetenzen und schulische Integration, pädagogisch bearbeitbar bzw. beeinflussbar sind.

Problematisch für das Lernumfeld sind aus der Sicht von Frau Akay hingegen „erschwerte Familienverhältnisse“ (Z. 22). Unter erschwerte Familienverhältnisse subsumiert sie Eltern,

die sich äh zum Teil nicht so wirklich ähm dahinter stellen hinter die-hinter die Schule also hinter-hinter dem Kind dass sie dann die Hausaufgaben kontrollieren oder ähm dass die Kinder zu Hause Unterstützung oder Förderung kriegen (Fallstudie 1, Interview Frau Akay, Z. 26-33)

Die Ausführungen legen nahe, dass die familiale Unterstützung bedeutsam für die pädagogische Arbeit ist. Insbesondere die schulfachliche Hilfe der Eltern erscheint als Enaktierungspotenzial für das pädagogisches Handeln. Eltern, die ihr Kind in schulischen Angelegenheiten nicht unterstützen können, stellen in dieser Perspektive den negativen Gegenhorizont des Elternbildes dar. Ebenfalls im Zusammenhang von den Auswirkungen erschwerter Familienverhältnisse 
auf schulisches Lernen schildert Frau Akay die starke Hilfsbedürftigkeit der Schüler*innen:

und ähm allgemein sind unsere Kinder die Kinder die hier auf die Schule gehen sehr ähm (.) ja die brauchen immer viel mehr Hilfe sei es im Unterricht sei es in den lebenspraktischen Dingen wie ähm Schule binden Jacke anziehen ähm mansch-meine-meine Schulmaterialien organisieren Hefte immer ordentlich haben und dabeihaben und die Fächer in-in den Klassen immer ne da-da brauchen die immer zusätzlich mehr viel mehr Hilfe auch im Unterricht auch wenn es darum geht Dinge zu erklären (.) das ist dann nicht so wie in anderen Schulen dass man das dann einmal erklärt und die Kinder verstehen das hier muss man das immer wieder man (.) muss die immer wieder dran erinnern und diese Rituale (.) äh hehelfen ihnen sehr gut eigentlich die Rituale die haben ja ganz feste Strukturen ganz feste Rituale (.) und diese Rituale äh Strukturen bieten den Kindern Sicherheit und Orientierung (.) und sie fühlen sich einfach ähm (.) sicherer dann im Alltag (Fallstudie 1, Interview Frau Akay, Z. 453-485)

Der generell große Unterstützungsbedarf der Schüler*innen bezieht sich aus der Perspektive von Frau Akay nicht nur auf den Unterricht, sondern darüber hinaus auf das Erlernen basaler Fähigkeiten (,,die brauchen immer viel mehr Hilfe sei es im Unterricht sei es in den lebenspraktischen Dingen wie ähm Schule binden Jacke anziehen“, Z. 454 ff.) Die genannten Phänomene münden in einer starken Hilfsbedürftigkeit der Schüler*innen, die es als Lehrkraft permanent zu bearbeiten gilt. Auffallend ist hierbei die Reihenfolge der Merkmale, in der Frau Akay den Unterstützungsbedarf beschreibt, so thematisiert sie zunächst Aspekte der Förderung im Hinblick auf die praktische Lebensführung und erst dann schulfachliches Lernen. Das Erlernen basaler Fähigkeiten erscheint in dieser Abfolge als grundlegende Voraussetzung für die schulische Bildung. Dem negativen Gegenhorizont der allgemein starken Hilfsbedürftigkeit der Schüler*innen aus erschwerten Familienverhältnissen stellt Frau Akay das positive Ideal der schnellen Auffassungsgabe der Schüler*innen anderer Schulen gegenüber. Sowohl der Vergleich zwischen den eigenen und den fremden Schüler*innen als auch die mehrfache Wiederholung des Adverbs ,immer' bekräftigen ihre Konstruktion einer außergewöhnlich unterstützungsbedürftigen Schüler*innenschaft. Aus der Wahrnehmung der starken Hilfsbedürftigkeit der Schüler*innen resultieren vor allem Praktiken des Ausgleichs von erschwerten Familienverhältnissen durch schulisch festgelegte Strukturen und Ritualen, welche zugleich das Enaktierungspotenzial für die schulische Bearbeitbarkeit der vermeintlich familialbedingten Defizite bereitstellen. Darüber hinaus erscheint implizit als negativer Gegenhorizont, dass Kinder aus erschwerten Familienverhältnissen nicht nur keine schulbildungsbezogene Unterstützung und Förderung in der Familie erfahren, sondern überdies Regeln und 
Tagesstrukturen im Elternhaus fehlen. Die Schule stellt hierbei in pädagogischer Hinsicht den positiven Horizont zu den erschwerten Familienverhältnissen dar. Kern der Orientierung ist, dass sich der familiale Hintergrund der Kinder hinderlich auf die Lernvoraussetzungen und das Lernpotenzial auswirkt und eine Herausforderung für die pädagogische Arbeit darstellt.

\subsubsection{Berufsbezogenes Selbstkonzept}

Im Hinblick auf ihre Anstellung als Sonderpädagogin berichtet Frau Akay, dass die Schule Probleme hatte, Förderschullehrkräfte zu finden. Grund für die geringe Anzahl von Bewerbungen ist Frau Akays Einschätzung nach ein hoher Anteil an Kindern mit Migrationshintergrund und Kindern mit Fluchterfahrung in dem Einzugsgebiet der Schule:

ich denke das liegt daran dass ähm dass hier ähm ein Stadtteil ist wo der Migrantenanteil sehr hoch ist wo einfach auch viel Arbeit ist (.) wir haben hier auch die äh (.) meisten Flüchtlingskinder an der Schule die aus äh (.) den verschiedenen Län-wir haben Wirtschaftsflüchtlinge wie zum Beispiel die aus den äh ähm jugoslawischen Raum Balkangebieten wir haben aber auch Kriegsflüchtlinge die aus Syrien kommen (.) ist natürlich eine anstrengende Arbeit hier ne äh mit den (.) Kindern mit den Familien auch die die Sprache ist natürlich auch ein Problem (.) dass man äh sich mit vielen Eltern auch nicht richtig verständigen kann äh ich denke dass es einfach viele abschreckt viele Lehrer dass die einfach sagen ähm nee da gehe ich nicht hin da ist viel zu tun oder das ist so anstrengend es ist wirklich anstrengend es ist eine sehr anstrengende Arbeit aber man kriegt von den Kindern auch immer viel zurück das ist das Schöne (Fallstudie 1, Interview Frau Akay, Z. 848-881)

Bemerkenswert ist, dass Frau Akay in ihrer Argumentation sowohl in quantitativer Hinsicht (,viel Arbeit“, Z. 849) als auch in qualitativer Hinsicht (,anstrengende Arbeit“", Z. 865) die besonderen Arbeitsbedingungen an Schulen mit einem hohen Anteil an Kindern mit Migrationshintergrund und Kindern mit Fluchterfahrung differenziert. Als „Problem“ (Z. 866) markiert Frau Akay die sprachliche Verständigung mit den Eltern mit Migrationshintergrund. Auffällig ist zudem die Unterscheidung unterschiedlicher Motive für Flucht („Wirtschaftsflüchtlinge“ (Z. 855) und „Kriegsflüchtlinge“ (Z. 864)), die als Hinweis auf einen öffentlich geführten Diskurs über legitime und illegitime Gründe, das Herkunftsland zu verlassen, gedeutet werden kann. Der Annahme, dass ein sehr hoher Anteil an Kindern mit Migrationshintergrund und Kindern mit Fluchterfahrung mit übermäßiger Arbeit und Anstrengung für Lehrkräfte verbunden und dies Grund für die geringe Anzahl von Bewerbungen sei, setzt Frau Akay entgegen, dass „man 
von den Kindern auch immer viel zurück[kriegt]“" (Z. 876 f.). Im Kontext der Arbeit an einer Schule in sozialräumlich deprivierter Lage entfaltet Frau Akay nachfolgend ihren Orientierungsrahmen:

ich ähm bin auch vor einem Jahr hierher gezogen und äh kannte die Gegend hier nicht so gut ich wusste aber dass [Stadtteil X] ein sozialer Brennpunkt ist (.) das wusste ich ich war hier zwar noch nie vorher aber (.) hatte das gehört und die Schulleiterin hatte mich auch darauf äh hatte mich auch vorgewarnt hatte mir auch gesagt was da auf mich zukommt (.) aber da ich auch selber einen Migrationshintergrund habe und ähm (.) das alles selber auch schon mal erlebt habe (.) ich bin zwar hier geboren und aufgewachsen aber ich (.) kam auch aus einem sozial ähm sozialen Brennpunkt aus einer Gegend früher als-als ich noch selber Kind war und ich kann mich vielleicht auch ein Stück weit so hinein fühlen hinein versetzen das war für mich nicht ganz so fremd obwohl ich den Stadtteil nicht kenne das war schon irgendwie war schon was Vertrautes (.) alleine schon durch die ganzen türkischen ähm Mitbürger hier ich bin selber auch türkischer Herkunft und alleine das-da deswegen schon ähm war da schon noch was Vertrautes das merkt man aber auch in der Arbeit mit den Eltern dass die (.) sehr viel Vertrauen in meiner Person haben obwohl sie mich noch nicht so lange kennen obwohl die anderen Lehrer viel länger hier sind und dass sogar äh Eltern mit deren Kinder ich eigentlich überhaupt ga-gar nichts zu tun habe äh unterrichtstechnisch die dann auch zu mir kommen und äh wenn sie Probleme haben oder Schwierigkeiten haben und dann mich drauf ansprechen vielleicht weil ich die Sprache auch spreche ich denke das liegt daran (Fallstudie 1, Interview Frau Akay, Z. 902-950)

Zunächst gibt Frau Akay an, vor einem Jahr neu zugezogen zu sein und den Stadtteil, in dem sich die Schule befindet, nicht gekannt zu haben. Allerdings habe sie gehört, und wurde vorab von der Schulleiterin ,,vorgewarnt“ (Z. 913), dass es sich um einen ,sozialen Brennpunkt“ (Z. 907) handle, wobei die Warnung unspezifisch bleibt (,hatte mir auch gesagt was da auf mich zukommt“, Z. 913 f.). Auffallend ist zudem, dass Frau Akay den Begriff sozialer Brennpunkt nicht konkretisiert. Unmittelbar anschließend argumentiert Frau Akay, dass sie sich angesichts ihres eigenen Migrationshintergrundes und Aufwachsens im „,sozialen Brennpunkt“ (Z. 916) in gewisser Hinsicht „,so hinein fühlen hinein versetzen“ (Z. 918) könne und das unbekannte Viertel ihr vertrauter erscheine. Das von der eigenen Erfahrung geprägte Wissen um die Lebensbedingungen im sozialen Brennpunkt und der eigene Migrationshintergrund erscheint demzufolge als positiver Horizont für die Arbeit an einer Schule mit einer ethnisch und sozial segregierten Schüler*innenschaft. Frau Akay kann sich hierbei aufgrund der vermeintlich homologen Aufwachsensbedingungen im sozialen Brennpunkt mit den Voraussetzungen des Einzugsgebiets der Schule identifizieren. Im Folgenden verengt Frau Akay die scheinbar kollektiven biografischen Erfahrungen 
auf die türkische Herkunft (,,alleine schon durch die ganzen türkischen Mitbürger hier, ich bin selber auch türkischer Herkunft und alleine das-da deswegen schon war da schon noch was Vertrautes", Z. 927). Auf der einen Seite sind die angenommenen gemeinsamen Erfahrungen bezüglich der türkischen Herkunft positiver Horizont für die Tätigkeit an einer Schule im sozialen Brennpunkt, auf der anderen Seite verweist die Formulierung „türkische Mitbürger“ (Z. 928) auf eine Besonderung und Abgrenzung dieser Gruppe von den anderen Stadtteilbewohner*innen, zu der sie sich aber zugehörig zu fühlen scheint. Darüber hinaus führt Frau Akay aus, dass die Eltern mit Migrationshintergrund - auch ohne Frau Akay zu kennen - ,sehr viel Vertrauen“ (Z. 934) in ihre Person haben und bei Problemen ihren Rat suchen. Als Grund hierfür nennt Frau Akay ihre türkischen Sprachkenntnisse. Das Vertrautsein bzw. die Verbundenheit aufgrund der eigenen Betroffenheitsperspektive sowie darüber hinaus die Mehrsprachigkeit erleichtern ihrer Ansicht nach die Zusammenarbeit mit Eltern mit Migrationshintergrund und stellen zugleich das Enaktierungspotenzial für die Zusammenarbeit mit diesen Eltern dar. Über dem besonderen Zugang zu Eltern mit Migrationshintergrund hinaus wird deutlich, dass sich Frau Akay eine exklusive Rolle innerhalb des Kollegiums zuweist: Obgleich sie neu im Kollegium ist und die Schüler*innen nicht selbst unterrichtet, suchen die Eltern mit Migrationshintergrund bei ihr Rat.

Abgesehen von der vertrauensvollen Zusammenarbeit mit Eltern mit Migrationshintergrund benennt Frau Akay weitere Vorteile aufgrund ihres eigenen Migrationshintergrundes für den Umgang mit Schüler*innen mit Migrationshintergrund:

ich denke auch für die Kinder ist es von Vorteil weil die Kinder sehen da jemandenalso die Kinder mit Migrationshintergrund meine ich jetzt die sehen dann da äh eine Lehrerin vorne stehen die äh (.) ähm ist auch ähm hat auch schwarze Haare sage ich mal so ganz krass und dunkle Augen und ähm (.) ist hier auch als Gastarbeiterkind hingekommen und hat es auch irgendwie-irgendwie geschafft ne und das ist ja dann auch so vielleicht auch so ein Stück weit äh Vorbildfunktion aber auch für die anderen Kinder für die deutschen Kinder kann das ja auch nur eine Bereicherung sein (.) ähm verschiedenen Kulturen kennen zu lernen und ähm wie-sich vertraut $\mathrm{zu}$ machen damit (.) also ich finde das kann eigentlich in allen Lebenslagen nur (.) nur äh positiv sein finde ich (.) ich finde das gut (Fallstudie 1, Interview Frau Akay, Z. 1015-1036)

Infolge ihres äußeren Erscheinungsbildes und der persönlichen Entwicklung vom „Gastarbeiterkind“ (Z. 1023) zur Lehrperson schreibt sich Frau Akay selbst eine Vorbildfunktion für Kinder mit Migrationshintergrund zu. In dieser Sichtweise erscheint der Migrationshintergrund zwar als individuelles Manko, welches aber 
überwunden werden kann. An ihrer Person können die Schüler*innen mit Migrationshintergrund sehen, dass sie es auch ,irgendwie geschafft" (Z. 1024) habe. Die Funktion als Rollenvorbild ist demgemäß das Enaktierungspotenzial für den Umgang mit Schüler*innen mit Migrationshintergrund. Durch die Selbstbezeichnung als ,Gastarbeiterkind“ und die Beschreibung ihres Aussehens (,die sehen dann da äh eine Lehrerin vorne stehen die äh (.) ähm ist auch ähm hat auch schwarze Haare sage ich mal so ganz krass und dunkle Augen“, Z. 1017 ff.) grenzt Frau Akay zudem abermals die Gruppe der Personen mit Migrationshintergrund von der Gruppe der Personen ohne Migrationshintergrund ab. Über die Vorbildfunktion für Schüler*innen mit Migrationshintergrund hinaus markiert sie zudem ihren Werdegang auch als Bereicherung für Kinder ohne Migrationshintergrund. Gleichwohl die Formulierung ,verschiedene Kulturen kennen lernen [...] sich vertraut zu machen“" (Z: 1030 f.) impliziert, dass Frau Akay Kulturdifferenzen wahrnimmt und eine Andersheit konstruiert, steht sie der Begegnung von Menschen mit unterschiedlichen kulturellen Prägungen positiv gegenüber und sieht darin Vorteile für alle Schüler*innen ,,in allen Lebenslagen“ (Z. 1034 f.). Die eigenen biografischen Erfahrungen haben somit insgesamt das Potenzial zur Enaktierung für den Umgang mit einer soziokulturell vielfältigen Schüler*innenschaft.

Im Wesentlichen erhält die in der Dimension Konstruktion der Schüler*innenund Elternklientel herausgearbeitete Orientierung, dass mit der Migration verbundene Bedürfnisse und Herausforderungen schulisch bearbeitbar sind, durch die Verknüpfung von biografischen Erfahrungen und dem berufsbezogenen Selbstkonzept einen differenzierten Sinngehalt. Kern der Orientierung ist die Handhabbarkeit der migrationsbedingten herausfordernden Arbeit an einer Schule im sozialen Brennpunkt. Positiver Horizont für den Umgang mit Schüler*innen und Eltern mit Migrationshintergrund ist der besondere Zugang aufgrund des eigenen Migrationshintergrundes und Aufwachsens im sozialen Brennpunkt. Die durch eigene biografische Erfahrungen vermeintlich angelegten Ressourcen wie bspw. der besondere Zugang zu Eltern mit Migrationshintergrund und die Funktion des Rollenvorbilds, die Frau Akay sich selbst zuschreibt, stellen das Enaktierungspotenzial für einen gelingenden Umgang mit einer soziokulturell vielfältigen Schüler*innenschaft dar.

Der Migrationshintergrund und das Aufwachsen im sozialen Brennpunkt sind jedoch nicht allein konstitutive Elemente des berufsbezogenen Selbstbildes, vielmehr runden das Studium der Heilpädagogik und die mehrjährige Arbeit in einer Kinder- und Jugendpsychiatrie Frau Akays selbstkonstruiertes Profil ab: 
bevor ich hier angefangen haben zu arbeiten haben ich sieben Jahre in der Kinder und Jugendpsychiatrie gearbeitet [...] da habe ich auf einer äh geschlossenen Station für Kinder und Jugendliche im Alter bis sechzehn Jahren gearbeitet sechs bis sechzehn Jahre (.) und ähm (.) das waren vorwiegend Kinder mit emotional sozialen Auffälligkeiten sehr schwieriges Klientel ähm (.) und die meisten Kinder hier bei uns an der Schule haben auch im em-emotional soziale Auffälligkeiten (.) das ist einfach (.) das ist einfach so das kann man jetzt auch nicht verheimlichen so (.) und ähm die Arbeit dort in der Kinder und Jugendpsychiatrie hat mich sehr geprägt und ich merke dass ich hiermit so äh mit-mit den Kindern mit diesen ähm Verhaltensauffälligkeiten viel besser umgehen kann dass ich da viel mehr Methoden habe ähm (.) dass ich da einfach viel sensibler und viel verständnisvoller (.) umgehen kann weil ich weiß wieso die Kinder so sind wie sie sind (.) wieso sie sich aufregen so schnell und (.) ähm sich nicht an Regeln halten können dass-da habe ich einfach ähm (.) mehr Verständnis zum einen aber auch mehr Handlungskompetenz (Fallstudie 1, Interview Frau Akay, Z. 1246-1294)

Im Kontext ihrer bisherigen Berufserfahrung nennt Frau Akay zunächst emotionale und soziale „Auffälligkeiten“ (Z. 1271) als gemeinsamen Nenner zwischen den Kindern auf der geschlossenen Station einer Kinder- und Jugendpsychiatrie und den Kindern an ihrer Schule. Der Vergleich der beiden Klientel verweist hierbei auf therapeutische Aspekte des Lehrberufs und bedeutet zugleich eine Pathologisierung der ,Verhaltensauffälligkeiten“ (Z. 1282) ihrer Schüler*innen. Darüber hinaus bewertet Frau Akay die Kinder und Jugendlichen der psychiatrischen Einrichtung als „sehr schwieriges Klientel“" (Z. 1270), was impliziert, dass es sich bei den von ihr identifizierten verhaltensauffälligen Kindern an ihrer Schule auch um eine schwierige Klientel handelt. Die Auffälligkeiten in der emotionalen und sozialen Entwicklung stellen zudem den negativen Gegenhorizont der Sichtweise auf ihre Schüler*innenschaft dar. Unmittelbar anschließend äußert Frau Akay mehr Verständnis und Handlungskompetenz für Schüler*innen mit Auffälligkeiten im emotionalen und sozialen Bereich. Die Empathie sowie die wahrgenommenen Fähigkeiten im Umgang mit emotional und sozial auffälligen Kindern, die zugleich das Enaktierungspotenzial für die pädagogische Arbeit bereitstellen, resultieren jedoch im Gegensatz zum besonderen Zugang zu Schüler*innen mit Migrationshintergrund nicht aus unterstellten kollektivbiografischen Erfahrungen, sondern basieren auf ihrem Fach- und Methodenwissen in der Heilpädagogik (,,ich weiß wieso die Kinder so sind wie sie sind (.) wieso sie sich aufregen so schnell und (.) ähm sich nicht an Regeln halten können dass-da habe ich einfach ähm (.) mehr Verständnis zum einen aber auch mehr Handlungskompetenz", Z. 1287). Grundsätzlich zeichnet sich der Orientierungsrahmen dadurch aus, dass sie mit Kindern, denen sie emotionale und soziale Auffälligkeiten zuweist, umzugehen weiß. 
Insgesamt lässt sich durch die fallinterne komparative Analyse der heterologen Themenfelder Umgang mit Kindern mit Migrationshintergrund und Kindern mit Fluchterfahrung sowie Umgang mit emotional und sozial auffälligen Kindern ein gemeinsamer ,Modus Operandi ' rekonstruieren: Probleme und Herausforderungen, die mit den beiden Differenzdimensionen Migration und Verhaltensauffälligkeiten einhergehen (können), sind aus der Sicht von Frau Akay pädagogisch handhabbar und bearbeitbar. Gemeinsam ist den Bearbeitungsweisen unterschiedlicher thematischer Passagen zudem die Abgrenzung zum Kollegium durch einen Wissens- und Kompetenzvorsprung - für den Umgang mit Schüler*innen und Eltern mit Migrationshintergrund aufgrund des eigenen Migrationshintergrundes und Aufwachsens im sozialen Brennpunkt und für den Umgang mit auffälligen Kindern im emotionalen und sozialen Bereich infolge des Fach- und Methodenwissens in der Heilpädagogik sowie der mehrjährigen Berufserfahrung in der Kinder- und Jugendpsychiatrie.

\subsubsection{Auseinandersetzung mit Spannungsfeldern der pädagogischen Arbeit}

Im Zusammenhang mit der Frage nach Schlüsselkompetenzen von Lehrkräften im Umgang mit Kindern in besonderen Lebenslagen thematisiert Frau Akay das Bedürfnis dieser Kinder nach Aufmerksamkeit und Zuwendung und der Verantwortlichkeit für die Erfüllung dieses Bedürfnisses:

Frau Akay: was diese Kinder auch brauchen ist so-hört sich vielleicht doof an aber die brauchen auch oft Liebe (.) habe ich den Eindruck (.) dass man sie mit ähm (.) Liebe und Aufmerksamkeit dass man ihnen damit begegnet (.) weil die suchen auch nach körperlicher Nähe die kommen dann immer und nehmen uns (.) von $\underline{\text { sich aus in den-in den Arm (.) oder ähm umarmen uns ähm (.) ich habe letztens }}$ eine-eine Schülerin gehabt die sagt mir sogar ich liebe sie wo ich dann sagte ups (.) @ das habe ich noch nie zu einer Lehrerin gesagt@ ne also ich habe das Gefühl die suchen so wirklich danach nach Wärme (.) nach Zu-zuneigung

Interviewerin: fühlen Sie sich auch dafür verantwortlich denen das dann auch zu geben?

Frau Akay: nein also gerade-gerade Liebe und Aufmerksamkeit sind ja sehr starke Gef-oder Liebe ist halt ein sehr starkes Gefühl ne $\mathrm{mhm}$ (.) nein also (.) ehrlich gesagt nicht (.) ich ich-ich lasse es natürlich zu wenn ein Kind von sich aus kommt und-und mich umarmt ne (.) ich drücke das Kind dann nicht weg oder so das finde ich dann auch ganz schlimm ne ich lasse das dann zu das ist dann auch e-ehrlich gemeint äh von mir (.) aber ähm (.) ich fühle mich nicht verantwortlich dafür dass 
ich diesem Kind jetzt-ähm ich finde das ist Aufgabe der Eltern oder der BezugsBetreu-Bezugsperson wenn das Kind jetzt äh zum Beispiel in-in bei Pflegeeltern oder im Heim wohnt oder so das ist Aufgabe der Bezugs-(.)person finde ich weil es ist nur für eine vorübergehende Zeit sind die Kinder ja bei uns und (.) dann muss ja auch eine gewisse Professionalität sein man gibt auch-es gibt ja auch Grenzen die man nicht überschreiten sollte finde ich (.) das tut dem Kind dann auch nicht gut ähm diese Grenze zu überschreiten und mir selber als Lehrperson auch nicht finde ich finde das muss man schon gewahren diese (.) Distanz (Fallstudie 1, Interview Frau Akay, Z. 1692-1757)

Einleitend schildert Frau Akay ihren Eindruck, dass Kinder in besonderen Lebenslagen ,auch oft Liebe brauchen“ (Z. 1693), wobei sich der Wunsch nach „Liebe und Aufmerksamkeit" (Z. 1694) in der Herstellung von körperlicher Nähe ausdrückt. Die Wortwahl , auch` impliziert hierbei, dass es noch weitere (unerfüllte) Bedürfnisse zu geben scheint. Zudem betont Frau Akay den aktiven Part der Kinder, Liebe und Aufmerksamkeit von der Lehrperson einzufordern. Das Beispiel von einer Schülerin, die zu ihr ,ich liebe dich` gesagt hat, und dem anschließend lachend vorgetragenen Kommentar, dass sie das selbst noch nie zu einer Lehrerin gesagt habe, dokumentiert Frau Akays Irritation über die Zuneigungsbekundung. Dass in der Lehrer*innen-Schüler*innen-Beziehung das vermeintlich gesteigerte Bedürfnis der Kinder nach Liebe und Zuwendung zum Tragen kommt, ist für sie anscheinend eine neue Erfahrung. Grundsätzlich bringt Frau Akay in dieser anekdotenhaften Beschreibung die Annahme zum Ausdruck, dass im Elternhaus körperliche Zuneigung und emotionale Aufmerksamkeit zu fehlen scheint. Diese Sichtweise stellt zugleich Frau Akays negativen Gegenhorizont des Elternbildes dar. Unklar ist, auf welche Gruppe von Kindern in besonderen Lebenslagen sich Frau Akay bezieht. Jedoch liegt aufgrund einer ähnlichen Sinnstruktur bezüglich des Mangels auf unterschiedlichen Ebenen (keine schulfachliche Unterstützung der Eltern bei schulischen Angelegenheiten, großer Unterstützungsbedarf hinsichtlich lebenspraktischer Fähigkeiten und schulischem Lernen, fehlende Regeln und Tagesstrukturen im Elternhaus) die Vermutung nahe, dass sie Kinder aus erschwerten Familienverhältnissen meint (vgl. 3.3.1 Konstruktion der Schüler*innen- und Elternklientel) Die unmittelbar anschließende Nachfrage zu der Verantwortlichkeit für die Bedürfniserfüllung grenzt sich Frau Akay deutlich von ab und verweist zunächst auf die Stärke des Gefühls Liebe. Weiterhin führt sie aus, dass sie zwar eine Umarmung zulässt, wenn ein Kind auf sie zukommt und das Kind nicht von sich weist, sich aber nicht für die Erfüllung des Bedürfnisses nach Liebe verantwortlich fühlt. Überdies verweist Frau Akay darauf, in solch einer Situation authentisch auf das Kind zu reagieren (,das ist dann auch e-ehrlich gemeint äh von mir“, Z. 1731). Unmittelbar anschließend 
argumentiert Frau Akay, dass die liebevolle Zuwendung Aufgabe der Eltern oder der Bezugsperson sei, da zum einen die Kinder nur für eine begrenzte Zeit in der Grundschule seien und zum anderen eine professionelle Distanz gewahrt werden müsse. Die Annahme, dass ein Überschreiten dieser Grenzen weder dem Kind noch der Lehrperson guttue, führt Frau Akay nicht näher aus.

Grundsätzlich dokumentiert sich anhand der Passage zum besonderen Bedürfnis nach Liebe und Aufmerksamkeit ein Verständnis von Liebe als starkes Gefühl, das die Beziehung zwischen Lehrkraft und Schüler bzw. Schülerin übersteigt. Der (Selbst-)Anspruch einer Grenzwahrung drückt sich auch in der konkreten Praxis aus, so beschreibt Frau Akay sich im Umgang mit einer solchen Situation als reaktiv handelnd (,,ich ich-ich lasse es natürlich zu wenn ein Kind von sich aus kommt und-und mich umarmt ne (.) ich drücke das Kind dann nicht weg oder so das finde ich dann auch ganz schlimm ne ich lasse das dann zu“, Z: 1725 ff.). Kern der Orientierung ist die Herstellung einer Balance von Nähe und Distanz in Lehrenden-Lernenden-Beziehungen. Eine Schlüsselkompetenz und zugleich Enaktierungspotenzial für den Umgang mit Kindern aus erschwerten Familienverhältnissen ist demzufolge die Fähigkeit, eine professionelle Distanz und Grenzen in der Gestaltung pädagogischer Beziehungen zu wahren.

\subsubsection{Positionierung innerhalb der Schule bzw. im Kollegium}

Frau Akay entwirft im Gesamten ein exklusives berufliches Profil beruhend auf den Komponenten Migrationshintergrund, Aufwachsen im sozialen Brennpunkt und heilpädagogische Qualifikationen, welches sie von den anderen Lehrpersonen abhebt. Wie bereits im Rahmen des berufsbezogenen Selbstkonzepts ausführlich analysiert, ist für Frau Akay die Arbeit an einer Schule mit einem hohen Anteil an Schüler*innen mit Migrationshintergrund und Schüler*innen mit Fluchterfahrung aufreibend und sinnstiftend zugleich (,es ist wirklich anstrengend es ist eine sehr anstrengende Arbeit aber man kriegt von den Kindern auch immer viel zurück das ist das Schöne“, Z. 876 ff.). Dadurch, dass die geringen oder fehlenden Kenntnisse der deutschen Sprache von geflüchteten Kindern in der Schule zügig kompensiert sowie die soziale Integration von Kindern mit Migrationshintergrund durch pädagogische Arbeit gefördert werden, erlebt sich Frau Akay als handlungswirksam. Die Annahme, dass die Kinder mit Migrationshintergrund gerne zur Schule kommen und sich wohlfühlen, trägt zudem zur beruflichen Zufriedenheit bei. Aufgrund ihres Migrationshintergrundes und Aufwachsens im sozialen Brennpunkt unterstellt 
Frau Akay kollektive Erfahrungen zu (insbesondere türkeistämmigen) Einwandererfamilien und erfährt in diesem Zusammenhang die Schüler*innen- und Elternschaft mit Migrationshintergrund als angenehm. Vor dem Hintergrund eigener biografischer Erfahrungen schreibt sie sich selbst Kompetenzen und Funktionen $\mathrm{zu}$, die ihr im Gegensatz zu Lehrkräften ohne Migrationshintergrund die Arbeit mit den Kindern und Eltern mit Migrationshintergrund erleichtern und darüber hinaus eine Bereicherung für alle Schüler*innen darstellen. Ferner verschaffen das Fach- und Methodenwissen in der Heilpädagogik sowie die mehrjährige Berufserfahrung in einer Kinder- und Jugendpsychiatrie Frau Akay gegenüber den Kolleg*innen einen weiteren Kompetenzvorsprung im Umgang mit emotional und sozial auffälligen Schüler*innen (vgl. 3.3.1 Konstruktion der Schüler*innen- und Elternklientel; 3.3.2 Berufsbezogenes Selbstkonzept).

Insgesamt kann die Konstruktion eines sich von den Kolleg*innen abgrenzenden, anspruchsvollen berufsbezogenen Selbstkonzepts auch als Selbstaufwertung im Platzierungskampf innerhalb eines multiprofessionellen Teams von Regelschullehrkräften, Sonderpädagog*innen, Sozialpädagog*innen und Heilpädagog*innen gedeutet werden. Gerade vor dem Hintergrund ihres Quereinstiegs in den Lehrberuf scheinen die Selbstdeutungen von vermeintlichen Rollen und Kompetenzen und die daraus resultierende Selbstpositionierung im Kollegium zu ihrer beruflichen Identitätsstärkung beizutragen.

\subsubsection{Zuschreibung von Verantwortung für Bildungschancen}

Die Rekonstruktionen der vorliegenden Fallstudie lassen darauf schließen, dass im Grundsatz die Bearbeitung von Bildungsungleichheit zu dem beruflichen Selbstverständnis von Frau Akay zählt. So verweisen insbesondere die Darstellungen zu Schüler*innen mit Migrationshintergrund und emotional und sozial auffälligen Schüler*innen auf vielfältige Unterstützungsbemühungen.

Indessen misst Frau Akay im Kontext des Themas Grenzen des pädagogischen Handelns dem familialen Hintergrund der Schüler*innen einen bedeutsamen Stellenwert für Bildungs- und Lebenschancen bei:

Frau Akay: aber letztendlich dreht sich da-da [zu Hause, Anm. d. Verf.] ja das Meiste ne wenn sie da äh eine-eine Struktur eine feste Basis haben eine sta-ähm ein starkes Fundament haben kann man ja besser (.) drauf aufbauen das ist bei vielen Kindern denke ich mir wenn die aus anderen familiären Verhältnissen kämen hätten die viel mehr Chancen denke ich manchmal 
Interviewerin: mhm (.) wie sehen Sie da die Rolle der Schule? kann die Schule das kompensieren was sie da so an ja an fehlendem Fundament beschreiben?

Frau Akay: mhm (.) das ist natürlich schwierig man kann das ja nicht bei allen Kindern ne machen das kann man-kann man gar nicht tragen aber wir sind wirklich alle bemüht was so Regeln und Strukturen angeht dass wir die hier für alle Kinder gleichwertig verbindlich machen dass sie zumindest hier Regeln und Strukturen haben (.) und ähm (.) wir selber auch mit eigenem Vorbild an die Kinder herangehen darauf achten wie reden wir? re-gehen wir höflich-das ist zum Beispiel auch ein ganz aktuelles Thema bei uns dass wir auch mit den Kindern ähm besprechen wir gehen höflich miteinander um wir sagen Bitte und Danke wir ähm benutzen keine Schimpfwörter(.) das wir einfach als Vorbild dann auch agieren und ich glaube mehr ka-wenn man das erreicht hat (.) das ist schon ganz viel ich glaube äh viel mehr kann man auch jetzt nicht erwarten in so einem Einzugsgebiet glaube ich wenn man das so erreicht hat das die einigermaßen höflich miteinander umgehen sich an bestehende Regeln halten hat man eigentlich schon ganz viel erreicht hier

Interviewerin: mhm (.) wie sehen Sie die Bildungschancen für die Kinder hier in diesem Stadtteil?

Frau Akay: mhm das ist echt schwierig (.) also ich bin froh wenn die meisten Kinder eine Ausbildung machen würden eine gute Ausbildung machen würden da wäre ich schon richtig froh drüber das fände ich schon richtig gut (.) ich glaube das Abitur das-da braucht man gar nicht wirklich so drüber zu reden (.) ich weiß nicht ob die das äh (.) vielleicht kann man die dann an einer Hand zählen wo ich sage gut die-die würden vielleicht ein Fachabitur noch hinkriegen schaffen oder ein Vollabi aber das (.) ist echt schwierig (.) also ich bin wirklich froh wenn die eine Ausbildung haben ein Schulabschluss haben und eine Ausbildung da bin ich schon richtig froh drüber (Fallstudie 1, Interview Frau Akay Z. 1529-1613)

Zunächst markiert Frau Akay die Familie als zentrale Sozialisationsinstanz, in der Grundstrukturen der Erziehung gelegt werden (,da dreht sich das Meiste“, Z. 1529). Wurde mit der Primärsozialisation ein ,starkes Fundament“ (Z. 1534) geschaffen, so Frau Akay, könne die Schule an diese grundlegenden Voraussetzungen besser anknüpfen und aufbauen. Eine gelungene sozialisatorische Vorarbeit der Familie scheint aus ihrer Sicht ausschlaggebend für die pädagogische Arbeit zu sein.

Auf die Frage nach den schulischen Kompensationsmöglichkeiten des fehlenden Fundaments antwortet Frau Akay zusammenfassend, dass die Institution Schule bzw. das pädagogische Handeln der Lehrkräfte nur begrenzt auf strukturelle familiale Unterschiede zwischen den Schüler*innen Einfluss nehmen könne. Die Formulierung ,das ist natürlich schwierig man kann das ja nicht bei allen Kindern ne machen das kann man-kann man gar nicht tragen“ (Z. 1548 ff.) lässt offen, ob es in quantitativer Hinsicht nicht möglich sei, alle Kinder zu fördern, 
weil es mengenmäßig zu viele sind, und/oder in qualitativer Hinsicht, weil das fehlende Fundament zu schwerwiegend und in der Schule nicht auszugleichen sei. Infolge betont Frau Akay die Bemühungen des pädagogischen Personals, für alle Kinder gleichermaßen verbindliche Regeln und Strukturen innerhalb der Schule zu schaffen. Durch die Aussage, dass die Schüler*innen ,zumindest hier“ (Z. 1561) Regeln und Strukturen haben, verweist Frau Akay auf das Fehlen dieser in der Familie. Ferner nennt Frau Akay als weitere Praktik des Ausgleichs des fehlenden Fundaments die schulische Vermittlung eines respektvollen sozialen Umgangs. Abschließend fasst sie zusammen, dass ein annähernd höflicher Umgang miteinander und das Einhalten von Regeln das bestmögliche Resultat pädagogischer Arbeit in diesem Einzugsgebiet der Schule darstellen. Auf die Frage nach der persönlichen Einschätzung der Bildungschancen der Schüler*innen aus dem sozialräumlich benachteiligten Stadtteil antwortet Frau Akay zunächst zögerlich. Etwa wäre sie „froh“ (Z. 1595), wenn die Mehrheit der Schüler*innen einen Schulabschluss erreichen und eine „gute Ausbildung“ (Z. 1596) absolvieren würde. Das Erlangen der allgemeinen Hochschulreife schließt Frau Akay für ihre Schüler*innenklientel im Grunde genommen aus, zudem traut sie nur wenigen Schüler*innen den Abschluss der Fachhochschulreife zu.

Grundsätzlich wird der bereits herausgearbeitete Orientierungsrahmen hinsichtlich des familialen Hintergrundes validiert und um den Aspekt der ungleichen Bildungschancen ausgearbeitet. So kann sich die Lebenssituation nicht nur nachteilig auf die Lernvoraussetzungen und das Lernpotenzial der Schüler*innen auswirken und eine Herausforderung für die pädagogische Arbeit darstellen, sondern darüber hinaus eine Einschränkung der Bildungschancen sein. Enaktierungspotenzial für die Bearbeitung von Bildungsungleichheit besteht aus der Perspektive von Frau Akay in der Etablierung von Strukturen, Ritualen und Regeln in der Schule sowie der Vermittlung eines respektvollen sozialen Umgangs. Wenngleich schätzt Frau Akay die Bildungschancen der Schüler*innen insgesamt als eher gering ein: Mehrmals betont sie, dass ein Schulabschluss und eine Ausbildung aus ihrer Sicht die Grenzen des Möglichen darstellen und nur für wenige Schüler*innen die Fachhochschulreife überhaupt erreichbar sei.

\subsubsection{Gefahren und Fallstricke der handlungsleitenden Orientierungen}

Zusammenfassend ist festzuhalten, dass bei Frau Akay Wertschätzung und Empathie im Mittelpunkt des pädagogischen Handelns stehen. Angesichts ihres eigenen Migrationshintergrundes und Aufwachsen im sozialen Brennpunkt sowie ihren 
heilpädagogischen Qualifikationen präsentiert sie sich durchgängig förder- und ressourcenorientiert, insbesondere in Bezug auf Schüler*innen mit Migrationshintergrund und emotional und sozial auffälligen Schüler*innen.

Jedoch ist ihr Bild einer Herkunft, die sie als ähnlich zu ihrer eigenen zu erkennen glaubt, nicht ohne Einschränkungen zu verwenden. So ist fraglich, inwiefern tatsächlich ein gemeinsamer Erfahrungsraum zwischen Frau Akay und den Schüler*innen mit Migrationshintergrund an ihrer Schule besteht. Möglicherweise ist außer einem vage definierten Migrationshintergrund keine weitere Verbindung vorhanden. Das besondere empathische Empfinden von Frau Akay für Kinder und Eltern mit Migrationshintergrund würde sich demzufolge als ethnisierendes Konstrukt erweisen: Auch bei Vorliegen gleicher nationaler, ethnischer oder kultureller Herkunft können sich Lebens- und Sozialisationsbedingungen erheblich voneinander unterscheiden. Dies kann einerseits zur Folge haben, dass in Bezug auf Schüler*innen aus Einwandererfamilien mit nicht homologen Sozialisationsbedingungen Berührungspunkte - ebenso wie bei Lehrkräften ohne Migrationshintergrund - auf die Schule beschränkt sind und Frau Akay tiefergehende Einblicke in die spezifischen Lebensumstände dieser Schüler*innen fehlen. Dies deutet sich im Zusammenspiel mit der Differenzkategorie erschwerte Familienverhältnisse an: Zwar legt die Bezeichnung sozialer Brennpunkt als eigene Aufwachsensbedingung nahe, dass sie in einem Umfeld geprägt wurde, das durch Knappheit auf mehreren Ebenen gekennzeichnet war, jedoch scheint die von ihr wahrgenommene große Hilfsbedürftigkeit der Schüler*innen aus erschwerten Familienverhältnissen nicht ihren eigenen biografischen Erfahrungen zu entsprechen. Insgesamt besteht folglich die Gefahr, dass Frau Akay unüberlegt die eigenen mit der Migration in Verbindung stehenden Erfahrungen auf Schüler*innen mit Migrationshintergrund überträgt und somit für die Bedürfnisse und Probleme einzelner Kinder nicht offen und sensibel ist. In diesem Zusammenhang ist auch die Fokussierung auf deutschsprachliche Kompetenzen kritisch zu betrachten. Etwa konstruiert Frau Akay die Gruppe der geflüchteten Kinder ausschließlich anhand des Merkmals Sprachstand in der deutschen Sprache - die Gemeinsamkeit wird folglich über das Nichtvorhandensein der Deutschkenntnisse zu Beginn des Schuleintritts hergestellt. Anderer Merkmale wie Herkunftsstaat, Herkunftssprache, Familien- und Lebenssituation, Bildungsvoraussetzungen, psychische Belastungen und Traumatisierungen, Aufenthaltsstatus u. v. m. werden von Frau Akay nicht thematisiert.

Über das Interview hinweg können des Weiteren Zuschreibungen von Defiziten und Mangel an den familialen Hintergrund rekonstruiert werden. So beschreibt 
Frau Akay, dass sich erschwerte Familienverhältnisse hinderlich auf die Lernvoraussetzungen und das Lernpotenzial der Kinder auswirken und eine Herausforderung für die pädagogische Arbeit darstellen. Negative stereotype Vorstellungen beziehen sich hierbei vor allem auf die Erziehungsfähigkeit der Eltern: Zum einen erhalten Kinder aus erschwerten Familienverhältnissen in Frau Akays Perspektive wenig bis keine schulbildungsbezogene Förderung, zum anderen fehlen aus ihrer Sicht Zuhause Regeln und Tagesstrukturen sowie darüber hinaus in vielen Fällen körperliche Zuneigung und emotionale Zuwendung. Diese problemorientierte Sichtweise auf die Erziehungsfähigkeit der Eltern zieht eine entsprechend gelagerte pädagogische Praxis im Umgang mit einer als stark bedürftig konstruierten Schüler*innen- und Elternschaft nach sich und geht zugleich mit der Einschätzung über eine eher geringe Leistungs- und Lernfähigkeit der Schüler*innen einher. Letztlich führen aus Sicht von Frau Akay erschwerte Familienverhältnisse zu ungleichen Bildungschancen und eher geringen schulischen Erfolgsaussichten.

\subsection{Frau Antonova}

Die offene Ganztagsgrundschule, an der das 45 Minuten dauernde Gespräch mit Frau Antonova stattfand, verlief ohne äußere Störungen. Die Grundschule liegt in einer Kleinstadt im östlichen Nordrhein-Westfalen in einer strukturstarken, ländlich geprägten Region. Die für die Grundschule zuständige Kommune weist eine vergleichsweise günstige wirtschaftliche Lage auf, so ist das Einkommen der privaten Haushalte höher und der Schuldenstand niedriger als der Durchschnitt aller Kommunen in Nordrhein-Westfalen. Zudem ist die Arbeitslosenquote relativ gering und der Anteil an Einwohner*innen, die öffentliche Sozialleistungen beziehen, unterdurchschnittlich. Die Bevölkerungsdichte und der Anteil an Einwohner*innen mit Migrationshintergrund ist im Vergleich der umliegenden Landkreise sehr gering.

Insgesamt besuchen knapp 250 Schüler*innen die Grundschule und werden hierbei von ca. 20 Lehrkräften sowie zwei Förderschullehrkräften unterrichtet. Zum Interviewzeitpunkt ist Frau Antonova Anfang 30 Jahre alt und arbeitet seit einem halben Jahr an der Grundschule. Ihr erfolgreich abgeschlossener Vorbereitungsdienst liegt erst kurze Zeit zurück. 


\subsubsection{Konstruktion der Schüler*innen- und Elternklientel}

Frau Antonova schildert im Kontext der Frage nach einem positiven Erlebnis in der Schule, dass ihre Schüler*innen bereits wenige Wochen nach der Einschulung lesen konnten:

in der ersten Klasse da ähm kam irgendwie ein Mädchen an äh auch aus meiner Klasse kam dann morgens in die Klasse und sagte dann äh (.) [verstellt Stimme] Frau Antonova äh ich kann schon total gut lesen (.) und dann habe ich gesagt Mensch ja dann-dann zeig mir das doch mal ja ich hab das schon alles gelesen (.) und dann hat die mir wir-und das war äh ich weiß es war sechs Wochen glaube ich sechs sieben Wochen nachdem die Kinder eingeschult waren und ich hatte dann so eine Eingangsdiagnostik gemacht und wusste dass die halt (.) gar nicht bis ga-also fast gar nicht noch lesen können ne wirklich nur so Buchstaben erkennen und das auch noch nicht mal alle (.) und dann kam die wirklich so sechs sieben Wochen nachdem die Schule angefangen hatte (.) und hatte mir dann wirklich so ein Buch dahingelegt und hat dann so zwei drei Zeilen aus diesem Buch vorgelesen und dann habe ich gedacht Wahnsinn was ist denn da los? ne also dass die auf einmal so einen riesen Schwung gemacht hatte und ähm (.) und das hat so meinen Blick irgendwie darauf geschärft dass ich dann auch gemerkt habe ähm (.) dann habe ich das bei den anderen Kindern auch mal so ich sag mal abgeprüft ähm oder mal so überprüft und habe dann wirklich festgestellt dass die innerhalb von kürzester Zeit wirklich so äh w-wirklich teilweise echt schon richtig gut lesen konnten ne das war Wahnsinn also d-da habe ich echt gedacht (.) also ich hätte nicht gedacht dass-dass die Kinder das so schnell lernen (Fallstudie 2, Interview Frau Antonova, Z. 89-126)

Am Beispiel einer Schülerin, die innerhalb kurzer Zeit des Unterrichtens in der Lage war, einige Zeilen aus einem Buch vorzulesen, stellt Frau Antonova die rasche Lernfähigkeit der Kinder heraus. Ihrer Erzählung fügt sie hinzu, dass sie aufgrund der zu Schulbeginn durchgeführten Eingangsdiagnostik wusste, dass der Großteil der Kinder „fast gar nicht“ (Z. 100) lesen kann. Der zügige Erwerb von Lesekompetenzen der Erstklässlerin habe dazu geführt, auch die anderen Kinder genauer zu beobachten und zu überprüfen. Hierbei habe sie festgestellt, dass die Schüler*innen teilweise innerhalb weniger Zeit ,schon richtig gut“ (Z. 120) lesen können. In der gesamten Passage bringt Frau Antonova ihr Erstaunen über das enorme Lernpotenzial der Schüler*innen zum Ausdruck. Insgesamt erscheint der schnelle Lernfortschritt der Kinder im Lesen als positiver Horizont ihres Schüler*innenbildes. Diese schulleistungsbezogene Perspektive wird im Zusammenhang der Frage nach ihrer Erwartungshaltung an die Kinder zu Schuleintritt elaboriert: 
ja ich erwarte von denen dass-dass-dass die sich auf die Schule freuen ne also-also eine gewisse Freude (.) ähm und auch eine Lernfreude oder-oder-s-oder so diesesdieses-dieses-diesen Lernwillen den finde ich auch ganz wichtig bei Kindern dass die das haben ähm (3) weil alles andere ist ja im Grunde genommen äh das was ich-was die auch lernen sollen und wo die auch Zeit haben sollen also (.) bei mir müssen die Kinder nicht unbedingt äh ist nicht die Voraussetzung dass die eine Stunde still auf dem Stuhl sitzen können denn das können die nicht ähm aber dass die wirklich so-so sich auch-auch selber auf die Schule auch freuen so-so diese intrinsischen Motivation irgendwo so da ist ich möchte was lernen und ich bin jetzt da und ähm ja (Fallstudie 2, Interview Frau Antonova, Z. 149-177)

Frau Antonova spitzt in mehreren Schritten ihren Anspruch an die Schüler*innen zu, so sind eine ,gewisse Freude“ (Z. 154) auf die Schule, „Lernfreude“ (Z. 154), „Lernwillen“ (Z. 159) und ,intrinsische Motivation“ (Z. 176) zugleich positiver Horizont ihres Schüler*innenbildes. Darüber hinaus stellen diese Eigenschaften nach ihrer Einschätzung entscheidende Voraussetzungen für die pädagogische Arbeit dar, für ,,alles andere“ (Z. 164) erhalten die Kinder in der Schule Gelegenheit und Zeit zum Lernen. Als Beispiel führt sie an, dass es keine Grundbedingung bei ihr sei, eine Stunde lang still auf dem Stuhl zu sitzen - denn das können die Schüler*innen ihrer Ansicht nach ohnehin nicht. Eine grundlegende innere Motivation lernen $\mathrm{zu}$ wollen erscheint in dieser Perspektive als nicht im Laufe der Schulzeit entwickelbar, sondern im Elternhaus angeboren bzw. anerzogen zu sein.

Alles in allem attestiert Frau Antonova den Schüler*innen eine hohe Wissbegierde und Bildungsbeflissenheit im Schulkontext:

also die sind wirklich alle ich habe auch no-noch noch nie so eine Klasse gesehen das ist Wahnsinn die sind wirklich auch alle angekommen und das war nach kürzester Zeit dass die (.) ähm (.) echt alle auch äh (.) auch Fragen gestellt haben sich auch alle beteiligt haben und ähm (.) hm ja das auch irgendwie wollten und äh das ist klar dass dann ähm oft oder ne dann-dann so nach-nach einigen Wochen war das oft so dass man gemerkt hat die sind so ausgelaugt ne die-die können dann nicht mehr aber das war auch einfach ähm ich habe immer versucht diese Punkte auch-auch im Unterricht immer diese Punkte als Anlass dafür zu sehen nicht zu sagen Mensch jetzt reißt euch mal zusammen sondern ich habe diese Punkte dann immer genutzt um zu sagen ach komm wir machen eine Bewegungspause ne dann habe ich immer ganz viele Be-ganz verschiedene Bewegungspausen die Kinder kennen das eigentlich auch schon also ähm (.) dass ich (.) den Kindern das immer zugestanden habe auch irgendwann nicht mehr zu können ne und ähm dass ich auch dann immer wieder versucht habe neue Impulse zu kriegen und immer wieder neue Motivationsanlässe zu kriegen und-und auch Übungsformate (.) auch so abzuwechseln dass die Kinder immer wieder was Neues (.) so neuen Input kriegen und mal wieder ähm (2) ja was Neues zu schaffen ne oder dass-dass ich zum Beispiel denen auch ganz oft ähm (.) auch einfach bewusst gemacht habe was die 
schon alles gelernt haben [...] dann äh ja ist man ja auch stolz natürlich auch drauf und man hat auch neue Motivation wo man dann wieder ansetzt ne (Fallstudie 2, Interview Frau Antonova, Z. 194-271)

Abermals betont Frau Antonova die geringe Zeitspanne und hohe intrinsische Motivation der Kinder, die sich mithin in einer eifrigen Beteiligung am Unterrichtsgeschehen präsentiert. Diese Beschreibung ist ebenso der positive Horizont ihres Schüler*innenbildes. Die Formulierung ,ich habe auch no-noch noch nie so eine Klasse gesehen das ist Wahnsinn“ (Z. 194 f.) verweist darüber hinaus auf die außergewöhnliche Lernfähigkeit der Schüler*innen, die bislang nicht zum Erfahrungsraum von Frau Antonova zu gehören scheint. Als legitim erscheinende Konsequenz der hohen Motivation und Lernfähigkeit seien die Kinder ferner nach einigen Schulwochen erschöpft und ,,ausgelaugt“ (Z. 203). Frau Antonova reagiert entsprechend und gesteht den Schüler*innen eine Erholungsphase im Unterricht $\mathrm{zu}$, indem sie bewusst Bewegungspausen einplant. Darüber hinaus gestaltet sie nach eigenen Aussagen die schulischen Lernprozesse derart, dass sie Übungsformate abwechselt und kontinuierlich neue Lernanstöße gibt. Zu Frau Antonovas pädagogischem Handeln gehört auch das Aufzeigen des Lernfortschrittes, um den Schüler*innen Erfolgserlebnisse zu vermitteln, die wiederum motivierend für den weiteren Lernprozess sind. Demzufolge stellt selbstwirksames Lernen im Kontext von Erfolgserfahrungen sowie abwechslungsreichen und kognitiv-aktivierenden Aufgaben das Enaktierungspotenzial für gelingendes Lernen im Schulkontext dar.

Grundsätzlich ist der Orientierungsrahmen des Schüler*innenbildes somit durch eine wertschätzende und anerkennende Haltung gegenüber den Schüler*innen geprägt. Als Kern der Orientierung erscheint, dass sich die Bildungseinstellung respektive die Lernvoraussetzungen der Kinder und das daraus resultierende hohe Lernpotenzial positiv auf die pädagogische Arbeit auswirken.

\subsubsection{Berufsbezogenes Selbstkonzept}

Im Zusammenhang der Frage nach beruflichen Stärken beschreibt Frau Antonova, dass sie aufgrund eigener Migrationserfahrung mehr Verständnis für die herausfordernde Situation neu eingewanderter Kinder habe, andererseits Unverständnis für geringe Integrationsbemühungen neu eingewanderter Eltern hege:

dieses Verständnis für die Kinder irgendwo ne (.) dass man sagt ähm ich weiß wie es auf der ein-ja auf der einen Seite Verständnis dass man sagt ich weiß wie das ist (.) ich weiß wie blöd das ist wenn man da steht ich stand-ich weiß damals ich stand auf dem Schulhof und ich konnte nicht verstehen wie die Menschen 
sich gegenseitig verstehen weil für mich klang das alles blabla blablablablabla bla blablabla bla blablabla für mich wa-ist alles gleich und ich-ich das ka-hat total lange gedauert bis ich (.) bis ich das so durchdrungen hatte dass die ne und auf dalso auf der einen Seite wirklich dieses Verständnis da zu stehen und gar nichts zu verstehen und da irgendwo ähm (.) aufgefangen zu werden (.) aber auf der anderen Seite dieses Nicht-Verstehen von den Eltern und äh dass die da nicht mehr tun für ihre Kinder ne dass-dass die da nicht-nicht versuchen ihr Kind zu integrieren und sich selber auch nicht integrieren (.) ich könnte nicht in einem Land leben ähm (.) äh wo ich nicht wo ich niemanden kenne wo ich Angst haben muss vor die Tür zu gehen weil ich mich da nicht verständigen kann (Fallstudie 2, Interview Frau Antonova, Z. 681-719)

Insgesamt zeichnet sich die Passage durch eine besondere metaphorische Dichte aus und gewinnt somit den Charakter einer Fokussierungsmetapher. Mit einem hohen Detaillierungsgrad schildert Frau Antonova retrospektiv ihre damalige Schulsituation kurz nach der Einwanderung (,ich stand-ich weiß damals ich stand auf dem Schulhof und ich konnte nicht verstehen wie die Menschen sich gegenseitig verstehen weil für mich klang das alles blabla blablablablabla bla blablabla bla blablabla für mich wa-ist alles gleich“, Z. 687 ff.). Die szenische Darstellung der vergangenen Erfahrung dokumentiert neben den wahrgenommenen Sprachbarrieren vor allem das Erleben von sozialer Ausgrenzung. Insgesamt erscheint die Fremdheitserfahrung aufgrund fehlender Deutschkenntnisse als negativer Gegenhorizont der Sichtweise auf neu eingewanderte Schüler*innen. Darüber verweist der bildhafte Ausdruck ,aufgefangen zu werden“ (Z. 707) vage auf Kompensationsmöglichkeiten von Verständigungsproblemen aufgrund der Sprache und dem Gefühl des Nicht-Dazugehörens. Hierbei impliziert die unmittelbar anschließende kritische Beurteilung von Eltern, ,die da nicht mehr tun für ihre Kinder" und ,die da nicht-nicht versuchen ihr Kind zu integrieren und sich selber auch nicht integrieren" (Z. 708 ff.), dass die Anstrengungen der neu eingewanderten Eltern im Hinblick auf den Erwerb von Deutschkenntnissen und den Aufbau sozialer Kontakte das Enaktierungspotenzial für das schulische Vorankommen dieser Kinder darstellen. Dementsprechend erscheinen die fehlende Verantwortungsübernahme und Bereitschaft zur Integration zugleich als negativer Gegenhorizont des Bildes von neu eingewanderten Eltern. Als Maßstab für die Kritik dient Frau Antonova unterdessen die eigene Einwanderungsgeschichte:

mir kann dann keiner erzählen dass ich es-dass-dass es nicht möglich ist so ne also mir kann keiner sagen es geht nicht (.) weil es geht (.) ich sitze hier ne und ich habe einen deutschen Mann und ich habe deutsche Freunde und ich habe überhaupt eigentli-außer meiner Verwandtschaft habe ich mit wenigen Aussiedlern überhaupt so in dem Sinne zu tun ne und mir kann keiner sagen ne oft sagen die ja auch die 
akzeptieren uns ja nicht und die gucken ja auch immer komisch und ne das wird dann ja auch oft aber es stimmt nicht es stimmt einfach nicht wenn ich das wirklich möchte und wenn ich auf die Leute zugehe (.) dann geht das auch (Fallstudie 2, Interview Frau Antonova, Z. 725-739)

Zunächst bewertet Frau Antonova die von ihr antizipierte Haltung einiger Einwander*innen, dass Integration nicht möglich sei, als abwegig - an ihrer Person sei die Realisierbarkeit schließlich ersichtlich. Weiter führt sie aus, dass sie einen „deutschen Mann“ (Z. 730) und „deutsche Freunde“ (Z. 730) habe und mit Ausnahme zu ihrer Verwandtschaft nur wenig Kontakt zu anderen „Aussiedlern“ (Z. 732) bestehe. Unter diesem Blickwinkel erscheint Assimilation auf sozialer Ebene als positiver Horizont von Integration. Zugespitzt könnte auch formuliert werden, dass sich Frau Antonova durch die nachdrückliche Hervorhebung von Beziehungen zu Personen ohne Migrationshintergrund selbst als bestes Beispiel für gelungene Integration präsentiert. Ihrer Ansicht nach ermöglicht allein der Wille und die Bereitschaft, auf Menschen zuzugehen, soziale Integration. Diese Erwartungshaltung stellt zugleich das Enaktierungspotenzial für eine erfolgreiche gesellschaftliche Integration in Deutschland bereit. Darüber hinaus findet eine betonte Unterscheidung zwischen Personen mit Migrationshintergrund und Personen ohne Migrationshintergrund statt. Zwar lässt die Konstruktion eines geteilten Erfahrungsraumes prinzipiell den Schluss zu, dass sich Frau Antonova zu der Gruppe der Aussiedler*innen zählt, jedoch differenziert sie innerhalb der Gruppe der Einwander*innen zwischen denjenigen, die sich der Mehrheitsbevölkerung anpassen, und denjenigen, die nicht integriert bzw. nicht bemüht sind, sich zu integrieren. Hierbei grenzt sich Frau Antonova deutlich von letztgenannter Teilgruppe der ,Integrationsunwilligen' ab. Ferner dokumentiert die von Frau Antonova vorgenommene Kategorisierung von ,Integrationsverweiger*innen“ versus ,Integrationsbemühten 'bzw. ,Integrierten` eine Vorstellung von einer willentlichen und aktiven Separation mancher Einwander*innen.

Neben der besonderen Empathie für die herausfordernde Lage kürzlich eingewanderter Kinder beschreibt Frau Antonova im Kontext des Themenfeldes Zusammenarbeit mit den Eltern, dass ihrer Ansicht nach der eigene Migrationshintergrund auch die vertrauensvolle Zusammenarbeit mit Eltern mit Migrationshintergrund erleichtere:

also wa-was mir mal im Zusammenhang mit den Eltern (.) natürlich immer zugutekam dass ich einfach selber irgendwo diesen Migrationshintergrund habe also das war wirklich immer das war für ganz viele immer wie so eine Erleuchtung ne wenn ich dann wirklich gesagt habe (.) ähm ja ich bin ja selber oder habe selber diese Geschichte dann haben die (.) dann hat man wieder die so ein bisschen mehr auf 
ihrer Seite ich habe auch (.) oft Gespräche geführt wirklich ganz absichtlich (.) dass ich nicht gesagt habe (.) erstmal wirklich gar nicht verraten habe dass ich ähm (.) dass ich diesen Migrationshintergrund habe und ich (.) meine das merkt man ja aus jetzt nicht sofort ne wenn ich es nicht sofort sage das heißt die haben es auch nicht gemerkt ganz ganz lange Zeit und wenn man dann diesen Punkt so rein schmeißt (.) dann merkt man es ändert sich total diese ganze Situation ändert sich total ne weil die dann (.) das Gefühl haben (.) ähm (.) sie ist eine von uns vielleicht auch (.) ne also ich denke auch ganz oft so dieses Denken ach ne das ist ja auch eine von uns so denken die ja oft das ist ja echt total-total strange aber es ist (Fallstudie 2, Interview Frau Antonova, Z. 419-442)

Zunächst schätzt Frau Antonova den eigenen Migrationshintergrund als vorteilhaft für die Zusammenarbeit mit den Eltern ein und äußert, dass es ,wie so eine Erleuchtung“ (Z. 424) für Eltern mit Migrationshintergrund wäre, von ihrer Einwanderungsgeschichte zu erfahren. Prinzipiell stellt demnach die Verbundenheit infolge der Migrationserfahrung das Enaktierungspotenzial für die Zusammenarbeit mit Eltern mit Migrationshintergrund dar. Frau Antonova gibt jedoch an, nicht über ihr Aussehen als Einwanderin identifizierbar zu sein und Informationen zu ihrem Migrationshintergrund gezielt in Gesprächen mit Eltern einzusetzen. Auffällig an der Passage ist, dass eine vermeintliche Verbundenheit zwischen ihr und den Eltern mit Migrationshintergrund, die auf der Gemeinsamkeit Migrationserfahrung beruht, Frau Antonova befremdet (,,weil die dann (.) das Gefühl haben (.) ähm (.) sie ist eine von uns vielleicht auch (.) ne also ich denke auch ganz oft so dieses Denken ach ne das ist ja auch eine von uns so denken die ja oft das ist ja echt total-total strange aber es ist so“, Z. 440 ff.). Gleichwohl leitet Frau Antonova wiederum aus der gemeinsam geteilten Erfahrung, als Schulkind in Deutschland neu eingewandert zu sein, ein besonderes Mitgefühl für eben diese Kinder ab. Generell offenbart die Passage im Kern Frau Antonovas Idealvorstellung von Integration. So erscheint die Ununterscheidbarkeit von Personen mit Migrationshintergrund und Personen ohne Migrationshintergrund als positiver Horizont von Integration. Insgesamt zeigt sich ein assimilierendes, einseitiges Verständnis von Integration, bei dem deutscher Sprachgebrauch, Äußerlichkeiten und soziale Beziehungen entscheidende Indikatoren darstellen.

Darüber hinaus präsentiert sich Frau Antonova aufgrund ihrer eigenen biografischen Erfahrungen als Rollenvorbild für Schüler*innen mit Migrationshintergrund:

ja dass man den Kindern immer wieder (2) ja (2) irgendwo ja auch ein Vorbild ist ne und dass man ja den Kindern auch immer wieder ähm auch aufzeigt dass man so eine (.) Geschichte hinter sich [...] ich habe das-diese Situation den Kinder genau so dargestellt und habe dann auch gesagt ne so und so einen Werdegang 
hatte ich auch und ich hatte die gleiche Geschichte und ich habe es auch geschafft

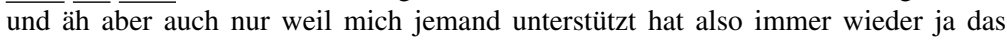
auch zu thematisieren und auch ähm als Vorbild irgendwo dazustehen und zu sagen ähm man kann es schaffen (Fallstudie 2, Interview Frau Antonova, Z. 812-834)

Grundsätzlich erscheint in der Passage die Vorbildfunktion für Kinder mit Migrationshintergrund und das Aufzeigen der eigenen Einwanderungsgeschichte als positiver Horizont des berufsbezogenen Selbstbildes. Angesichts dessen, dass ihr Migrationshintergrund nach eigenen Aussagen nicht sichtbar ist (s. o.) wirkt das Thematisieren der eigenen Einwanderungsgeschichte mit Schüler*innen mit Migrationshintergrund, ähnlich der Zusammenarbeit mit Eltern mit Migrationshintergrund, abermals wie eine strategische Ressource für den Umgang mit Familien mit Migrationshintergrund. Es dokumentiert sich unter anderem anhand der Aussage ,so eine Geschichte hinter sich zu haben“ (Z. 818), dass der Migrationshintergrund zwar ein Hindernis darstellt und Schwierigkeiten birgt, diese aber überwunden werden können. Überdies nennt Frau Antonova die Unterstützung von außen als Gelingensbedingung für die eigene erfolgreiche Bildungslaufbahn (,und ich habe es auch geschafft und äh aber auch nur weil mich jemand unterstützt hat", Z. 831 f.). ,Aufgefangen" und unterstützt zu werden ist demnach ein zentraler Fluchtpunkt in der Perspektive auf neu eingewanderte Kinder und stellt das Enaktierungspotenzial für den Bildungserfolg von neu eingewanderten Schüler*innen dar.

Alles in allem tritt als zentrale Orientierung zu Tage, dass mit der Migration verbundene Herausforderungen, wie etwa geringe bzw. keine Kenntnisse der deutschen Sprache und das Gefühl von Fremdsein, zu bewältigen sind. Als Ressource für den Umgang mit neu eingewanderten Kindern und Eltern erscheint Frau Antonovas eigene Migrationserfahrung, angesichts dieser scheinbar gemeinsamen lebensgeschichtlichen Verbindung schreibt Frau Antonova sich selbst Kompetenzen wie beispielsweise besondere Empathie und eine Vorbildfunktion zu. Im Mittelpunkt dieser Perspektive stehen jedoch die Bemühungen der (neu) eingewanderten Eltern. Deren An- und Einpassungsleistung erscheint als unerlässliche Voraussetzung für die soziale Integration der Kinder. 


\subsubsection{Auseinandersetzung mit Spannungsfeldern der pädagogischen Arbeit}

Das besondere Verständnis für neu eingewanderte Schüler*innen löst bei Frau Antonova ein starkes Verantwortungsgefühl für ein kürzlich eingewandertes polnisches Mädchen aus. Aufgrund des mangelnden Einsatzes der zuständigen Klassenleitung, so Frau Antonovas Kritik, initiiert sie selbst eine Deutschförderstunde, die sie indes an ihre persönliche Grenze bringt:

bei diesem einen Mädchen jetzt die aus Polen gekommen ist ne muss ich auch sagen das ist äh unheimlich schwierig-ich bin (.) nicht in dieser Klasse drin (.) also ich habe nicht die Klassenleitung sie ist ja in der vierten Klasse (.) und ich habe da Englisch und Musikunterricht (.) in dieser ähm (.) in dieser Jahrgangsstufe und das ist ähm für mich einfach unheimlich schwierig ähm sie aufzufangen ne weil da kommt vom Klassenlei-also von der Klassenleitung kommt da einfach unheimnicht so viel ne an-an Unterstützung und ich habe eine Zeit lang habe ich echt versucht sie (.) so-also ihr so viel Stoff zu geben dass sie eine ganze Woche ohne mich arbeiten kann quasi ne also ihr s-un-so viel Unterstützung zu geben dass sie das-dass sie-dass ich sie da weiterbringe hab dann aber echt gemerkt dass ichda komme ich so ins Straucheln weil es mir unheimlich schwierig fällt das ist ja auch für mich eine totale Zusatzarbeit ne also ich habe ja sowieso mit dieser Klassenleitung das ist auch alles komplett neu für mich (.) habe ich einfach schon unheimlich viel zu tun und dann noch nebenbei und diese eine Stunde die ich mit ihr habe (.) in der Woche (.) das ist ne es ist sehr wenig und in dieser Stunde alles das vorzubereiten was sie die ganze Woche machen soll auch für mich das gedanklich vorher vorzubereiten ist ein riesen Arbeitsaufwand wo ich inzwischen so ein bisschen von weg bin (.) ich habe es am Anfang versucht zu stemmen ich habe es einfach nicht geschafft ich habe es einfach auch zeitlich nicht geschafft dass ich irgendwann mal sagen musste ich-ich kann es einfach nicht (.) ich muss (.) es tut mir total leid und ich würde sie so gerne (.) richtig unterstützen aber ich kann es nicht ich kann es alleine auch nicht stemmen (.) geht nicht (Fallstudie 2, Interview Frau Antonova, Z. 283-339)

Zunächst verweist Frau Antonova auf die Schwierigkeit, der Schülerin zu Hilfe zu kommen, da sie nicht die hauptverantwortliche Klassenlehrerin, sondern die Englisch- und Musiklehrerin dieser Jahrgangsstufe sei und die Klassenleitung wenig Einsatz zeige. Die mangelnde Unterstützung durch die Klassenleitung ist demzufolge negativer Horizont hinsichtlich der Förderung neu eingewanderter Kinder. Bemerkenswert ist die wiederkehrende Formulierung, es sei problematisch, die Schülerin „aufzufangen“ (Z. 292) - diese Wortwahl trat bereits im Kontext des Verständnisses für neu eingewanderte Schüler*innen und des Unverständnisses gegenüber Eltern auf, die ihr Kind nicht unterstützen (,,also auf der 
einen Seite wirklich dieses Verständnis da zu stehen und gar nichts zu verstehen und da irgendwo ähm (.) aufgefangen zu werden (.) aber auf der anderen Seite dieses Nicht-Verstehen von den Eltern und äh dass die da nicht mehr tun für ihre Kinder“, Z. 706 ff.). In der Passage zu Grenzen der Unterstützung sind jedoch nicht die Eltern diejenigen, die das Mädchen auffangen (sollen), sondern Frau Antonova selbst. Die Eltern des polnischen Mädchens werden von ihr nicht thematisiert. Vielmehr versucht Frau Antonova die neu eingewanderte Schülerin in einer wöchentlichen Deutschförderstunde durch entsprechendes Lernmaterial zu unterstützen. Aufgrund der mit viel Arbeit verbundenen eigenen Klassenleitung, die sie zum ersten Mal übernimmt, und dem hohen Vorbereitungsaufwand der Deutschförderstunde habe sie es jedoch zeitlich nicht mehr geschafft, dem Mädchen zu helfen. Generell erscheint die Deutschförderstunde als Enaktierungspotenzial für die schulische Unterstützung neu eingewanderter Kinder. Die Ausführungen dokumentieren insgesamt die fehlende kollegiale Unterstützung im Hinblick auf die Deutschförderung des kürzlich eingewanderten Mädchens und die hohe Eigeninitiative des pädagogischen Handelns (,es tut mir total leid und ich würde sie so gerne (.) richtig unterstützen ab er ich kann es nicht ich kann es alleine auch nicht stemmen (.) geht nicht“, Z. 334 ff.), die von Frau Antonova vor dem Hintergrund von wenig Berufserfahrung als Belastung erlebt werden (,also ich habe ja sowieso mit dieser Klassenleitung das ist auch alles komplett neu für mich (.) habe ich einfach schon unheimlich viel zu tun“, Z. 318 ff.). Dies führt dazu, dass Frau Antonova ihren pädagogischen (Selbst-)Anspruch reduziert, eine qualitativ hochwertige Deutschförderstunde anzubieten und die Deutschförderstunde entgegen ihrer Vorstellung von optimaler Unterstützung neu eingewanderter Kinder wieder der Klassenleitung übergibt.

Grundsätzlich verschiebt Frau Antonova das Thema der Handhabbarkeit von migrationsbedingten Herausforderungen weg von dem Erfordernis der elterlichen Unterstützung hin zu der schulischen Verantwortung. Die fehlende Unterstützung der Klassenleitung des Mädchens sowie der hohe Arbeitsaufwand der eigenen Klassenleitung und der Deutschförderstunde im Kontext des Berufseintritts stellen den negativen Horizont hinsichtlich der Förderung neu eingewanderter Kinder dar. Enaktierungspotenzial für die Unterstützung besteht in dieser Perspektive aus einer gut vorbereiteten, strukturierten Deutschförderstunde sowie in der Zusammenarbeit und Unterstützung im Kollegium. In groben Zügen zeichnet sich bei Frau Antonova ein kritisches Bewusstsein dafür ab, dass die inadäquate Deutschförderung der polnischen Schülerin durch die zuständige Klassenleitung ein Bildungsrisiko für das Mädchen darstellt. Die zuvor entfaltete Fokussierung auf die Verantwortlichkeit der neu eingewanderten Eltern für den Bildungserfolg der Schüler*innen wird an dieser Passage um den Aspekt institutioneller 
Bedingungen erweitert: Dass Bildungsrisiko besteht nicht darin, dass es an Integrationsbereitschaft der polnischen Eltern mangelt, sondern dass die Schule nicht angemessen fördert.

\subsubsection{Positionierung innerhalb der Schule bzw. des Kollegiums}

Insgesamt sind Frau Antonovas pädagogische Orientierungen an Leistung und Anstrengung sowie an Eigenverantwortung und Selbstdisziplin kongruent mit der von ihr beschriebenen Lernhaltung und schulischen Performanz der Kinder. Etwa betont Frau Antonova allgemein das hohe Leistungspotenzial der Schüler*innen und beschreibt bestmögliche Lernvoraussetzungen, denn die Kinder sind aus ihrer Sicht durchweg intrinsisch motiviert und bildungseifrig. So erscheint nicht nur die Leistung, sondern auch die Einstellung der Kinder gegenüber der Schule beispielhaft. Frau Antonova vermittelt den Eindruck, dass sie in ihrer pädagogischen Arbeit an das Bildungsinteresse der Schüler*innen anschließen und aufbauen kann. Die scheinbar reibungslose pädagogische Arbeit und die Freude und Motivation der Kinder trägt insgesamt zur Stabilisierung der beruflichen Identität bei.

Eine Herausforderung für die berufliche Entwicklung und Aufrechterhaltung einer positiven Identität sind hingegen die Geschehnisse um das kürzlich eingewanderte Mädchen aus Polen. So kann Frau Antonova zwar die schwierige Lage angesichts mangelnder deutscher Sprachkenntnisse und des Gefühls des Ausgegrenztseins kürzlich eingewanderter Kinder aufgrund eigener Migrationserfahrung empathisch nachempfinden und sich mit diesen Kindern identifizieren. Ihr biografisch angelegtes Engagement und Verantwortungsgefühl für die kürzlich eingewanderte Schülerin scheint jedoch durch fehlende Teamstrukturen bzw. kollegiale Unterstützung gebremst zu werden. Im Kontext von beruflichen Anforderungen und Aufgabenstellungen in der Berufseinstiegsphase, wie zum Beispiel die zum ersten Mal übernommene Klassenleitung, wird die scheinbar alleinige Verantwortung für die neu eingewanderte Schülerin von Frau Antonova als Überforderung erlebt. Letztlich gibt sie zur Selbstentlastung die von ihr initiierte Deutschsprachförderstunde an die Klassenleitung der polnischen Schülerin ab.

Denkbar ist, dass aufgrund des geringen Anteils an Schüler*innen mit Migrationshintergrund an der Schule innerhalb des Kollegiums eine Distanz bzw. kaum Erfahrung zum Thema Umgang mit migrationsbedingter Vielfalt besteht. Der fehlende kollegiale Rückhalt kann entsprechend darauf verweisen, dass Frau Antonova in die Nischenposition der ,Migrationsbeauftragten' gedrängt wird. 


\subsubsection{Zuschreibung von Verantwortung für Bildungschancen}

Gleichwohl Frau Antonova im thematischen Kontext von Grenzen der Fördermöglichkeiten auch die schulische Verantwortung für die Unterstützung neu eingewanderter Kinder thematisiert (vgl. 3.4.3 Auseinandersetzung mit Spannungsfeldern der pädagogischen Arbeit) und aufgrund der eigenen Migrationserfahrung pädagogische Ressourcen für den Umgang mit eingewanderten Kindern und Eltern nennt (vgl. 3.4.2 Berufsbezogenes Selbstkonzept), hängen aus ihrer Sicht die Bildungschancen der Kinder mit Migrationshintergrund vor allem von den elterlichen Integrationsbemühungen ab:

also ich glaube die Eltern (.) bei den Kindern mit Migrationshintergrund (.) die-die machen die-die können da (.) Berge versetzten also ich glaube die sind wirklich der a-allerwichtigste Anknüpfungspunkt (.) das (.) glaube ich das ist so-das ist so der Schlüssel der Schlüssel zum Ganzen glaube ich (Fallstudie 2, Interview Frau Antonova, Z. 295-302)

Die Metaphern „Berge versetzen“ (Z. 296) und „Schlüssel zum Ganzen“ (Z. 301 f.) dokumentieren die außergewöhnliche Leistungsfähigkeit der Eltern mit Migrationshintergrund, die über allem zu stehen scheint. Insgesamt wird deutlich, dass die Unterstützung der Eltern Dreh- und Angelpunkt in der Perspektive von Frau Antonova auf Schüler*innen mit Einwanderungsgeschichte ist und den Kern der Orientierung hinsichtlich des schulischen Erfolgs und der Herstellung von Bildungschancen bildet.

\subsubsection{Gefahren und Fallstricke der handlungsleitenden Orientierungen}

Zentral für Frau Antonovas pädagogische Arbeit ist Schüler*innen kognitiv zu aktivieren, zu unterstützen und herauszufordern. Im Hinblick auf (neu) eingewanderte Kinder zeigt sich Frau Antonova förderorientiert. So verweist sie angesichts eigener Migrationserfahrungen auf die besondere Empathie für Kinder aus Einwandererfamilien sowie auf die Vorbildfunktion und Rolle der Mutmacherin für Schüler*innen mit Migrationshintergrund. Ein spezielles Anliegen von Frau Antonova ist es, durch eine strukturierte deutsche Sprachförderung die Bildungschancen dieser Kinder zu erhöhen.

Ein vermuteter gemeinsamer Erfahrungsraum zwischen ihr und Schüler*innen mit Migrationshintergrund und die daraus abgeleiteten spezifischen Funktionen 
und Kompetenzen können hierbei jedoch eine kulturalistische Orientierungsfigur darstellen. Mit Blick auf das polnische Mädchen wird deutlich, dass die Vielfalt von Differenzlinien bei Frau Antonova unterbelichtet bleibt. Etwa können nicht zuletzt abweichende familiale Ressourcen ungleiche (schulische) Ausgangsbedingungen zur Folge haben. Problematisch kann mithin sein, dass in Folge individuelle Bedarfe neben dem Aufbau der deutschen Sprache aus Frau Antonovas Blick geraten.

Ferner fällt auf, dass über die Differenzkategorie ,Migration“ hinaus das Thema Bildungschancen bei Frau Antonova keine weitere Rolle spielt. Schichtgebundene Leistungsunterschiede und nach sozialer Herkunft variierende Bildungseinstellungen thematisiert Frau Antonova nicht bzw. konstruiert sie ausnahmslos eine schulleistungsstarke und intrinsisch motivierte Schüler*innenschaft. Angesichts des privilegierten, ländlichen Einzugsgebiets der Schule scheint Frau Antonova mit soziokultureller Vielfalt nur wenig Berührungspunkte zu haben und überwiegend Schüler*innen aus Familien mit hohem Sozialstatus und Schulbildungsniveau zu unterrichten. Die Wahrscheinlichkeit für diese Kinder, die Schule ohnehin erfolgreich zu durchlaufen, ist hierbei relativ groß. Die mutmaßlich privilegiertere soziale Herkunft der Schüler*innen scheint auch Frau Antonovas Erwartungshaltung an die Kinder im Hinblick auf intrinsische Motivation zu orientieren. Heikel an diesem leistungsbezogenen Anspruch ist, dass Interesse an Unterrichtsinhalten bereits Schulbildungsnähe voraussetzt. Kinder aus sozial benachteiligten und schulbildungsungewohnten Milieus verfügen jedoch qua Herkunft nicht in gleicher Weise über diese Einstellungsmuster. Die Gefahr besteht, dass Frau Antonova der Zugang zu diesen Kindern und Eltern fehlt. So muss Frau Antonova aufpassen, solidarisch genug gegenüber schulleistungsschwächeren Schüler*innen und denjenigen zu bleiben, die sich dem Leistungsprinzip nicht unterordnen wollen. Im Gegensatz zu dieser kritischen Betrachtungsweise können sich die positiven stereotypen Leistungsvorstellungen im Sinne einer selbsterfüllenden Prophezeiung aber auch positiv auf das Selbstkonzept sozial benachteiligter Schüler*innen auswirken und Raum für anregungsreiche Lernund Entwicklungsmöglichkeiten schaffen.

Die vorliegenden Analysen zeigen, dass die mit der Migration verbundene eigene Anstrengungs- und Leistungsbereitschaft die tragende Hintergrundfolie ihrer berufsbezogenen Orientierung im Hinblick auf Schüler*innen und Eltern mit Migrationshintergrund bildet. Hierbei erfolgt ein undifferenzierter Blick von Frau Antonova, denn sie überträgt ihre eigenen Erfahrungen Eins-zu-eins auf alle anderen Einwander*innen. So erscheint soziale Integration in dieser Perspektive als meritokratisches Prinzip, wonach allein der Wille und die Selbstdisziplin ausschlaggebend für gleiche gesellschaftliche Teilhabechancen sind. 
Hierbei blendet Frau Antonova jedoch aus, dass Eigeninitiative und Selbstanstrengung keine ausschließlich individuelle Anlage oder Entscheidung sind, sondern vielmehr gesellschaftliche Strukturen und diskriminierende Ausschlussmechanismen, wie z. B. politische und rechtliche Vorgaben, den Rahmen für Integration vorgeben. Die egozentrische Sichtweise kann zur Folge haben, dass ganz unterschiedliche Startbedingungen der Familien nicht wahrgenommen und Eltern mit Migrationshintergrund, die nicht dem Leistungsethos folgen und Bereitschaft zur Anstrengung vorweisen bzw. sozial integriert sind, von ihr als defizitär etikettiert werden.

\subsection{Frau Kamper}

Frau Kamper arbeitet an einer Grundschule im Süden von Nordrhein-Westfalen, an der auch das einstündige, ungestörte Interview stattfand. Die Kommune, in der sich die Schule befindet, ist ein ländlicher Ort fernab der großen Ballungszentren. Allgemein handelt es sich um ein eher strukturschwaches schulisches Einzugsgebiet. So ist die Bevölkerungsdichte für die Region relativ niedrig, mit der Tendenz zur stagnierenden Einwohner*innenzahl in den letzten Jahren. Die Gemeinde ist vorwiegend Wohnort und hat keine große Bedeutung als Wirtschaftsstandort. Insgesamt ist die finanzielle Situation der Kommune angespannt. Für ein ländliches, westliches Bundesland besteht zudem ein relativ großes Ausmaß sozialer Notlagen: Das Einkommensniveau der Einwohner*innen ist niedrig und die Anteile von Arbeitslosen und Sozialhilfeempfänger*innen ist hoch. Darüber hinaus werden im Verhältnis zu anderen Kommunen in der Region viele Geflüchtete der Ortschaft zugewiesen, sodass insgesamt ein hoher Anteil an Einwohner*innen mit Migrationshintergrund zu verzeichnen ist.

Die Grundschule umfasst knapp 180 Schüler*innen sowie ca. 15 Lehrkräfte und Sonderpädagog*innen. Frau Kamper ist zum Interviewzeitpunkt Anfang 30 Jahre alt. Bei dem derzeitigen Arbeitsverhältnis handelt es sich um die erste Anstellung nach dem Vorbereitungsdienst. Insgesamt unterrichtet sie seit drei Jahren an dieser Grundschule.

\subsubsection{Konstruktion der Schüler*innen- und Elternklientel}

Im Zusammenhang der Interviewfrage nach schulspezifischen Bedarfen schildert Frau Kamper zu Beginn des Interviews ihren Eindruck von der Schüler*innenschaft: 
also ich würde sagen speziell für unsere Schule ähm die ich jetzt mal als Brennpunktschule bezeichne ähm viele Kinder aus ja bildungsfernen Elternhäusern sozial schwachen Familien ähm (.) in allen möglichen Lebensbereichen (.) ähm und auch in der Schule eigentlich einen sehr großen Bedarf haben an zusätzlicher Hilfe würde ich sagen wir bräuchten viel mehr Personal (.) gerade was Sozialarbeiter angeht ähm müsste eigentlich jeder Jahrgang einen eigenen haben (.) weil die Bedürfnisse so: groß sind und die Unterstützung einfach durch Außenstehende dass ich sagen würde dort bräuchte man viel mehr- auch viel mehr Förderlehrkräfte speziell für unser Klientel (Fallstudie 3, Interview Frau Kamper, Z. 141-152)

An der Argumentation wird ersichtlich, dass das sozial benachteiligte Einzugsgebiet der Schule einen zentralen Faktor in der Perspektive von Frau Kamper einnimmt. So charakterisiert sie ihre Schule als „Brennpunktschule“ (Z. 142) und verweist unmittelbar auf den hohen Anteil von Schüler*innen aus „,bildungsfernen Elternhäusern sozial schwachen Familien“ (Z. 142 f.). Die Zusatzinformation ,,in allen möglichen Lebensbereichen" (Z. 143) drückt hierbei die Vielfalt an individuellen Problemlagen aus. Aufgrund des damit in Verbindung zu stehenden „sehr großen Bedarf[s] an zusätzlicher Hilfe“ (Z. 144 f.) bräuchte die Schule aus ihrer Sicht mehr Unterstützung von außen. Die Hilfsbedürftigkeit auf mehreren Ebenen ist demzufolge der negative Gegenhorizont Bildes von Schüler*innen aus schulbildungsfernen Elternhäusern und sozial schwachen Familien. Der wahrgenommene personelle Mangel und der Wunsch nach Unterstützung speziell in den Bereichen Schulsozialarbeit und sonderpädagogische Förderung unterstreicht zum einen die Hilfsbedürftigkeit der Schüler*innen in unterschiedlichen Lebensbereichen. Zum anderen verweist die Differenzierung unterschiedlicher Berufsgruppen auf spezifische Funktions- und Aufgabenbereiche innerhalb der pädagogischen Arbeit. Die Formulierungen ,zusätzliche Hilfe“ (Z. 144 f.) und „Unterstützung durch Außenstehende“ (Z. 147 f.) implizieren überdies, dass ,Regelschullehrkräfte" den ,inneren Kern' des Systems Schule darstellen und Sozialarbeiter*innen und Förderschullehrkräfte ergänzend hinzukommen. Ausreichend Personalressourcen in verschiedenen pädagogischen Handlungsfeldern bilden aus dieser Perspektive das Enaktierungspotenzial, um soziale Benachteiligung zu kompensieren.

Aufgrund der Wahrnehmung des großen Unterstützungsbedarfs orientiert Frau Kamper ihre pädagogische Praxis vor allem an dem Ausgleich materieller Bedürftigkeit der Kinder sowie an alltagspraktischer Beratung der Eltern:

ja das bezieht sich auf jeden Fall so auf die hm ja (.) materielle Ausstattung der Kinder dass ich auch oft losgegangen bin und Sachen gekauft habe Hefte besorgt habe wir haben zwar in der Schule auch einen Schrank äh für bedürftige Kinder denen halt solche Dinge fehlen aber (.) der ist halt auch irgendwann aufgebraucht 
da kam dann irgendwie aus Spenden oder irgendwelchen Restbeständen-stände hm (2) ja bis hin dass ich mich darum gekümmert habe dass Kinder einen Schulranzen haben dass es Sportzeug gibt eine Federmappe ähm das habe ich jetzt nicht selber gekauft sondern mich wirklich ge-o-also darum gekümmert ähm dass mitzusammen mit der Sozialarbeiterin wo bekommen wir diese Sachen her [...] oder dass dann halt wirklich jemand was von zu Hause mitgebracht hat was noch übrig gewesen ist hm (.) dass ich mit den Eltern über Sachen wie Körperpflege gesprochen habe und denen erklärt habe ihr Kind muss warm angezogen sein das muss sich morgens die Zähne putzen die Haare kämmen ein Kind muss jeden Tag frische Unterwäsche anziehen die Kleidung muss regelmäßig in der Woche gewechselt werden (Fallstudie 3, Interview Frau Kamper, Z. 957-988)

Zunächst berichtet Frau Kamper, dass sie „,bedürftige Kinder“ (Z. 963) unterstützt, indem sie Schulmaterialien selbst kauft oder gemeinsam mit der Schulsozialarbeiterin mittels Spenden oder privaten Restbeständen organisiert. Ferner gebe es zwar in der Schule auch einen Schrank mit Schulmaterialien für auf Hilfe angewiesene Kinder, dieser sei jedoch ,auch irgendwann aufgebraucht“ (Z. 964). Hieran dokumentiert sich der enorme Unterstützungsbedarf der Schüler*innen, denen es an materieller Ausstattung für die Schule mangelt. Aus Sicht von Frau Kamper reicht nicht einmal der Schrank mit Schulbedarf aus, um alle Schüler*innen hinlänglich versorgen zu können. Des Weiteren bespricht Frau Kamper mit den Eltern alltagspraktische Themen wie die tägliche Körperpflege und wetterangemessene Kleidung. Die Ausführungen implizieren hierbei, dass Frau Kamper die Körperpflege und die Kleidung der Kinder als unzureichend wahrnimmt. Grundsätzlich elaboriert Frau Kamper anhand dieser Passage den negativen Horizont ihres Bildes von Schüler*innen aus schulbildungsfernen Elternhäusern und sozial schwachen Familien. So besteht der Unterstützungsbedarf der Familien nicht nur in finanzieller Hinsicht, sondern die Hilfsbedürftigkeit bezieht sich auch auf grundlegende Lebensbereiche wie Körperpflege und Kleidung. Materielle Unterstützung und alltagspraktische Beratung stellen in dieser Hinsicht weiteres Enaktierungspotenzial für die Kompensation der sozialen Benachteiligungslage dar.

Der Orientierungsrahmen bezüglich Schüler*innen aus schulbildungsfernen Elternhäusern und sozial schwachen Familien ist insgesamt gekennzeichnet durch die Wahrnehmung der Schüler*innenschaft als in vielerlei Hinsicht hilfsbedürftig. Der große Unterstützungsbedarf über das schulfachliche Lernen hinaus ist der negative Gegenhorizont der Sichtweise auf diese Schüler*innen. Die Schule stellt hierbei den positiven Horizont zu der sozialen Benachteiligungslage der Familien dar. In der Perspektive von Frau Kamper treten ausreichend Personalressourcen in unterschiedlichen pädagogischen Handlungsfeldern sowie materielle 
Unterstützung der Kinder und alltagspraktische Beratung der Eltern als Enaktierungspotenzial auf, um der sozialen Benachteiligung entgegenzuwirken. Als zentrale Orientierung erscheint, dass sich der sozial benachteiligte familiale Hintergrund erschwerend auf die Lernvoraussetzungen der Schüler*innen auswirkt und eine Herausforderung für die pädagogische Arbeit darstellt.

Einen thematisch anders gelagerten Diskurs zu dem Schüler*innenbild, in dessen Mittelpunkt die starke Bedürftigkeit steht, wirft Frau Kamper im Kontext der Frage zum subjektiven Verständnis von Problemschüler*innen auf:

@(.)@(4) ich würde jetzt als erstes sagen ähm die die sozusagen von der Norm abweichen was man selber so als normal empfindet (.) dass es so einen bestimmten Bereich (.) äh gibt in dem man sagt (.) so ein Verhalten ist irgendwie gesellschaftlich akzeptiert ähm (.) und Kinder die davon groß abweichen (.) nach oben oder [...] ja ich überl-denk jetzt mal an meine Klasse Kinder die zum Beispiel durch besonders aggressives oder gewalttätiges (.) Verhalten auffallen hm ja diese Gewalttätigkeit gegenüber Mitschülern oder auch den Lehrern (2) oder (.) Kinder die best- bestimmte Lernschwächen haben da w-wären ja einmal die Kinder mit dem sonderpädagogischen Förderbedarf oder (.) Kinder die (.) eine Lese-Rechtschreibschwäche haben eine Rechenschwäche (.) auf der anderen Seite auch Kinder die ähm eine besondere Begabung haben die (.) mehr geförd-gefordert werden müssen als andere (.) hm (4) ja (5) oder Kinder die halt von Zuhause einfach ähm (.) bestimmte Defizite mitbringen wie Körperpflege was dann im Schulkontext ähm halt zu Mobbing führen kann durch die Mitschüler und dadurch dass sie eben nicht angemessen gekleidet sind (.) und so diese Probleme von Zuhause halt mit in den Schulalltag bringen und dort- es dort zum Problem wird einfach durch (.) dadurch dass Mitschüler sie dann mobben ärgern (Fallstudie 3, Interview Frau Kamper, Z. 264-307)

An die Frage, was Frau Kamper unter einem Problemschüler bzw. einer Problemschülerin versteht, schließt sich zunächst ein Auflachen und eine mehrsekündige Gesprächspause an. Diese erste Reaktion kann im Zusammenhang der nachfolgenden Begriffsauslegung als Wissen über den suggestiven Gehalt der Fragestellung bzw. der Kategorie ,Problemschüler*in“ interpretiert werden. So beruft sich Frau Kamper zunächst auf Normabweichungen und subjektiven Normalitätsempfindungen (,,die sozusagen von der Norm abweichen was man selber so als normal empfindet", Z. 264 f.) Diese Bezugnahme scheint hierbei den Rahmen ihres Begriffsverständnisses abzustecken. Weiterhin bestehe ihrer Ansicht nach ein ,bestimmter Bereich“ (Z. 266), in dem Verhalten als ,normal“ (Z. 265) angesehen und ,irgendwie gesellschaftlich akzeptiert“ (Z. 267) werde. Schüler*innen, die in ihren Verhaltensweisen deutlich von dem gesellschaftlich akzeptierten Normbereich abweichen, sind unter diesem Blickwinkel Problemschüler*innen. Diese Definition verweist darauf, dass Abweichungen von der Norm nicht als solche 
bestehen, sondern erst in sozialen Interaktionen hergestellt werden. Im Folgenden kommt Frau Kamper der Aufforderung der Interviewerin nach, die Kategorie ,Problemschüler*in“ inhaltlich zu füllen und konkretisiert ihr Verständnis exemplarisch an ihrer Klasse. Dazu gehören zum einen Kinder, die durch „,besonders aggressives oder gewalttätiges Verhalten auffallen“ (Z. 282 ff.) und gewalttätig gegenüber Mitschüler*innen und Lehrkräften sind. Zum anderen benennt Frau Kamper als Problemschüler*innen Kinder mit „,bestimmten Lernschwächen“ (Z. 287), wie z. B. Schüler*innen mit sonderpädagogischem Förderbedarf oder Schüler*innen mit einer Leserechtschreib- oder Rechenschwäche. Dieser Dimension stellt sie Schüler*innen mit „,besondere[r] Begabung“ (Z. 293 f.) als weitere Unterkategorie gegenüber, die ,mehr geförd-gefordert werden müssen als andere“ (Z. 298). Bemerkenswert ist, dass Lernschwächen und besondere Begabungen hierbei wie zwei Seiten einer Medaille zu Tage treten und sich auszuschließen scheinen. Darüber hinaus führt Frau Kamper Kinder als Problemschüler*innen an, „die halt von Zuhause einfach ähm (.) bestimmte Defizite mitbringen wie Körperpflege" (Z. 299 f.) und daraufhin von ihren Mitschüler*innen gemobbt werden. Interessant ist an dieser Stelle die Hervorhebung der Peers. So tangiert dieser Typ von Problemschüler*in im Gegensatz zu den anderen Dimensionen ihr pädagogisches Handeln bzw. ihren Unterricht nur mittelbar, sondern rekurriert in erster Linie auf schädigende Interaktionen zwischen Schüler*innen. Die differenzierte Bezugnahme auf die Kategorie ,Problemschüler*in“ elaboriert Frau Kamper am Beispiel einer vermeintlich ungepflegten Schülerin:

\begin{abstract}
es hängt natürlich auch von meiner Wahrnehmung ab Dinge die ich zum Beispieldass ich eine Schülerin hatte ähm die u-immer ungekämmt in die Schule gekommen ist mit ähm zerwühlten Haaren fand ich jetzt persönlich nicht so schlimm weil ich es von mir auch kenne dass ich mir manchmal vielleicht die Haare morgens nicht ordentlich (.) kämme aber eine andere Kollegin diese Situation ganz anders bewertet und mich angesprochen hat und gesagt hat Mensch guck mal wie die immer auf dem Kopf aussieht das ist ja wirklich verwahrlost ähm (.) da musst du der Mutter mal Bescheid sagen (Fallstudie 3, Interview Frau Kamper, Z. 333-340)
\end{abstract}

Die Passage kann insofern zusammengefasst werden, dass Frau Kamper aus eigener Erfahrung heraus das äußere Erscheinungsbild des Mädchens toleriert und die „,ungekämmt[en]“ und „Zerwühlten Haare“ (Z. 334 f.) nicht als problematisch einschätzt. Eine Kollegin bewertet die Angelegenheit hingegen „ganz anders“ (Z. 338) und schließt auf Verwahrlosung. Zudem fordert sie von Frau Kamper die Bearbeitung des vermeintlichen Missstandes (,da musst du der Mutter mal Bescheid sagen“, Z. 341 f.). Das von Frau Kamper genannte Beispiel demonstriert die große Spannweite der Definition von Problemschüler*innen bzw. der 
Toleranzunterschiede von Lehrkräften: Für Frau Kamper ist es ein ,normaler Zustand, sich morgens nicht immer „ordentlich“ (Z. 337) die Haare zu kämmen, für die Kollegin ein extremer Fall von körperlicher Vernachlässigung. In diesem Zusammenhang erscheint auch der Verweis auf Mobbing von Kindern, die familialbedingte „Defizite mitbringen“ (Z. 299) plausibel, denn aus dem Blickwinkel von Frau Kamper sind (vermeintlich) ungepflegte Kinder nicht per se Problemschüler*innen.

Insgesamt dokumentieren die Ausführungen zu den subjektiven Bewertungen von Problemschüler*innen eine reflexive Perspektive auf schulische Klassifizierungen von sogenannten Problemschüler*innen. So lässt sich Frau Kamper nicht unmittelbar auf die Aufforderung der Interviewerin ein, Problemschüler*in zu definieren, sondern verweist zunächst auf perspektivgebundene Konstruktionen von Normen und Normabweichungen. Erst dann elaboriert Frau Kamper im Modus einer Exemplifizierung verschiedene Dimensionen von Problemschüler*innen. Am Beispiel einer Schülerin zeigt sich letztlich der Ermessensspielraum der Lehrkräfte. Sowohl die Maßstäbe, die herangezogen werden, um Normabweichungen zu erkennen und zu beschreiben, als auch die Wertung der Ergebnisse unterscheiden sich: Frau Kamper findet das äußere Erscheinungsbild des Mädchens ,,persönlich nicht so schlimm“ (Z. 335 f.), die Kollegin dagegen nimmt die Schülerin als ,wirklich verwahrlost“ (Z. 339) wahr. Zugespitzt kann formuliert werden, dass im Fall von Frau Kamper zwei Konstruktionen der Schüler*innenschaft aufeinandertreffen: Einerseits wird das Schüler*innenbild entlang eigener Normvorstellungen entworfen, zum anderen reibt sich ihre Sichtweise an der Bewertung von Äußerlichkeiten einer Schülerin durch ihre Kollegin.

\subsubsection{Berufsbezogenes Selbstkonzept}

Im Kontext der Frage nach dem Einfluss eigener biografischer Erfahrungen auf die pädagogische Arbeit gibt Frau Kamper an, sich bereits im Vorfeld der Befragung mit dem Zusammenhang zwischen ihren Aufwachsensbedingungen und ihrem beruflichen Werdegang auseinandergesetzt zu haben:

darüber habe ich mir auch schon Gedanken gemacht (.) dass ich mir überlegt habe warum habe ich mir diesen Beruf ausgesucht? warum möchte ich gerade Kinder unterrichten? ähm warum (.) möchte ich Kinder erziehen? warum ist es mir so wichtig sie auch zu unterstützen und mich da so aufzuopfern? was mich dann an meine Grenzen bringt (.) und ich würde schon sagen ähm dass ich da (.) Parallelen sehe aus meinem Leben zum Leben der Kinder (.) ähm ich denke das hat auch einen Grund warum ich gerade ähm zu Beginn (.) ähm meines Berufs mir eine F-eine 
Schule ausgesucht habe in der gerade sozial schwache Kinder mit vielen Problemen sind (.) und da würde ich ei-würde ich auch (.) einfach sagen ich komme halt auch aus einer eher bildungsfernen Familie (.) hm (.) die Mutter (.) hat (.) keine AuBerufsausbildung gehabt zu Beginn (.) Kinder bekommen da lag der Schwerpunkt dass ich ähm jetzt rückblickend auch beurteilen kann (.) ähm (.) ja (.) dass (.) wir auch nicht besonders viel Geld hatten wir auch in einer kleinen Wohnung gewohnt haben dass wir (2) ja dass hm wie soll ich das jetzt beschreiben? ja dass ich da schon Ähnlichkeiten zu den Kindern sehe die ich jetzt habe (.) hm wo halt welche sind die vernachlässigt worden sind wo die Mutter halt emotional ähm (.) nicht so dagewesen ist das war eb-halt bei mir auch so (.) hm (.) oder vielleicht ein Vater der sich nicht so kümmert wie ein Vater es sollte (.) das habe ich ja in der Schule auch ja da schon viele Parallelen sehe (.) auch dass die Eltern oft überfordert sind den Eindruck habe ich jetzt rückblickend von meinen Eltern auch hm (.) dass Bildung zu Hause (.) nicht so eine große Rolle spielt bei diesen Kindern sondern eher so das Überleben und ähm (.) dass ich das bei mir auch sehe wobei ich sagen muss meine Mutter sich immer bemüht hat dass äh sie mal mit- mal mit uns in ein Museum gegangen ist einfach um so (.) bestimmte Dinge die sie selber auch nicht hatte weil sie auch aus einer bildungsfernen Familie kommt so aufzufangen (.) und da sehe ich halt ähm (.) die Parallelen auf jeden Fall dass ich selber daraus komme mich in den Kindern teilweise selbst sehe und weiß die brauchen einfach Hilfe und Unterstützung (Fallstudie 3, Interview Frau Kamper, Z. 1285-1325)

Zunächst einmal stellt Frau Kamper Fragen in den Raum, die sich auf ihr Berufswahlmotiv (,warum habe ich mir diesen Beruf ausgesucht?“", Z. 1286), die Schulformwahl (,warum möchte ich gerade Kinder unterrichten?", Z. 1286 f.) und ihr außerordentliches Engagement für hilfsbedürftige Kinder (,warum ist es mir so wichtig sie auch zu unterstützen und mich da so aufzuopfern? was mich dann an meine Grenzen bringt“, Z. 1287 ff.) beziehen. Nachfolgend wirft Frau Kamper eine Argumentationslinie auf, die die vermuteten Gemeinsamkeiten zwischen ihrem Leben und dem Leben der Kinder in den Mittelpunkt rückt. Diese scheinbaren lebensgeschichtlichen „Parallelen“ (Z. 1289) sind aus ihrer Sicht auch ein Grund dafür, dass sie sich zu Berufsbeginn eine Schule mit ,sozial schwache[n] Kinder[n] mit vielen Problemen“ (Z. 1292) ausgesucht habe. Hierbei betont Frau Kamper die gezielte Entscheidung für eine Schule mit einer ausdrücklich hilfsbedürftigen Schüler*innenschaft. Anscheinende Ähnlichkeiten zwischen ihr und den Schüler*innen bestehen Frau Kamper zufolge hinsichtlich der Aufwachsensbedingungen. So verortet Frau Kamper sich selbst in einer „,eher bildungsfernen Familie“ (Z. 1294) und begründet dies mit der zunächst fehlenden Berufsausbildung ${ }^{2}$ und der frühen Mutterschaft ihrer Mutter, finanzieller

\footnotetext{
${ }^{2}$ Im Nachgang des Interviews erzählt Frau Kamper, dass ihre Mutter mit Ende Dreißig eine Berufsausbildung in der Altenpflege absolviert habe.
} 
Knappheit und bescheidenen Wohnverhältnissen (,,die Mutter (.) hat (.) keine AuBerufsausbildung gehabt zu Beginn (.) Kinder bekommen da lag der Schwerpunkt dass ich ähm jetzt rückblickend auch beurteilen kann (.) ähm (.) ja (.) dass (.) wir auch nicht besonders viel Geld hatten wir auch in einer kleinen Wohnung gewohnt haben“, Z. 1294-1301). Neben den sozioökonomisch schwächeren Lebensbedingungen kommt Frau Kamper darüber hinaus zu der Einschätzung, dass ihre Eltern mit der Kindererziehung überfordert gewesen waren. Etwa vergleicht sie Schüler*innen, ,die vernachlässigt worden sind wo die Mutter halt emotional ähm (.) nicht so dagewesen ist“ (Z. 1307 f.) mit ihrer Mutter. Ihr Vater habe ,sich nicht so kümmert wie ein Vater es sollte“ (Z. 1308 f.). Die Ausführungen lassen hierbei offen, inwiefern ihre Eltern den kindlichen Bedürfnissen und Anforderungen nicht gerecht werden konnten, lediglich in Bezug auf die Mutter deutet sie Vernachlässigung auf emotionaler Ebene an. Eine weitere Gemeinsamkeit zwischen ihr und den Schüler*innen besteht ihrer Ansicht nach darin, dass „Bildung zu Hause (.) nicht so eine große Rolle“ (Z. 1315) spielt, sondern vielmehr das „Überleben“ (Z. 1316) im Vordergrund steht. Die Verwendung des Begriffs ,Überleben` drückt hierbei die Schwere der damaligen Lebenssituation aus und impliziert eine permanente Existenzgefährdung, die es zu überstehen galt. Gleichwohl würdigt Frau Kamper die Bildungsbemühungen der eigenen Mutter, die nach ihren Aussagen ebenfalls aus einer ,,bildungsfernen Familie“ (Z. 1323) stammt und mit kulturellen Praktiken wie dem Museumsbesuch nicht vertraut zu sein schien. Zusammenfassend hält Frau Kamper fest, dass sie sich ,,in den Kindern teilweise selbst [sieht] und weiß die brauchen einfach Hilfe und Unterstützung“" (Z. 1324 f.).

Im Zentrum von Frau Kampers berufsbezogenen Selbstbild steht infolgedessen das besondere Einfühlungsvermögen für Familien, ,,die Probleme haben sich nicht so gut kümmern können“ (Z. 1398):

ich denke dass (.) ähm (.) ich mich (.) besonders in solche Familien einfühlen kann die Probleme haben die sich nicht so gut kümmern können (.) dass ich besonders empathisch bin so ein Gespür habe ähm für den Umgang mit diesen Kindern und Eltern (.) ähm (4) dass ich nachvollziehen kann dass (.) Kinder (.) nicht (.) ähm (.) so einen graden Weg gehen sondern dass halt bestimmte Lebensumstände (.) ähm dazu führen (.) dass Kinder (.) halt besch-Auffälligkeiten haben oder dass die ja wie soll ich das sagen dass die Schullaufbahn nicht gerade verläuft sondern dass es halt mal Einbrüche gibt $\mathrm{mhm}$ (.) so wie es bei mir halt auch gewesen ist ich hatte häufige Schulwechsel (.) ähm (.) hatte dann wirklich Leistungshochs und dann kamen wieder extreme Tiefs aus denen ich mich hochgezogen habe und dass ich denke (.) d-dass (.) also dass ich es gut nachvollziehen kann (.) hm (.) wenn Kinder (.) ja ähm so- so eine Schullaufbahn haben und dass ich daran denke es ist ja auch kein Wunder wenn man sich mal die Familie dahinter anguckt und die Sorgen (Fallstudie 3, Interview Frau Kamper, Z. 1397-1417) 
Frau Kampers berufliches Selbstverständnis zeichnet sich zum einen durch eine besondere Empathiefähigkeit für Familien, ,die Probleme haben sich nicht so gut kümmern können“ (Z. 1398) und zum anderen durch ein „Gespür“ (Z. 1399) für den Umgang mit diesen Kindern und Eltern aus. Dieser besondere Zugang zu Schüler*innen und Eltern in vermeintlich problematischen Lebenslagen stellt zugleich den positiven Horizont des berufsbezogenen Selbstkonzepts dar. Auffallend ist hierbei die vage Beschreibung des familialen Hintergrundes - weder werden die Probleme konkretisiert, die die Familien in der Wahrnehmung von Frau Kamper haben, noch führt Frau Kamper aus, inwiefern sich die Eltern ,nicht so gut' kümmern können. Ihr eigener schulischer Werdegang, der aus ihrer Sicht durch „häufige Schulwechsel“ (Z. 1408 f.) sowie „Leistungshochs“ und „extreme Tiefs" (Z. 1409 f.) gekennzeichnet ist, führt darüber hinaus zu mehr Verständnis dafür, dass Kinder nicht immer einen „geraden Weg“ (Z. 1401) gehen, sondern aufgrund bestimmter Lebensumstände Auffälligkeiten zeigen und die Schullaufbahn „Einbrüche“ (Z. 1404) aufweist. Sie konkludiert ihre Ausführungen zum empathischen Umgang mit diesen Kindern, indem sie auf die scheinbare Erwartbarkeit schulischer Brüche angesichts des familialen Hintergrunds verweist (,es ist ja auch kein Wunder wenn man sich mal die Familie dahinter anguckt und die Sorgen“, Z. 1416 f.).

Grundsätzlich dokumentiert die Passage zu Familien in vermuteten problematischen Lebenslagen zum einen auf emotionaler Ebene Frau Kampers Mitgefühl für diese Kinder und Eltern, zum anderen zeigt sich auf kognitiver Ebene ihre Fähigkeit zur Perspektivenübernahme. So kann Frau Kamper nicht nur aufgrund ihrer eigenen Schulzeit, sondern auch angesichts der "Sorgen“ (Z. 1417) der Familien nachvollziehen, dass Lernbiografien nicht ausschließlich positiv verlaufen. Durch die Argumentation tritt die bereits im Kontext des subjektiven Verständnisses von Problemschüler*innen aufgeworfene Orientierung konturierter hervor: Infolge eigener Erfahrungen ist Frau Kamper sensibel und aufgeschlossen für Abweichungen von Normalitätsvorstellungen und Verhaltenserwartungen im Schulkontext.

Auf die Nachfrage, welche Stärken die Schüler*innen ihrer Klasse auszeichnen, nennt Frau Kamper darüber hinaus ein vertrauensvolles Verhältnis zu den Schüler*innen:

dass die Kinder auch sehr offen zu mir sind ist eine Stärke also wirklich mit ihren Sorgen zu mir kommen das auch ansprechen können egal ob es jetzt ähm (.) den Raum Schule oder das Zuhause betrifft also d-das ist-haben auch schon andere Lehrer gesagt dass die Kinder wirklich mit vielen Dingen zu mir kommen und mir anvertrauen (.) ähm was die zum Beispiel aus ihrer Klasse nicht kennen aber 
nicht nur die Kinder auch die Eltern auf mich zukommen und mich um Rat fragen

(Fallstudie 3, Interview Frau Kamper, Z. 568-582)

Als positiv hebt Frau Kamper die Offenheit der Kinder hervor, sich mit ihren Sorgen anvertrauen zu können. Hierbei treten die Kinder sowohl mit schulischen als auch mit familialen Belangen an sie heran. Frau Kamper betont, dass bereits Kolleg*innen auf das große Vertrauen der Kinder in Frau Kampers Person aufmerksam geworden seien und selbst diese Erfahrung mit Schüler*innen nicht gemacht hätten. Darüber hinaus kommen aber nicht nur die Kinder auf Frau Kamper zu, sondern auch die Eltern suchen bei ihr Rat. Die Rolle als Vertrauensperson für Schüler*innen und Eltern in von ihr wahrgenommenen problematischen Lebenslagen erscheint demzufolge als positiver Horizont des berufsbezogenen Selbstverständnisses. Zudem grenzt sich Frau Kamper durch die Ausführungen von ihren Kolleg*innen ab, die kein vertrauensvolles Verhältnis zu ihren Schüler*innen pflegen, und markiert ihren Status als außergewöhnlich im Kollegium.

Insgesamt ist Frau Kampers Orientierungsrahmen bezüglich Familien in anscheinend problematischen Lebenslagen durch eine mitfühlende und wohlwollende Haltung aufgrund vermeintlich homologer eigener Erfahrungen gekennzeichnet. Darüber hinaus scheint sie eine vertrauensvolle Beziehung zu den Kindern herzustellen und wird sowohl für ihre Schüler*innen als auch für deren Eltern bei biografischen Krisen zu einer Vertrauensperson und Beraterin.

\subsubsection{Auseinandersetzung mit Spannungsfeldern der pädagogischen Arbeit}

Bereits im Rahmen der Dimension Konstruktion der Schüler*innen- und Elternklientel wurde dargestellt, dass Frau Kamper bemüht ist, aus ihrer Sicht bedürftige Kinder mit Schulmaterialien auszustatten und Eltern in grundlegenden Lebensbereichen wie Körperpflege und Kleidung zu beraten. An diese Beschreibung unmittelbar anschließend hinterfragt Frau Kamper kritisch ihre Befugnis, in die Privatsphäre der Familie einzudringen:

das sind ja auch so sehr private Bereiche in die ich dann eingreife wo ich mich immer gefragt habe darf ich das auch überhaupt? weil ich eine Auseinandersetzung mit einer Mutter hatte die meinte es würde uns ja gar nichts angehen wie ihr Kind angezogen ist (.) und sie hätte halt nicht viel Geld um gute Kleidung zu kaufen und da war ich dann halt auch verunsichert (.) bin ich da jetzt in einen Bereich gekommen der mich nichts mehr angeht? hm wobei ich dann immer (.) denke (.) 
ja wenn das Kind darunter leidet oder es friert oder es gemobbt wird dann muss ich ja was tun und mir das $\overline{\text { dann auch nicht verbieten lasse (Fallstudie 3, Interview }}$ Frau Kamper, Z. 989-1010)

Infolge einer Auseinandersetzung mit einer Mutter, die sich über den Eingriff in ihren persönlichen Lebensbereich beschwert, ist Frau Kamper hinsichtlich ihrer Zuständigkeit für die vermeintlichen familialen Probleme verunsichert. So zweifelt Frau Kamper daran, ob sie überhaupt in ,,so sehr private Bereiche [...] eingreife[n]" (Z. 989) dürfe bzw. ob es sich nicht um Bereiche handle, die sie nichts mehr ,angehen“ (Z. 991). Hieran dokumentiert sich zunächst einmal, dass Frau Kamper den Einwand der Mutter ernst nimmt und mit der Kritik in Bezug auf ihre eigene Rolle als Lehrerin reflektierend umgeht. Sobald das Kind jedoch "leidet“, „friert" oder ,gemobbt wird“ (Z. 1001 ff.) fühlt sich Frau Kamper hingegen zum Handeln verpflichtet. Das Wohlergehen des Kindes steht demnach an erster Stelle; diesfalls lasse sich Frau Kamper auch nichts ,,verbieten“ (Z. 1010). In dieser Perspektive tritt der wahrgenommene Handlungsbedarf als positiver Horizont des Rechts zum Handeln zutage - die Missachtung der Privatsphäre der Familie erscheint hingegen als negativer Horizont. Das Spannungsfeld von Handlungsbedarf und Handlungsberechtigung löst Frau Kamper für sich auf, indem sie die Beeinträchtigung von kindlichen Grundbedürfnissen in den Vordergrund ihrer pädagogischen Arbeit stellt. Die Wortwahl, sich nichts verbieten lassen` schließt hierbei jegliche Unsicherheit über die Pflicht und das Recht in die elterliche Erziehung einzugreifen aus. Der von ihr markierte Handlungsdruck führt letztlich dazu, trotz möglichen Widerstands der Eltern zu intervenieren.

Ein weiteres Thema, zu dem Frau Kamper in einem kritischen Verhältnis zu stehen scheint, ist die institutionelle Zuständigkeit für Kinder in problematischen Lebenslagen. So entfaltet Frau Kamper auf die Frage nach der Verantwortung der Schule ihre Sichtweise auf ungleiche Umgangsweisen der Lehrkräfte mit diesen Kindern:

also ich (.) hab wirklich Kollegen gesehen die ähm ihren Unterricht halt durchziehen (.) und alles was irgendwie darüber hinausgeht w-was für Probleme die Kinder mitbringen darauf gar nicht groß eingegangen wird (.) dass ich dann aber auch Kollegen sehe die sich wirklich aufopfern und ähm Sachen für die Kinder kaufen ähm Material selber besorgen also die wirklich bis an ihre Grenzen gehen (.) und ähm ich glaube da ist (.) nie ein Ende in Sicht bei den großen Bedürfnissen die da (.) bestehen (.) ja das Problem ist halt es ist nirgendswo (.) hm geschrieben wie-wo die Grenzen sind also unsere Aufgabe ist ja schon zu (.) also Bildung und Erziehung (.) aber wie weit der Rahmen des Erziehens geht ist nirgends ähm festgelegt (Fallstudie 3, Interview Frau Kamper, Z. 922-935) 
Auf der einen Seite führt Frau Kamper Kolleg*innen an, die ihren Unterricht „,durchziehen“ (Z. 924) und auf Probleme der Kinder „nicht groß“ (Z. 925) eingehen. Auf der anderen Seite gibt es Lehrkräfte, die sich ,aufopfern“ (Z. 926) und Material für die Kinder kaufen bzw. besorgen und „bis an ihre Grenzen gehen“ (Z. 927). Hieran dokumentiert sich, dass der Einsatz für bedürftige Kinder eine bedeutsame Differenzlinie zwischen den Lehrkräften darstellt. Frau Kamper unterscheidet zwischen ,ignoranten " und , aufopferungsvollen` Lehrkräften, wobei sie sich offenbar zu den , aufopferungsvollen' Lehrkräften zählt. Die Formulierungen , aufopfern' und ,bis an die Grenze gehen' sind von hoher Emotionalität gekennzeichnet, weisen sie doch auf eine Hingabe ohne Rücksicht auf die eigene Person hin. Resümierend hält Frau Kamper fest, dass aufgrund der „großen Bedürfnisse“ (Z. 928) der Kinder der Unterstützungsbedarf niemals endet. Für problematisch erachtet sie hierbei fehlende formale Richtlinien für die Förderung bedürftiger Schüler*innen, insbesondere das Fehlen von festgelegten Grenzen des schulischen Erziehungsauftrages. Keine institutionell verankerte Zuständigkeit und keine Verbindlichkeiten bilden entsprechend ihren negativen Gegenhorizont von der schulischen Verantwortung für unterstützungsbedürftige Kinder. So erscheint als Kern der Orientierung, dass sich ,ignorante' Lehrkräfte entziehen (können) und sich allein die ,aufopferungsvollen' Lehrkräfte mit den Spannungsfeldern und Unsicherheiten von Handlungsberechtigung, -bedarf und -druck auseinandersetzen und die Verantwortung für diese Kinder übernehmen. Die Kritik an ,ignorante' Lehrkräfte, die sich für die Probleme der Schüler*innen nicht zu interessieren scheinen, tritt hierbei offen zutage.

\subsubsection{Positionierung innerhalb der Schule bzw. im Kollegium}

Frau Kamper schreibt sich selbst ein spezifisches Kompetenzprofil zu, das aus einer besonderen Empathiefähigkeit für Schüler*innen aus Familien in problematischen Lebenslagen sowie einem „Gespür“ (Z. 1399) für den Umgang mit diesen Kindern und Eltern besteht. Hierbei leitet Frau Kamper ihren besonderen Zugang zu Schüler*innen aus vermeintlich schwierigen Familienverhältnissen aus eigenen biografischen Erfahrungen ab. Angenommene Gemeinsamkeiten des Erfahrungshintergrundes bestehen aus ihrer Sicht hinsichtlich bescheidener Lebensverhältnisse und (emotionaler) Vernachlässigung durch die Eltern. Die eigene belastete Familiensituation und die erschwerten Bedingungen des eigenen Aufwachsens führen aus der Perspektive von Frau Kamper zu mehr Verständnis für die herausfordernde Lebenssituation der Schüler*innen und deren Auswirkung auf die Lern- und Leistungsfähigkeit und versetzen sie darüber hinaus 
offenbar in die Position einer Vertrauensperson. Der besondere Zugang und die Rolle einer ,natürlichen Verbündeten' für Schüler*innen und Eltern in problematischen Lebenslagen unterscheide sie ferner von den Kolleg*innen. So hebt Frau Kamper die Rückmeldung der Kolleg*innen hervor, dass die vertrauensvolle Beziehung zwischen ihr und den Kindern außergewöhnlich sei (vgl. 3.5.2 Berufsbezogenes Selbstkonzept). In Bezug auf ihr Engagement für bedürftige Schüler*innen scheint Frau Kamper auch aus dem Rahmen des ,Stammkollegiums" herauszuragen. So beschreibt sie im Zusammenhang des Fort- und Weiterbildungsbedarfs, dass erfahrene und mit den lokalen Gegebenheiten vertraute Kolleg*innen Informationen zu weiteren unterstützenden Institutionen und Einrichtungen fehlen:

als mein Berufseinstieg war (.) wusste ich überhaupt gar nicht (.) wo schicke ich diese Eltern hin? wo bekommen die welche Hilfe? dass ich puh zum Beispiel (.) hm (.) bei einer Schülerin gleich von Anfang an ähm große Defizite in Mathematik aufgefallen sind und ich gar nicht wusste wo kann ich jetzt diese Mutter überhaupt hinschicken? wo kann die das überprüfen lassen? welche Hilfen stehen ihr dann $\mathrm{zu}$ ? wo bekommt man welche Hilfe (.) ähm (.) dass mir das einfach gefehlt hat und selbst Kolleginnen die schon seit äh fast dreißig Jahren im Beruf sind erstaunt waren dass ich die dann ähm in [Stadt B] zu einem Institut zur Überprüfung geschickt hatte nicht mal die alte Kollegin wusste das und hat mich dann nach der Nummer gefragt dass sie das auch weitergeben konnte (Fallstudie 3, Interview Frau Kamper, Z. 1039-1052)

Am Beispiel einer Schülerin, die ,große Defizite in Mathematik“ (Z. 1046) aufweist, schildert Frau Kamper ihre anfängliche Unkenntnis über außerschulische Hilfsangebote. Bemerkenswert ist aus ihrer Sicht, dass sogar Kolleg*innen, die seit langer Zeit im Beruf stehen, das von ihr recherchierte Institut nicht zu kennen scheinen und Frau Kamper um die Kontaktdaten bitten. In der Erzählung ist die Auseinandersetzung mit Unterstützungsangeboten anderer Einrichtungen bereits zum „Berufseinstieg“ (Z. 1039) positiver Horizont für den Umgang mit unterstützungsbedürftigen Schüler*innen und Eltern, wohingegen die Unwissenheit der Kolleg*innen mit jahrzehntelanger Berufserfahrung als negativer Gegenhorizont hervortritt. Grundsätzlich zeichnet sich in dieser Passage dieselbe Orientierung $a b$, wie sie bereits in der Auseinandersetzung mit Spannungsfeldern der pädagogischen Arbeit herausgearbeitet wurde: Frau Kamper differenziert zwischen Lehrkräften, die interessiert und bemüht sind, Kinder und Eltern in problematischen Lebenslagen bestmöglich zu unterstützen und Lehrkräften, die eher desinteressiert sind und nicht eigenständig tätig werden. 
Insgesamt scheint Frau Kamper die Rolle einer Vertrauensperson als persönliche Auszeichnung wahrzunehmen und ihre lebensgeschichtlichen Erfahrungen als Ressource für den Umgang mit Familien in problematischen Lebenslagen zu werten. Gleichwohl sich Frau Kamper nach dem Vorbereitungsdienst gezielt eine Schule ausgesucht hat, ,in der gerade sozial schwache Kinder mit vielen Problemen sind" (Z. 1292) zeigt sich, dass die ,aufopferungsvolle" pädagogische Arbeit als Belastung erlebt wird, die sie scheinbar bis an ihre Grenzen bringt. Hierbei deutet sich an, dass Frau Kamper die im eigenen biografischen Hintergrund angelegte Eigenständigkeit hinsichtlich der Bewertung und Förderung von Kindern aus problematischen Familienverhältnissen im Zuge beruflicher Sozialisation einbüßen könnte. Dies dokumentiert sich am Beispiel der Schülerin mit „ungekämmt[en]“ und „zerwühlten Haare[n]“ (Z. 334 f.), bei der ihre Kollegin das äußere Erscheinungsbild des Mädchens als Hinweis für Verwahrlosung interpretiert und Frau Kamper auffordert, das Gespräch mit der Mutter zu suchen (vgl. 3.5.1 Konstruktion der Schüler*innen- und Elternklientel). Letzten Endes scheinen ihre Empathiefähigkeit und ihr besonderes Verständnis für diese Kinder in der Nische der Vertrauensperson Geltung zu finden. Die einseitige Rollenübernahme bzw. die informelle Zuständigkeit und Verantwortungsübernahme führt bei Frau Kamper zu Enttäuschung und Unzufriedenheit.

\subsubsection{Zuschreibung von Verantwortung für Bildungschancen}

Über das gesamte Interview hinweg kann die Auseinandersetzung mit Funktionen, Aufgaben, Rechten und Pflichten von Lehrkräften nachgezeichnet werden. So differenziert Frau Kamper immer wieder zwischen den Berufsgruppen ,Regel ‘und Förderschullehrkräften sowie Schulsozialarbeiter*innen, denen sie spezifische Aufgaben- und Funktionsbereiche zuschreibt. Etwa seien aus ihrer Sicht die Förderschullehrkräfte aufgrund ihrer „ganz andere[n] Ausbildung“ (Z. 835) hauptverantwortlich für Kinder mit sonderpädagogischem Förderbedarf. Die Sozialpädagog*innen bilden das Bindeglied zwischen Elternhaus, Schule und sozialen Institutionen und setzen sich für „die Belange der Kinder und Eltern ein“ (Z. 124 f.). Wie bereits in der Auseinandersetzung mit Spannungsfeldern der pädagogischen Arbeit herausgearbeitet, besteht für Frau Kamper ein generelles Problem darin, dass Zuständigkeiten für Schüler*innen in problematischen Lebenslagen auf institutioneller Ebene nicht klar geregelt sind (,,ja das Problem ist halt es ist nirgendswo (.) hmm geschrieben wie- wo die Grenzen sind also unsere Aufgabe ist ja schon zu (.) also Bildung und Erziehung (.) aber 
wie weit der Rahmen des Erziehens geht ist nirgends ähm festgelegt“, Z. 929935). Die Offenheit der Erziehungsarbeit von Lehrkräften führt aus ihrer Sicht dazu, dass sich ,ignorante' Lehrkräfte der Verantwortung für Schüler*innen aus problematischen Lebensverhältnissen entziehen können. Es dokumentiert sich, dass formale Richtlinien für die Erziehungsarbeit bzw. eine institutionelle Strukturierung von Verantwortlichkeiten aus der Perspektive von Frau Kamper als handlungsentlastend wahrgenommen werden. Beispielsweise wünscht sich Frau Kamper für den Umgang mit Schüler*innen aus problematischen Familienverhältnissen obligatorische Hausbesuche, die prinzipiell im Zuständigkeitsbereich der Schulsozialarbeiterin zu liegen scheinen:

was ich noch gut finden (.) würde wenn es sozusagen verpflichtend ist (.) und die Zeit dafür da ist wirklich auch (.) so Hausbesuche zu machen also das gibt's an unserer Schule auch dass manche Kollegen das dann machen mit der Sozialarbeiterin in speziellen Fällen Hausbesuche sich dann auch mal umgucken wie sieht es so aus (.) mit den Eltern sprechen hm (.) das hab ich jetzt nicht gemacht dass ich dort nach Hause gefahren bin (.) weil ich gar nicht den Anlass dafür gesehen habe und mir auch immer gesagt worden ist dafür ist die Sozialarbeiterin zuständig dort mal hinzufahren und zu gucken und nachzufragen (Fallstudie 3, Interview Frau Kamper, Z. 747-761)

Anhand dieser Passage wird die für Frau Kamper grundlegende Schwierigkeit des pädagogischen Handelns erneut deutlich: Es gibt scheinbar keine klare Zuordnung von Verantwortung bzw. besteht Handlungsspielraum bei Hausbesuchen. So unternehmen „manche Kollegen [...] in speziellen Fällen“ (Z. 749 f.) gemeinsam mit der Sozialarbeiterin Hausbesuche, um sich von der Wohnsituation einen Eindruck zu bilden und mit den Eltern zu sprechen. Frau Kamper hingegen habe noch keinen Hausbesuch selbst gemacht, da sie aus ihrer Sicht bislang keinen Anlass sah und ihr gesagt wurde, dass dafür die Sozialarbeiterin zuständig sei.

Insgesamt scheint Frau Kamper die Bearbeitung von Bildungsungleichheit als relevante Aufgabe ihrer eigenen pädagogischen Arbeit zu werten. So kann ihr großes Interesse und Engagement für Schüler*innen aus schwierigen Lebensverhältnissen im gesamten Interview rekonstruiert werden. Es zeichnet sich jedoch $\mathrm{ab}$, dass die fehlende bzw. unklare Zuordnung von Verantwortung hierbei zur Verantwortungsdiffusion führt: Nicht alle Lehrkräfte übernehmen Verantwortung für unterstützungsbedürftige Kinder. Auch scheinen die unterschiedlichen pädagogischen Handlungsfelder der ,Regel'-, Förderschullehrkräften und Schulsozialarbeiter*innen aus dem Blickwinkel von Frau Kamper wenig miteinander verbunden zu sein und vor allem der Entlastung von Verantwortlichkeit für ,Regelschullehrkräfte‘ zu dienen. 


\subsubsection{Gefahren und Fallstricke der handlungsleitenden Orientierungen}

Die Erfahrungen von bescheidenen und restriktiven Lebensumständen, von (emotionaler) Vernachlässigung durch die Eltern sowie der Entwurf einer mühevollen, durch Brüche gezeichneten Schulbiografie sind konstitutiv für ihr berufliches Selbstverständnis. So erscheint ihr eigener biografischer Hintergrund als Ressource im Hinblick auf Empathiefähigkeit und Verständnis für Kinder aus vermeintlich ähnlichen Lebensbedingungen. Ihre herkunftsbedingte Perspektive mag sich positiv auf Kinder aus problematischen Familienverhältnissen auswirken, indem diese Schüler*innen mit Frau Kamper auf eine verständnisvolle Vertrauensperson treffen, die eventuell mehr kritisches Bewusstsein für die Auswirkungen von Lebensbedingungen auf schulische Lernvoraussetzungen zeigt als Lehrkräfte aus sozial privilegierten Herkunftsverhältnissen (vgl. 3.5.2 Berufsbezogenes Selbstkonzept). Problematisch kann hierbei sein, dass eigene biografische Erfahrungen der Vernachlässigung und bescheidener Lebensumstände zu unreflektierten Identifizierungsprozessen mit Kindern, denen sie ähnliche Aufwachsensbedingungen unterstellt, führen können. Zudem scheint die Reichweite der Empathiefähigkeit auf vermeintlich homologen lebensgeschichtlichen Erfahrungen beschränkt zu sein. Mit Blick auf den eingangs erwähnten hohen Anteil an Einwohner*innen mit Migrationshintergrund im Einzugsbereich der Schule fällt der fehlende Bezug zu Schüler*innen ungleicher ethnischer, kultureller und sozialer Herkunft auf. So spielt das Thema Migration in dem Interview mit Frau Kamper kaum eine Rolle. Zwar berichtet sie ganz zu Beginn des Interviews von einer „Sprachlernklasse“ (Z. 32) in der Kinder, „die die deutsche Sprache nicht so gut beherrschen weil sie zum Beispiel erst vor Kurzem aus dem Ausland nach Deutschland gekommen sind [...] oder schon seit ein paar Jahren in Deutschland leben aber immer noch nicht so gut die deutsche Bildungssprache beherrschen“ (Z. 32-37), speziell gefördert werden. Zu diesem institutionalisierten Förderangebot für deutschsprachliche Kompetenzen scheint Frau Kamper aber in keiner weiteren Beziehung zu stehen. Im Zusammenhang mit ihrem subjektiven Verständnis von besonderen Lebenslagen kommt Frau Kamper darüber hinaus auf Kinder zu sprechen, ,die hier in Deutschland ähm (.) nur geduldet sind keine richtige Aufenthaltsgenehmigung haben also nie wissen ob sie ausreisen müssen wie lange sie noch da sind“ (Z. 215 ff.). Im weiteren Interviewverlauf werden die mit der Migration verbundenen Herausforderungen wie geringe Deutschkenntnisse und ein ungeklärter Aufenthaltsstatus nicht weiter thematisiert. Eine ähnliche Bezugnahme kann bei Schüler*innen mit sonderpädagogischem Förderbedarf festgestellt werden. So erwähnt Frau Kamper eingangs die „Integrationsklasse“ 
(Z. 104), in der ,immer eine Förderschullehrerin mit drin“ (Z. 105) ist. Darüber hinaus wird laut ihrer Aussage eine bestimmte Anzahl von „Förderschulkinder" (Z. 89) in den ,Regelklassen“ unterrichtet und von einer Förderschullehrerin betreut. Hierbei scheint sie wenig mit der Arbeit der sonderpädagogischen Lehrkräfte verbunden zu sein. Nach eigenen Aussagen kommt Frau Kamper ferner mit Schüler*innen aus nicht benachteiligten Lebensverhältnissen wenig in Kontakt. So beschreibt sie, dass in dem Einzugsgebiet der Schule größtenteils ,,sozial schwache Familien" (Z. 159) leben und nur sehr wenige Eltern in ihrer Wahrnehmung aus der ,mittleren Bildungsschicht“ (Z. 162) stammen. Kinder aus der „oberen Bildungsschicht“ (Z. 239 f.) gebe es an ihrer Schule überhaupt nicht.

Kritisch zu betrachten ist des Weiteren, dass der besondere Zugang zu unterstützungsbedürftigen Familien bei Frau Kamper nicht in einer selbstbewussten Bewertung von Rollenerwartungen mündet. So problematisiert Frau Kamper, dass es keine formalen Vorgaben für die Verantwortlichkeit für bedürftige Schüler*innen und Eltern gebe, die Zuständigkeiten regeln und einfordern, sondern die Umgangsweise im Ermessens- und Willkürspielraum der Lehrkräfte liege. Angesichts der fehlenden formalen Verpflichtung können sich ,ignorante' Lehrkräfte entziehen, sodass sich allein die ,aufopferungsvollen' Lehrkräfte mit den Spannungsfeldern von Handlungsberechtigung, -bedarf und -druck auseinandersetzen. So ist Frau Kamper im Hinblick auf Recht und Anlass des Eingreifens in den Privatraum ,Familie' sowie hinsichtlich des Rechts der Eltern auf Eigenwille verunsichert (vgl. 3.5.3 Auseinandersetzung mit Spannungsfeldern der pädagogischen Arbeit).

Zusammenfassend scheint Frau Kamper in einem ambivalenten Verhältnis gegenüber ihrer eingenommenen Rolle zu stehen. Auf der einen Seite schreibt sie sich selbst eine besondere Empathiefähigkeit und ein gewisses „Gespür“ (Z. 1399) für den Umgang mit Kindern und Eltern in problematischen Lebenslagen zu. Sie zeigt sich angesichts der Sorgen der Familien verständnisvoll gegenüber schulischen Krisen und berichtet von einem vertrauensvollen Verhältnis zu den Schüler*innen und Eltern. Ferner zählt sie sich selbst zu den ,aufopferungsvollen' Lehrkräften, die sich engagiert für das Wohlergehen der Kinder einsetzen. Dieses besondere Rollenverständnis ist ihr positiver Horizont des berufsbezogenen Selbstkonzepts, das sie auch von anderen Lehrkräften unterscheidet. Als negativer Gegenhorizont zeichnet sich zugleich Frust über diese einseitige Rollenübernahme ab. Etwa problematisiert sie das Fehlen von Verbindlichkeiten und obligatorischer Zuständigkeit in Bezug auf Kindern in problematischen Lebenslagen. Brisant im Hinblick auf die Entwicklung gleicher Bildungschancen dieser Schüler*innen erscheint, dass sich die ,Regel ${ }^{\star}-$ und Förderschullehrkräfte sowie 
die Sozialpädagog*innen nicht als pädagogische Handlungseinheit verstehen und sich nicht gleichermaßen aktiv in die Bildungs- und Erziehungsarbeit einbringen.

\subsection{Herr Jansen}

Das fast zweistündige Gespräch mit Herrn Jansen verlief ohne äußere Störungen und fand an der kleinstädtischen Grundschule im nördlichen Teil NordrheinWestfalens statt. Die Kommune der Schule befindet sich in einer eher strukturstarken Region. Aufgrund ortsansässiger Wirtschaftsunternehmen, die die größten Arbeitgeber der Region darstellen, ist die Arbeitslosenquote vergleichsweise gering und das Einkommensniveau der Bevölkerung relativ hoch. Die Anteile der Einwohner*innen, die öffentliche Sozialleistungen beziehen, ist unterdurchschnittlich für die Region. Insgesamt zeichnet sich die Kommune im Vergleich zu anderen Kommunen in Nordrhein-Westfalen durch eine verhältnismäßig wohlhabende Bevölkerung aus. Das gute Arbeitsplatzangebot in der Region führt ferner zu einem tendenziellen Bevölkerungswachstum, vor allem steigt der Anteil der Einwohner*innen mit Migrationshintergrund. Angesichts dieser Bevölkerungsentwicklung und der guten wirtschaftlichen Lage fällt der vergleichsweise schwache sozioökonomische Status von Einwohner*innen mit Migrationshintergrund umso schwerer ins Gewicht.

Die Grundschule, an der Herr Jansen unterrichtet, umfasst knapp 300 Schüler*innen sowie ungefähr 25 Lehrkräfte und Förderschullehrkräfte. Seit dem vergangenen Schuljahr werden Schüler*innen mit dem Förderschwerpunkt Hören und Kommunikation an der Schule aufgenommen. Herr Jansen ist zum Zeitpunkt des Interviews Anfang 30 Jahre alt. Unmittelbar nach dem Lehramtsstudium nahm er seinen Vorbereitungsdienst an der Grundschule auf, an der auch das Gespräch stattfand. Im Anschluss daran bot sich die Möglichkeit, an der Schule mit einer Festanstellung zu bleiben. Zum Interviewzeitpunkt unterrichtet er dort seit nunmehr anderthalb Jahren.

\subsubsection{Konstruktion der Schüler*innen- und Elternklientel}

Auf die Frage nach dem Einzugsgebiet der Schule beschreibt Herr Jansen eine vielfältige Schüler*innenschaft:

es ist bunt gemischt (.) also wir haben tatsächlich Kinder von den Ärzten oben aus dem Krankenhaus ne eine Bankerin hab ich da als Mutter drin und so weiter ich 
hab aber auch (.) ähm Hartz IV-Empfänger-Eltern (.) also wirklich bunt gemischt [...] ja und also wir gelten laut den Zahlen sogar teilweise als Problemschule wir haben Migrations- Kinder mit Migrationshintergrund von fünfundzwanzig bis zweiunddreißig Prozent je nachdem hat unser Chef mal gesagt (.) empfinden wir aber noch nicht so (Fallstudie 4, Interview Herr Jansen, Z. 657-682)

Aus Sicht von Herrn Jansen sind die Schüler*innen „bunt gemischt“ (Z. 657). So unterrichte er Kinder von Ärzt*innen und Bankangestellten sowie Kinder, deren Eltern Arbeitslosengeld II beziehen. Neben den unterschiedlichen sozioökonomischen Hintergründen nennt Herr Jansen einen Anteil an Kindern mit Migrationshintergrund von 25 bis 32 Prozent. „Laut den Zahlen“ (Z. 676) gelte die Schule „sogar teilweise als Problemschule“ (Z. 676). Das Kollegium schätze die Schulsituation ,aber noch nicht“ (Z. 682) als problematisch ein. Hieran dokumentiert sich, dass ein hoher Anteil an Schüler*innen mit Migrationshintergrund von Herrn Jansen (und dem Kollegium) nicht per se als Problem wahrgenommen wird und Herr Jansen negative Fremdzuschreibungen zurückweist.

Ein ähnliches Orientierungsmuster lässt sich im Hinblick auf das subjektive Verständnis von Problemschüler*in rekonstruieren. So antwortet Herr Jansen auf die Frage, was er unter einem Problemschüler' bzw. einer Problemschülerin versteht, folgendermaßen:

Herr Jansen: gewalttätige Kinder und solche wie ich sie gerade beschrieben habe die wirklich psychische Erkrankungen haben und vielleicht auch schwere Fälle von ADHS (.) aber würde ich erst mal generell gar nicht als Problemkinder bezeichnen

Interviewerin: mhm (.) wie meinst du das? also warum sind das nicht per se Problemkinder?

Herr Jansen: man kann die eigentlich bekommen nicht alle je nach Schweregrad oder je nach ähm (.) Erscheinungsbild der Krankheit (.) ähm (.) also ich würde sie erst mal nicht dazu zählen aber es gibt sicherlich welche die dazu zählen weil man ist-nicht immer so einfach manchmal sind nämlich Kinder mit ADHS auch ein bisschen mehr aggressiv und dann sind die schon ein Problemkind ne aber sie müssen es nicht zwingend sein ich hab zum Beispiel einen in der Klasse der ist super lieb der würde vielleicht als Problemkind gelten bei vielen Lehrern aber für mich ist das kein Problemkind (.) der hat zwar-ach so das ist eine krasse Story der w-die Mutter wollte den umbringen (.) die ähm der wohnt jetzt beim Vater [...] der hat sich getrennt und in diesem-und als der Mann sich getrennt hat dann hat sie irgendwie einen Tötungsversuch vorgenommen und (.) hat sich aber während des Vorgangs das-hat sie die Polizei und einen Krankenwagen gerufen (.) sich selbst angezeigt der kam in meine Klasse (.) der war vorher auf einer anderen Schule und der ist jetzt seit zwei Jahren bei uns und äh ka-wiederholte bei mir die dritte Klasse (.) ähm der hat halt schwer ADHS aber für mich gilt der trotzdem nicht als Problemkind weil sein Vater super engagiert ist das mit der Mutter sich wieder 
halbwegs eingerenkt (.) hat sie sogar Besuchsrecht hat oder er auch bei ihr ist (.) und dem geht es so ganz gut der ist kein Problemkind mehr das war er vielleicht mal ein Problemkind ist für mich wirklich ein Kind was täglich aneckt (.) so wie Anna oder bei mir der ein oder andere Junge die wirklich verhaltensauffällig sind in ihren Aggressionen (Fallstudie 4, Interview Herr Jansen, Z. 820-888)

Zunächst einmal kommt Herr Jansen der Aufforderung der Interviewerin im Sinne der Fragestellung nach und ordnet „gewalttätige Kinder“ (Z. 820) sowie Kinder mit „,psychische[n] Erkrankungen“ (Z. 824 f.) der Kategorie ,Problemschüler*innen“ zu. Letztere Dimension bezieht sich auf eine vorangegangene exemplarische Illustration eines vermutlich psychisch kranken Mädchens namens Anna. Hinzu kommen ,vielleicht auch schwere Fälle von $\mathrm{ADHS}^{3}$ “ (Z. 829), wobei diese Kinder aus seiner Sicht nicht generell als Problemschüler*innen zu bezeichnen sind. Auf die Nachfrage, warum schwere Fälle von ADHS aus seiner Perspektive an sich kein Problem darstellen, argumentiert Herr Jansen, dass man Schüler*innen mit ADHS „eigentlich bekommen“ (Z. 835) im Sinne von erreichen kann. Diese Auffassung, die zugleich seinen positiven Horizont von Schüler*innen mit ADHS darstellt, schränkt er durch den „Schweregrad“ oder „Erscheinungsbild der Krankheit“ (Z. 835 f.) ein, da Kinder mit ADHS „manchmal [...] ein bisschen mehr aggressiv“ (Z. 842) und in diesem Fall ein „Problemkind“ (Z. 843) seien. Aggressiveres Verhalten erscheint entsprechend als negativer Gegenhorizont seines Bildes von Kindern mit ADHS. Daran anschließend erzählt Herr Jansen von einem an ADHS erkrankten Schüler seiner Klasse. Die Betonung der positiven Charaktereigenschaft des Jungen (,,ich hab zum Beispiel einen in der Klasse der ist super lieb“, Z. 847) kann hierbei als Opposition zu der antizipierten Sichtweise der Kolleg*innen gedeutet werden. So würde der Schüler „vielleicht als Problemkind gelten bei vielen Lehrern“ (Z. 851), für ihn sei es aber kein Problemschüler. Herr Jansen ergänzt, dass der Junge angesichts seiner ADHS-Erkrankung und seiner „krasse[n] Story“ (Z. 852) „vielleicht mal ein Problemkind“ (Z. 882 ff.) gewesen sei. Hierbei bringt er seine Eindrücke zu den kritischen Lebensereignissen des Schülers wie die Trennung der Eltern, dem Tötungsversuch an dem Jungen durch die Mutter, der Trennung von der Mutter, dem Schulwechsel und der Klassenwiederholung in eine zeitliche und (suggerierte) kausale Ordnung, die auf den Befund ,schwerer Fall von ADHS * hinausläuft. Für Herrn Jansen zähle der Schüler ,trotzdem nicht als Problemkind“ (Z. 875 f.). Etwa haben sich mittlerweile die Familienverhältnisse stabilisiert (,weil sein Vater super engagiert ist das mit der Mutter sich wieder halbwegs eingerenkt (.) hat sie sogar Besuchsrecht hat oder er auch bei ihr ist“, Z. 880 f.)

${ }^{3}$ Die Abkürzung ADHS steht für Aufmerksamkeitsdefizit-Hyperaktivitätsstörung. 
und dem Schüler gehe ,es so ganz gut“ (Z. 881 f.). Solide Familienverhältnisse, inklusive Engagement der Eltern bzw. in diesem Fall des Vaters, erscheinen unter diesem Blickwinkel als Enaktierungspotenzial für den pädagogischen Umgang mit diesen Schüler*innen. Nachfolgend definiert Herr Jansen einen Problemschüler bzw. eine Problemschülerin als ,ein Kind was täglich aneckt“" (Z. 886) wie zum Beispiel das vermeintlich psychisch kranke Mädchen in seiner Klasse oder Kinder, die ,wirklich verhaltensauffällig sind in ihren Aggressionen“ (Z. 887 f.). Mit ,täglich anecken" und aggressivem Verhalten nennt Herr Jansen demnach zusätzliche notwendige Bedingungen für den Status ,Problemschüler*innen ' und markiert, dass diese Kriterien temporär, graduell oder auch gar nicht zutreffen können (,manchmal sind nämlich Kinder mit ADHS auch ein bisschen mehr aggressiv und dann sind die schon ein Problemkind ne aber sie müssen es nicht zwingend sein“, Z. 842 f.). Zugleich kontrastieren die Kennzeichen ,täglich anecken" und aggressives Verhalten das Beispiel von dem an ADHS erkrankten Jungen, denn der Schüler wird von Herrn Jansen weder als permanent auffällig noch als besonders aggressiv dargestellt.

Grundsätzlich wird in der Passage zum subjektiven Verständnis von Problemschüler*innen und auch anhand der Einschätzung, dass der scheinbar hohe Anteil an Schüler*innen mit Migrationshintergrund nicht per se problematisch sei, die Auseinandersetzung mit in Schule wirksamen Kategorisierungen deutlich. So distanziert sich Herr Jansen von einer pauschalen, problemorientierten Fremdzuschreibung im Hinblick auf den hohen Anteil an Schüler*innen mit Migrationshintergrund sowie von dem im Interview vorgegebenen Begriff ,Problemschüler*in“. Indem er angibt, dass Schüler*innen mit ADHS aus seiner Sicht nicht notwendigerweise als Problemschüler*innen gelten, löst er die Kategorie ,Problemschüler*in“ von der Dimension ADHS. Allerdings können je nach „Schweregrad“ oder „Erscheinungsbild der Krankheit“ (Z. 835 f.) bzw. aufgrund auffälliger Aggressionen Schüler*innen mit ADHS unter die Kategorie Problemschüler*in fallen. Am Beispiel eines an ADHS erkrankten Schülers veranschaulicht Herr Jansen, dass der Status zudem keine Eigenschaft, sondern vielmehr ein temporärer Zustand bzw. eine Lebensphase sein kann und veränderbar ist. Hierbei scheint sich die potenzielle Fremdzuschreibung als Problemkind durch andere Lehrkräfte an seiner eigenen Bewertung zu reiben. Generell stellt Herr Jansen das Beispiel von dem Schüler mit ADHS in den Kontext der Argumentation zur Differenz zwischen ihm und Kolleg*innen bei der Bewertung bestimmter Fälle: Der Junge sei für ihn trotz aller Umstände kein Problemschüler, was er mit einem Prozess der Stabilisierung von Familienverhältnissen begründet. 
Hier bestätigt Herr Jansen, dass der temporäre Charakter und die unterschiedlichen Ursachen und Ausprägungen von Verhaltensproblemen bei ADHS für ihn gegen die verallgemeinerte Zuschreibung ,Problemschüler*in' sprechen.

Im Kontext des Themas Zusammenarbeit mit dem Jugendamt führt Herr Jansen das im ganzen Interview präsente Beispiel der scheinbar psychisch kranken Schülerin ein, die er auch unter die Kategorie ,Problemschüler*in“ subsumiert. Auf die Nachfrage, ob eine psychische Störung offiziell festgestellt wurde, illustriert Herr Jansen anhand der Schülerin die unmittelbaren Auswirkungen von problematischen Lebensverhältnissen und der nicht diagnostizierten psychischen Erkrankung auf Lernvoraussetzungen, das Lehrer*innen-Schüler*innen-Verhältnis sowie auf den Alltag pädagogischen Handelns:

also sie ist relativ clever ne sie fordert aber ständig ein ähm dass du bei ihr stehst am Platz (.) und nur dann macht sie was und wenn du dann weggehst und wem anders hilfst oder so dann macht sie nichts mehr und sie wohnt halt bei Oma und das ist halt offensichtlich dass sie psychisch krank ist dazu braucht man kein Psychologe sein ähm und es kommt jetzt darauf an wie Oma jetzt da vorgeht und wie das so alles ist dass sie da wirklich Unterstützung bekommt sie hat auch schon die Klasse gewechselt weil sie einfach-es war kein Unterrichten mehr in der alten Klasse möglich (.) wir haben es jetzt so weit hingekriegt dass wir ähm sie handhaben können heißt ich in Mathe und in Deutsch die Klassenlehrerin aber vom Schwimm-Schwimmunterricht musste sie jetzt ausgeschlossen werden weil sie wieder ausgerastet ist und nicht aus dem Becken kommen wollte (.) da musste der Lehrer da äh da rein springen und und und also es ist immer ein riesen Theater gerade wenn es so wirklich um Sport Schwimmen ja und jetzt ist es so die Lehrerin hat gesagt ich kann das nicht verantworten und jetzt wird sie ausgeschlossen also so weit ist es schon (.) aber wir haben keine andere Möglichkeit wir kriegen dafür keine Förderstunden weil es noch nicht diagnostiziert ist ja und wir müssen mit der Situation so irgendwie umgehen und das ist einfach unser (.) Schulrecht und wir können es nicht machen wir müssen mit dem arbeiten was wir haben (.) also ja versuchen einfühlsam zu sein also ähm ja (.) die ja die ist zum Beispiel die erste morgens äh auf dem Schulhof die am-einem am Bein hängt und aber im Unterricht ist es oft sehr sehr anstrengend mit ihr und sie ist su-auch manchmal sehr fröhlich naja und wir vermuten halt dass sie sehr darunter leidet dass sie bei ihrer Oma wohnt (.) mit je-ähm sie hat zwei Schw-Geschwister die wohnen bei der Mutter und sie darf da irgendwie nicht warum keine Ahnung [...] und die musste jetzt vorher die Klasse wechseln weil es da mit einem Kind ständig Stress gab und die haben sich förmlich geprügelt (.) aber richtig (.) da sind Stühle geflogen und alles (Fallstudie 4, Interview Herr Jansen, Z. 492-575)

Zunächst leitet Herr Jansen seine Erzählung mit einer positiven Beschreibung der Schülerin ein (,relativ clever“, Z. 492) und geht dann zu Verhaltensweisen über, die eine Herausforderung für die pädagogische Arbeit darstellen (,,sie 
fordert aber ständig ein ähm dass du bei ihr stehst am Platz (.) und nur dann macht sie was und wenn du dann weggehst und wem anders hilfst oder so dann macht sie nichts mehr“, Z. 496 ff.). Vergleichbar mit der Einführung des Beispiels des an ADHS erkrankten Schülers deutet auch hier die anfängliche positive Charakterisierung des Mädchens eine Gegenpositionierung zu einer ausschließlich problemorientierten Sichtweise seiner Kolleg*innen an. Direkt anschließend thematisiert Herr Jansen die besondere Lebenssituation der Schülerin. So lebt die Schülerin bei ihrer Großmutter, die die Rolle der Erziehungsberechtigten einzunehmen scheint (,es kommt jetzt darauf an wie Oma jetzt da vorgeht und wie das so alles ist dass sie da wirklich Unterstützung bekommt", Z. 511 f.). An späterer Stelle der Passage ergänzt Herr Jansen, dass das Mädchen womöglich darunter leide, bei der Großmutter wohnen zu müssen, wohingegen weitere Geschwister bei der Mutter leben dürfen. Herr Jansen argumentiert in Folge, dass die Schülerin aufgrund ausstehender Diagnostik nicht die notwendige schulische Förderung erhalte (,wir kriegen dafür keine Förderstunden weil es noch nicht diagnostiziert ist", Z. 538 f.). An dieser Stelle nimmt Herr Jansen Bezug auf das Verfahren zur Feststellung des sonderpädagogischen Unterstützungsbedarfs, das auf Antrag der Erziehungsberechtigten eröffnet wird. Nur in Ausnahmefällen kann die Schule nach Prüfung durch die Schulaufsicht einen Antrag stellen ${ }^{4}$. Insofern erklärt sich sein Einwand, dass es darauf ankommt, wie die Großmutter weiter vorgeht. Ähnlich wie bei dem Schüler mit ADHS erscheinen auch hier stabile Familienverhältnisse und das Engagement der Eltern bzw. Erziehungsberechtigten als Enaktierungspotenzial für das pädagogische Handeln. Mittlerweile können Herr Jansen im Mathematikunterricht und die Klassenlehrerin im Deutschunterricht das Mädchen zwar „handhaben“ (Z. 518), jedoch bleiben schulische Ordnungs- bzw. Disziplinarmaßnahmen wie ein Klassenwechsel und der Ausschluss vom Schwimmunterricht aufgrund ihres auffälligen Verhaltens nicht aus. An der Aussage ,wir müssen mit der Situation so irgendwie umgehen und das ist einfach unser (.) Schulrecht und wir können es nicht machen wir müssen mit dem arbeiten was wir haben" (Z. 543 ff.) dokumentiert sich Herr Jansens Unmut über die fehlende Unterstützung und die unbefriedigende Situation für alle Beteiligten. So versuchen Herr Jansen und seine Kollegin „einfühlsam zu sein“ (Z. 553), wenngleich

\footnotetext{
${ }^{4}$ „Auf Antrag der Eltern entscheidet die Schulaufsichtsbehörde über den Bedarf an sonderpädagogischer Unterstützung und die Förderschwerpunkte. Vorher holt sie ein sonderpädagogisches Gutachten sowie, sofern erforderlich, ein medizinisches Gutachten der unteren Gesundheitsbehörde ein und beteiligt die Eltern. Besteht ein Bedarf an sonderpädagogischer Unterstützung, schlägt sie den Eltern mit Zustimmung des Schulträgers mindestens eine allgemeine Schule vor, an der ein Angebot zum Gemeinsamen Lernen eingerichtet ist. $§ 20$ Absätze 4 und 5 bleiben unberührt.“ ( 19 Abs. 5 SchulG NRW).
} 
es im Unterricht mit ihr „oft sehr sehr anstrengend“ sei (Z. 562). Der empathische Umgang stellt demzufolge weiteres Enaktierungspotenzial für die pädagogische Arbeit mit Problemschüler*innen bereit.

Prinzipiell tritt anhand der Passage die bereits herausgearbeitete Orientierung der Abgrenzung von einer individualisierenden Defizitperspektive auf Problemschüler*innen konturierter hervor. So stellen sowohl bei dem Schüler mit ADHS als auch bei der anscheinend psychisch kranken Schülerin problematische Familienverhältnisse den negativen Gegenhorizont von Problemschüler*innen dar. Die ausstehende sonderpädagogische Diagnostik hinsichtlich der mutmaßlich psychisch kranken Schülerin belastet darüber hinaus die pädagogische Arbeit - etwa bestehe bislang kein Rechtsanspruch auf Förderstunden. Das anhaltend auffällige Verhalten und die fehlenden schulischen Unterstützungsmöglichkeiten führen letztlich zu Disziplinierungsmaßnahmen wie Klassenwechsel und Ausschluss vom Schwimmunterricht. Keine vertretbare Möglichkeit der Einflussnahme bzw. eingeschränkte Handlungsfähigkeit bilden entsprechend den negativen Gegenhorizont der pädagogischen Arbeit mit Problemschüler*innen. Im Umkehrschluss stellt die offizielle Feststellung des sonderpädagogischen Förderbedarfs neben dem Engagement der Eltern bzw. der Erziehungsberechtigten und verlässliche Familienverhältnisse sowie ein einfühlsamer Umgang der Lehrkräfte weiteres Enaktierungspotenzial für das pädagogische Handeln dar. Zusammenfassend erscheint ein grundlegender Anspruch von bestmöglicher Unterstützung und Förderung auch von sogenannten Problemschüler*innen als Kern von Herrn Jansens Orientierung.

Dieser Anspruch führt mitunter zu Widerstand gegen die Schulleitung und Elternschaft. So fordern Eltern im Zuge eines Konflikts mit einem anderen Kind den Schulverweis des scheinbar psychisch kranken Mädchens. Herr Jansens tritt erfolgreich für den Verbleib des Mädchens an der Schule ein:

mit Anna gab es viel Stress mit den einen Eltern und da war ich derjenige der sich für Anna eingesetzt hat (.) ich habe mich aber nicht gegen das andere Kind entschieden (.) ich habe mich einfach nur (.) ich sag mal (.) der Herausforderung gestellt und es kann ja nicht sein dass die Eltern uns sagen welche Kinder wir von der Schule schmeißen oder nicht dass die ähm offensichtlich ein Rad ab hat das hat jeder gecheckt (.) aber deswegen kann ich es doch als Herausforderungforderung sehen als Mathelehrer ihr irgendwie eine Chance zu ermöglichen sie mit ins Boot zu holen (.) das ging mir da so ein bisschen schnell und da wollten die Eltern die raus mobben (.) und da gab es einen Elternabend da haben die meine Kollegin fertig gemacht die hat geweint (.) die hat gesagt (.) ähm wie kann man so (.) asozial sein? nur an sich denken und ähm dieses Mädchen (.) einfach abschieben wollen (.) vor allem wo hin naja (.) und das war halt schon wirklich Hammer hart (.) und (.) da war es aber so aber ich (.) sag mal ich habe auf der Elternfront (.) 
[?habe ich keinerlei Stress?] (.) und das ist das Gute (.) selbst die (.) Eltern die da vielleicht ein bisschen mehr von mir erwartet hätten die wissen nicht wie ich in der Konferenz gestimmt habe das ist erst mal auch gut so (.) weil die vielleicht dafür erwartet hätten dass ich dafür stimme dass Anna rausfliegt (.) also wer mich genau kennt ähm der wü-äh wusste so oder so-auch mein Chef wusste da hab ich auch gesagt (.) wenn du die von der Schule schmeißen willst (.) dann mach das (.) dann sag das aber auch so wir reißen uns hier seit drei Monaten den Hintern auf für dieses Kind und es kann jetzt nicht sein ähm dass die geht ja und dann haben wir uns auch in der Konferenz-er hat sich enthalten als Schulleiter und wir haben dann (.) also wir haben die Elternvertretung bearbeitet und dann haben die das gestimmt was wir wollten (Fallstudie 4, Interview Herr Jansen, Z. 2543-2599)

Herr Jansen bezieht zunächst Stellung gegen das ,Abschieben' der vermeintlich psychisch kranken Schülerin und markiert zugleich, dass er sich hierbei ,nicht gegen das andere Kind entschieden“ (Z. 2549) habe. Vielmehr habe er sich als Mathelehrer der „Herausforderung gestellt“ (Z. 2550), dem Mädchen „irgendwie eine Chance zu ermöglichen sie mit ins Boot zu holen“" (Z. 2557). An der Argumentation dokumentiert sich, dass die Unterstützung einer verhaltensauffälligen Schülerin aus Herrn Jansens Sicht auch eine pädagogische resp. institutionelle Aufgabe für ,Regelschulehrkräfte' darstellt. Hierbei fällt die negative Zuschreibung und Etikettierung der Schülerin (,,dass die ähm offensichtlich ein Rad ab hat das hat jeder gecheckt“", Z. 2555 f.) auf. Es kommt für Herrn Jansen ferner nicht in Frage, der Forderung des Schulverweises seitens der Elternschaft nachzugeben (,es kann ja nicht sein dass die Eltern uns sagen welche Kinder wir von der Schule schmeißen“, Z. 2550 f.). Aus seinem Blickwinkel reagieren die Eltern vorschnell und unangemessen (,,das ging mir da so ein bisschen schnell und da wollten die Eltern die raus mobben (.) und da gab es einen Elternabend da haben die meine Kollegin fertig gemacht die hat geweint“, Z. 2557 ff.). Im Gegensatz zu seiner Kollegin, die die Klassenlehrerin der scheinbar psychisch kranken Schülerin ist (vgl. o. g. Passage, Z. 492-575), habe er ,,auf der Elternfront [...] keinerlei Stress “ (Z. 2570). Etwa wissen die Eltern nicht, dass er auf der Klassenkonferenz für das Bleiben des Mädchens auf der Schule gestimmt habe. Es deutet sich an, dass eine reibungslose Zusammenarbeit mit den Eltern relevant für die pädagogische Arbeit ist, wobei die Formulierung „Elternfront“ (Z. 2570) eine Grenzziehung zwischen den Eltern und den Lehrkräften impliziert. Zwar kritisiert Herr Jansen die Erwartungshaltung bestimmter Eltern, löst aber innerhalb der entscheidenden Schulkonferenz die Interessenskonflikte strategisch auf (,,selbst die (.) Eltern die da vielleicht ein bisschen mehr von mir erwartet hätten die wissen nicht wie ich in der Konferenz gestimmt habe das ist erst mal auch gut so“, Z. 2572 f.). Bei einem Gespräch mit dem Schulleiter über die Auseinandersetzungen mit den 
Eltern führt Herr Jansen die harte Arbeit an dem Mädchen als Argument für ihr Bleiben an (,wir reißen uns hier seit drei Monaten den Hintern auf für dieses Kind und es kann jetzt nicht sein ähm dass die geht“", Z. 2585 f.). Insgesamt zeigt sich, dass Herr Jansen eine Haltung vertritt, der zufolge ein offensichtlich und auf unbestimmte Zeit schwieriges Kind und der entsprechende Einsatz der Lehrkräfte Gründe für eine gemeinsame Beschulung sind. Dadurch, dass die Eltern unwissend hinsichtlich seines Wahlverhalten sind, enttäuscht Herr Jansen darüber hinaus keine Erwartungen. Letztlich setzt Herr Jansen seine Forderung durch, ohne die Gunst der Eltern einzubüßen ("wir haben dann (.) also wir haben die Elternvertretung bearbeitet und dann haben die das gestimmt was wir wollten", Z. 2594 ff.). Hieran dokumentiert sich, dass Herr Jansen grundsätzlich solidarisch handelt und bemüht ist, möglichst einvernehmlich Verantwortung für sogenannte Problemschüler*innen zu übernehmen.

Aus Sicht von Herrn Jansen gibt es aber auch Fälle, in denen eine gemeinsame Beschulung nicht tragbar ist. Im Zusammenhang des Themas Bewilligung von Förderstunden von Schüler*innen mit sonderpädagogischem Unterstützungsbedarf befürwortet Herr Jansen anhand des Beispiels eines offensichtlich autistischen Schülers das besondere Setting einer Förderschule und begründet, dass unter inadäquaten Bedingungen die gemeinsame Beschulung an allgemeinbildenden Schulen zu Diskriminierung führt:

wir haben scheinbar einen Autisten aber die Eltern lassen das schleifen (.) gilt aber nicht als Inklusionskind ne zählt nicht doppelt und gar nichts (.) ist in normalen Klassen (.) malt Rechenaufgaben an die Wand ne (.) und (.) dieses Kind ich weiß nicht woran es liegt wirklich kann auch an unserer Schulleitung liegen auf jeden Fall dieses Kind kann bei uns nicht beschult werden (.) nur mit einem Einzelfallhelfer (.) den Einzelfallhelfer bekommen wir nicht frag mich nicht warum (.) ich weiß nicht ob es an unserer Schulleitung liegt oder an den Eltern dass die da irgendwas schleifen lassen auf jeden Fall (.) ähm ist es (.) nicht (.) also wir können es nicht wir können es nicht und natürlich kann man es nicht (.) ganz ehrlich das wäre jemand für eine Förderschule in Kl-(.) wo zwölf dreizehn Kinder sind ne und der hat sowas von einen am Sender dass man- das geht in Richtung Diskriminierung (.) und da sprechen wir nicht mehr von (.) ähm (.) da sprechen wir nicht mehr von Inklusion sondern wir gehen da richtig von Menschenrechtsverletzung aus und wir können nichts dagegen machen wir müssen das machen wir müssen den auf den Schulhof schicken und dann wird er gehänselt und wir können nichts dagegen machen der läuft durch die Gegend tutut Mama mach mal Platz tutut tutut völlig abgedreht ne und wir müssen den beschulen der hat (.) also (.) es ist unglaublich was da (.) gerade ab geht und (.) dann heißt es (.) also das hat schon nichts mehr mit Chancengleichheit zu tun ähm das ist Diskriminierung und (.) wir diskriminieren ihn weil wir es machen müssen weil das unser Schulrecht ist (Fallstudie 4, Interview Herr Jansen, Z. 1623-1664) 
Auch im Fall des vermeintlich autistischen Jungens scheint noch keine sonderpädagogische Diagnostik erfolgt zu sein, sodass er nicht offiziell als „Inklusionskind“ (Z. 1628) gilt und ,in normalen Klassen“ (Z. 1629) unterrichtet wird. Herr Jansen markiert deutlich, dass eine gemeinsame Beschulung unter diesen Voraussetzungen nicht möglich sei (,,malt Rechenaufgaben an die Wand“, Z. 1629 f.) und das gemeinsame Lernen nur mit Unterstützung durch eine Einzelfallhilfe gewährleistet werden könne. Analog zu der Beschreibung des scheinbar psychisch kranken Mädchens ist auch hier eine negative Wertung und Kategorisierung des Jungen (,der hat sowas von einen am Sender“, Z. 1655) auffällig. Ein Rechtsanspruch auf pädagogische Hilfe besteht in diesem Fall, genau wie Förderstunden, ausschließlich bei anerkannten sonderpädagogischen Unterstützungsbedarf. Nach Meinung von Herrn Jansen sind entweder die Eltern oder die Schulleitung nachlässig hinsichtlich der Feststellung des sonderpädagogischen Unterstützungsbedarfs (,,ich weiß nicht ob es an unserer Schulleitung liegt oder an den Eltern dass die da irgendwas schleifen lassen“, Z. 1634 f.). Eine Förderschule würde ihm zufolge bessere Rahmenbedingungen bieten (,ganz ehrlich das wäre jemand für eine Förderschule in Kl-(.) wo zwölf dreizehn Kinder sind“, Z. 1643 f.). Angesichts mangelnder pädagogischer Unterstützung von außen und ausgeprägten Verhaltensauffälligkeiten (,,der läuft durch die Gegend tutut Mama mach mal Platz tutut tutut völlig abgedreht", Z. 1653) führt die gemeinsame Beschulung aus Sicht von Herrn Jansen zu schulischer Diskriminierung und stellt eine „Menschenrechtsverletzung“ (Z. 1650) dar. An der Aussage ,wir können nichts dagegen machen wir

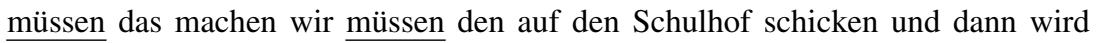
er gehänselt und wir können nichts dagegen machen“ (Z. 1651 f.) dokumentiert sich zum einen, dass dem scheinbar autistischen Jungen Diskriminierungserfahrungen zu ersparen sind. Zum anderen kritisiert Herr Jansen hierbei die fehlende Handhabe seitens der Schule, um gegen die widrigen Verhältnisse in der allgemeinbildenden Schule anzugehen. Herr Jansen legt schlussendlich sehr explizit dar, dass die Schule wider Willen zur Diskriminierung gezwungen sei (,wir diskriminieren ihn weil wir es machen müssen weil das unser Schulrecht ist", Z. 1663 f.).

Die Passage zusammenfassend kann festgehalten werden, dass das gefährdete Wohlergehen des wahrscheinlich autistischen Jungens ausschlaggebend für Herrn Jansens fallweise Ablehnung einer gemeinsamen Beschulung ist. So beeinträchtigt aus seiner Perspektive die mangelnde pädagogische Unterstützung aufgrund ausstehender sonderpädagogischer Diagnostik die Lernbedingungen für den Schüler. Letztlich führen die unzureichenden Möglichkeiten und Rahmenbedingungen an der allgemeinbildenden Schule zu Diskriminierung. Die schulische Ausgrenzung des Jungen markiert zugleich den negativen Gegenhorizont seines Anspruchs, alle 
Kinder bestmöglich zu unterstützen und zu fördern, so dass unter diesem Blickwinkel die Sonderbeschulung als geringerer Nachteil für den Jungen erscheint. Im Mittelpunkt von Herrn Jansen Argumentation stehen demnach Fragen der pädagogischen Bearbeitbarkeit und Realisierbarkeit von gemeinsamem Lernen. Ein weiteres Kriterium, welches den grundlegenden Anspruch von optimaler Unterstützung aller Schüler*innen eingrenzt, ist die Trennung zwischen temporärem und dauerhaftem hohen sonderpädagogischen Förderbedarf. An diesem Unterscheidungsmerkmal platziert Herr Jansen auch den Begriff Problemschüler*in. So scheint der offenkundig autistische Junge im Gegensatz zu dem anscheinend psychisch kranken Mädchen und dem Jungen mit ADHS anhaltend schwere Verhaltensauffälligkeiten aufzuweisen, die von den ,Regelschullehrkräften “ nicht handhabbar sind. Die vermeintliche Entwicklungsstörung scheint auch nicht in Verbindung mit besonderen Lebensumständen $\mathrm{zu}$ stehen, zumindest thematisiert Herr Jansen abweichend von den beiden anderen exemplarisch angeführten Problemschüler*innen nicht die Familienverhältnisse des Jungen.

\title{
3.6.2 Berufsbezogenes Selbstkonzept
}

Im Hinblick auf eine Schüler*innenschaft mit ganz unterschiedlichen Bedürfnissen legt Herr Jansen im Kontext der Interviewfrage nach schulischen Richtlinien für den Umgang mit verhaltensauffälligen Schüler*innen dar, dass es sich hierbei um einen fortwährenden Lern- und Entwicklungsprozess für Lehrkräfte handelt:

\begin{abstract}
das ist einfach learning by doing und ähm da haben wir (.) es gibt sicherlich Kollegen die: wenn man damit nicht zufällig irgendwelche Berührungspunkte hat dass das denen gar nicht so auffällt (.) oft haben (.) also (.) was mein Eindruck ist viele haben heutzutage ADHS und ich hab zum Beispiel (.) eins dieser Kinder war sehr aggressiv und hat andere geschlagen und hier und da (.) und da haben viele gesagt ähm oh hat der ADHS oder so (.) und im Endeffekt hat sich nach zwei Jahren herausgestellt dass der tatsächlich diese Wahrnehmungsstörung hat und deswegen höchstwahrscheinlich so oft überreagiert hat weil oft einfach vieles nicht bei ihm angekommen ist so und ähm das wäre dann so erst mal Verhaltensauffälligkeit (.) oder wenn die Kinder (.) oft mit dem Kopf hin und her sie wissen nicht genau wo sie hingucken sollen das sind halt alles so Dinge die müssen wir aber lernen (.) durch ähm einfach private Weiterbildung und sonst was ob man liest oder zufällig gerade mit einer guten Kollegin da in einer Klasse zusammenarbeitet oder oder oder (Fallstudie 4, Interview Herr Jansen, Z. 293-326)
\end{abstract}

Insgesamt beschreibt Herr Jansen, dass Ursachen und Symptome von Verhaltensauffälligkeiten von einigen Kolleg*innen zum Teil gar nicht erst wahrgenommen 
bzw. fehlgedeutet werden. So wurde das aggressive Verhalten eines Schülers zunächst als Anzeichen für ADHS interpretiert, bis sich zwei Jahre später herausstellte, dass der Junge an einer Wahrnehmungsstörung leidet, die mitunter zur Überreaktion führt. Den Lehrkräften fehlen aus seiner Sicht diagnostische Kompetenzen und Fachwissen, welches eher zufällig aufgegriffen bzw. im Laufe der Praxis erworben wird. Missdeutungen aufgrund unzureichenden Wissens über Verhaltensauffälligkeiten erscheinen demgemäß als negativer Horizont für die pädagogische Arbeit. Der Lern- und Entwicklungsprozess, in dem sich Lehrkräfte systematisch diagnostische Kompetenzen und Fachwissen zu Ursachen und Symptomen von Verhaltensauffälligkeiten aneignen, bildet entsprechend das Enaktierungspotenzial für den Umgang mit diesen Kindern. Darüber hinaus mobilisiert Herr Jansen im Wechselspiel mit zunehmender Berufserfahrung externe Fachkräfte zur Unterstützung im Umgang mit hör- und kommunikationsgeschädigten Kindern. Beispielsweise kontaktiert Herr Jansen bei Verdacht auf eine Wahrnehmungsstörung ein Beratungs- und Förderzentrum für Hörgeschädigte und veranlasst, dass eine Mitarbeiterin zur Begutachtung des Kindes in seinen Unterricht kommt: ,die ist die Expertin die guckt dann ob ähm diese Symptome da sind und dann verfolgt sie das weiter (.) dann wir er durchgecheckt also ich kann ja nur (.) ähm ich kann mir dann quasi die Hilfe holen die war schon bei mir im Unterricht und die würde auch wiederkommen“ (Z. 275 ff.). Die Zuhilfenahme externer Unterstützungsangebote stellt folglich weiteres Enaktierungspotenzial für den Umgang mit verhaltensauffälligen Kindern dar.

Zur Entwicklung von Handlungssicherheit im Umgang mit verhaltensauffälligen Kindern gehören des Weiteren Angewohnheiten praktischer Empathie. Etwa stellt Herr Jansen im Kontext der Frage nach sozialen Kompetenzen von Lehrkräften sein Bemühen heraus, die Perspektiven der Kinder einzunehmen:

ja Sozialkompetenzen von Lehrkräften wie gehe ich auf meine einzelnen Individuen ein ne wie schaffe ich es (.) ich sag immer ähm ich kann meinen Job nur richtig machen also das ist so ein Motto von mir ne die Welt mit Kinderaugen sehen (.) halt sich in die ver-in die Lage des Gegenübers hineinzuversetzen wenn jemand jetzt ausrastet (.) was könnte ihn geritten haben um jetzt so zu reagieren? mm naja ok (.) ne das liegt dann wirklich-also ich mache es dann immer an Beispielenalso ist ja jetzt so ne viel mache ich an Beispielen der Kinder fest das jetzt zum Beispiel dieses eine Inklusionskind habe ich kurz (.) vertreten in der Halle war es natürlich ein bisschen laut und da hat ihr Hörgerät ihr Knopf im Ohr irgendwie überfrequentiert sie ist einfach stehen geblieben und hat ganz schrill geschrien aber ganz laut (.) ne und das sind dann so soziale Kompetenzen die kann man auch nicht richtig lernen nur durch Erfahrungswerte und so (.) was habe ich gemacht? ich habe die Kinder in die Kabine geschickt und ich hab sie mir genommen und sie versucht zu beruhigen ne und dann hab ihr dieses Ding da aus dem Ohr-aus 
dem Ohr genommen so (.) so das ging dann auch aber man muss immer so (.) ja soziale Kompetenzen von Lehrkräften man muss halt immer von Fall zu Fall und ich sag immer in die La-(.) man müsste sich mal in die Lage des Gegenübers hineinversetzen (.) so und wenn ich ein (.) superlautes Fiepen auf dem Ohr hätte dann würde ich auch ganz anders reagieren und auch ganz anders reden als wenn ich jetzt hier so mit dir ganz normal spreche (Fallstudie 4, Interview Herr Jansen, Z. 1948-1994)

Aus Sicht von Herrn Jansen zählt zu den Sozialkompetenzen von Lehrkräften die Fähigkeit, sich ,in die Lage des Gegenübers hineinzuversetzen“ (Z. 1958 f.). Sein Leitspruch ist hierbei „die Welt mit Kinderaugen sehen“ (Z. 1958). Dazu gehört für ihn, die Ursachen für auffälliges Verhalten zu ermitteln (,was könnte ihn geritten haben um jetzt so zu reagieren?", Z. 1959 f.). Hierbei illustriert Herr Jansen am Beispiel eines ,Inklusionskind[es]“ (Z. 1969) die bedeutsame Rolle der Perspektivenübernahme für den Umgang mit verhaltensauffälligen Kindern. Nach seiner Schilderung verliert das Mädchen aufgrund eines lauten Pfeifens des Hörgeräts die Beherrschung (,,in der Halle war es natürlich ein bisschen laut und da hat ihr Hörgerät ihr Knopf im Ohr irgendwie überfrequentiert sie ist einfach stehen geblieben und hat ganz schrill geschrien aber ganz laut", Z. 1970 ff.). Herr Jansen kann die Reaktion der hörgeschädigten Schülerin empathisch nachvollziehen und zeigt Verständnis für ihre Situation (,,wenn ich ein (.) superlautes Fiepen auf dem Ohr hätte dann würde ich auch ganz anders reagieren und auch ganz anders reden als wenn ich jetzt hier so mit dir ganz normal spreche“, Z. 1992 ff.). Die Fähigkeit zur Perspektivenübernahme erscheint folglich als Enaktierungspotenzial für den Umgang mit verhaltensauffälligen Kindern.

Ein weiteres wichtiges Element seiner pädagogischen Arbeit ist, wie bereits in der Dimension Konstruktion der Schüler*innen- und Elternklientel angedeutet, die Gestaltung einer gelingenden Zusammenarbeit mit den Eltern:

generell denke ich muss man sich die Elternfront immer schön frei haben ähm halten weil ich sag mal wenn ich das Vertrauen der Eltern verliere oder wenn sie denken ich bin ein Idiot mit dem was er sagt dann hab ich eigentlich gar keine Chance (.) das heißt egal wie (.) doof in meinen Augen die Eltern sind ähm bringt es nichts die dann irgendwie anzumotzen oder so wenn sie jetzt was weiß ich offensichtlich irgendwelche komischen Sachen machen (.) keine Schulhefte kaufen oder oder oder dann versuch ich halt immer möglichst nett und freundlich zu sein egal wie mich die Situation gerade aufregt ähm weil ich sonst nichts erreichen kann für die Kinder das ist wirklich so (Fallstudie 4, Interview Herr Jansen, Z. 733-751)

Ohne detaillierte Interpretation kann eine gelingende Zusammenarbeit mit den Eltern als Enaktierungspotenzial für das pädagogische Handeln herausgearbeitet 
werden: Aus dieser Perspektive kann Herr Jansen für die Kinder nur etwas erreichen, wenn die Kooperation mit den Eltern möglichst problemlos verläuft und auf Vertrauen basiert. Indem er Schuldzuweisungen und Vorwürfe an die Eltern vermeidet und die eigene Meinung in den Hintergrund stellt, schafft Herr Jansen die Basis einer konstruktiven Kommunikation (,das heißt egal wie (.) doof in meinen Augen die Eltern sind ähm bringt es nichts die dann irgendwie anzumotzen [...] dann versuch ich halt immer möglichst nett und freundlich $\mathrm{zu}$ sein egal wie mich die Situation gerade aufregt"; Z. 739 ff.). Bemerkenswert ist hierbei die erneute Formulierung „Elternfront“ (Z.), die eine Abgrenzung der Eltern gegenüber den Lehrkräften nahelegt.

Neben der Ausbildung von Handlungskompetenzen bezüglich des Umgangs mit verhaltensauffälligen Schüler*innen gehört zu seinem beruflichen Selbstbild auch die „Leistungsspitze“ (Z. 1870) der Klasse zu fördern. So legt Herr Jansen im Zusammenhang des Themas Weiterbildungsbedarf dar, dass er nicht nur den leistungsschwächeren, sondern auch den leistungsstärkeren Schüler*innen erfolgreiches schulisches Lernen ermöglicht:

es geht immer nur darum irgendwie die Schwächeren mit ins Boot zu holen und die noch mit aufzufangen und die noch mit aufzufangen und (.) ich nehme mir zum Beispiel auch bewusst für Einserschüler Zeit und mache mit denen Knobelaufgaben weil die haben das gleiche Recht für mich (.) auf mich als (.) Lehrer wie das Kind mit ADHS und das bekommt sowieso schon viel mehr Aufmerksamkeit als die anderen (.) und dann muss ich finde ich um meinen Job richtig zu machen als Lehrer immer dran denken dass die Guten ja auch noch da sind und dass ich auch mal bei denen bin (.) und ähm da besteht eine riesen Gefahr was ich auch weiß von Kollegen ähm die sind am Machen und am Tun super bemüht aber immer nur mit den ganzen Schwächeren ne [...] ja das kann ja auch (.) ähm durchaus eine aber Chancengleichheit heißt für mich auch an die anderen zu denken (.) und das passiert überhaupt nicht in der Bildungspolitik nirgendwo an keiner Stelle (Fallstudie 4, Interview Herr Jansen, Z. 1902-1925)

Inhaltlicher Rahmen seiner Argumentation ist die Kritik an die Bildungspolitik, die Gruppe der leistungsstärkeren Schüler*innen zu Gunsten der leistungsschwächeren Schüler*innen zu vernachlässigen. Diese Ansicht stellt zugleich seinen negativen Gegenhorizont von individueller Förderung aller Schüler*innen dar. Aus Herrn Jansens Perspektive müssen auch die leistungsstarken Schüler*innen gezielt gefordert werden, etwa nimmt er sich ,,bewusst für Einserschüler Zeit und mach[t] mit denen Knobelaufgaben“ (Z. 1904 f.). Als Begründung hierzu führt er an, dass die leistungsstärkeren Schüler*innen ,das gleiche Recht“ (Z. 1905) auf ihn als Lehrer haben wie die leistungsschwächeren Schüler*innen und er seinen Beruf nur ordnungsgemäß ausüben kann, wenn er auch die Leistungsstarken im 
Blick habe. Insgesamt erscheint die konsequente Verwirklichung der individuellen und bestmöglichen Förderung aller Schüler*innen als Orientierungsrahmen seiner pädagogischen Praxis.

\subsubsection{Auseinandersetzung mit Spannungsfeldern der pädagogischen Arbeit}

Wie bereits in den vorangegangenen Dimensionen herausgearbeitet, interpretiert Herr Jansen seine pädagogische Aufgabe ganz praktisch als möglichst weitgehende Unterstützung und Förderung aller Schüler*innen. Am Beispiel eines scheinbar autistischen Jungens stellt Herr Jansen jedoch auch dar, dass die gemeinsame Beschulung in der aktuellen Praxis dazu führen kann, dass bestimmte Schüler*innen an allgemeinbildenden Schulen keine angemessene Förderung erhalten (,,dieses Kind kann bei uns nicht beschult werden (.) nur mit einem Einzelfallhelfer (.) den Einzelfallhelfer bekommen wir nicht“, Z. 1635) und von anderen Kindern verspottet werden (,wir müssen den auf den Schulhof schicken und dann wird er gehänselt und wir können nichts dagegen machen“, Z. 1651 f.). Aus seiner Sicht führt in so einem Fall die gemeinsame Beschulung nicht zu Chancengleichheit, sondern zu schulischer Diskriminierung (vgl. 3.6.1 Konstruktion der Schüler*innen- und Elternklientel).

Eine gemeinsame Beschulung erfordere ihm nach ein tiefgreifendes Umdenken und eine Neugestaltung des Schulsystems. Ein zentraler Kritikpunkt betrifft die Entscheidung über den sonderpädagogischen Förderbedarf:

ja ich weiß ja auch nicht ob es am Dezernenten liegt oder am Gesetz weil letztendlich ist er ja der Paragraphenreiter der sich nur (.) an die Vorgaben hält ne wo ich sage oh Gott zum Glück muss ich mich nicht an solche Vorgaben halten das ist ja echt (.) schlimm also diesen Job könnte ich nicht machen ne (.) er entscheidet halt knallhart über dieses Kind kriegt Förderstunden dieses Kind nicht (.) ohne das Kind zu kennen (.) nur weil er sich an irgendeinem Paragraphen langhangelt also das geht für mich gar nicht was da los ist wirklich (Fallstudie 4, Interview Herr Jansen, Z. 1586-1600)

Zusammenfassend erscheint eine pedantische Vorgehensweise, die sich ausschließlich nach Vorgaben und Gesetzen richtet ohne den Einzelfall zu berücksichtigen, als negativer Gegenhorizont einer gemeinsamen Beschulung.

Im Widerspruch zu seiner handlungsleitenden Orientierung, möglichst alle Schüler*innen zu unterstützen und zu fördern steht auch, dass der scheinbar 
autistische Schüler mitunter nicht im Klassenverband unterrichtet werden kann, sondern von der Förderschullehrerin einzelbeschult wird:

aber dass wir ihn auch teilweise in die anderen Klassen nicht sch-schicken können oder dass es teilweise nicht mehr ging selbst mit der Förderschullehrerin (.) ähm die hat ihn dann einzeln beschult das kann doch nicht sein dass Inklusion heißt sie nimmt ihn aus dem Unterricht raus und beschult ihn einzeln der kann gleich auf eine Förderschule gehen und in eine Gruppe integriert werden aber in eine kleinere oder so aber also es-es läuft hier überhaupt nicht (Fallstudie 4, Interview Herr Jansen, Z. 1705-1717)

Aus der Perspektive von Herrn Jansen kann „Inklusion“ (Z. 1707) nicht bedeuten, Schüler*innen aus dem Unterricht herauszunehmen und einzeln zu beschulen. Im Hinblick auf derartige unpassende Bildungsangebote, die weder das Wohlbefinden noch die Lern- und Leistungsentwicklung der Kinder stärken, wären diese Schüler*innen aufgrund adäquater Rahmenbedingungen auf einer Förderschule besser aufgehoben (,der kann gleich auf eine Förderschule gehen und in eine Gruppe integriert werden aber in eine kleinere“, Z. 1712 ff.) Die Ausgrenzung einzelner Kinder stellt demnach den negativen Gegenhorizont seines Inklusionsverständnisses dar.

\subsubsection{Positionierung innerhalb der Schule bzw. im Kollegium}

Im gesamten Interview wird deutlich, dass Herr Jansen seine pädagogische Praxis prinzipiell an dem Anspruch von weitestgehender Unterstützung und Förderung aller Schüler*innen orientiert und Möglichkeiten für Teilhabe zu eröffnen versucht. Dieses pädagogische Ideal umfasst zum einen die Distanznahme von einer generellen, problemorientierten Sichtweise auf vermeintlich schwierige Schüler*innen. Hierbei grenzt sich Herr Jansen von negativen Stereotypen anderer Lehrkräfte ab und entfaltet zugleich ein differenziertes Verständnis von sogenannten Problemschüler*innen. Zum anderen setzt er sich aktiv für unterstützungsbedürftige und als problematisch geltende Schüler*innen ein und leistet in diesem Kontext Widerstand gegen Schulleitung und Elternschaft. Als Teil einer scheinbar kleinen Minderheit im Kollegium handelt Herr Jansen zugunsten des Verbleibs eines mutmaßlich psychisch kranken Mädchens, wobei eine möglichst konfliktfreie Kommunikation mit allen beteiligten Akteuren (Eltern, Kinder, Kollegium, Schulleitung) aus Sicht von Herr Jansen ausschlaggebend für eine gemeinsame Beschulung ist (vgl. 3.6.1 Konstruktion der Schüler*innen- und Elternklientel). 
Für Herrn Jansen stehen grundsätzlich bestmögliche Lernbedingungen im Vordergrund seiner pädagogischen Arbeit. Dies betrifft nicht nur verhaltensauffällige und leistungsschwächere Schüler*innen, sondern auch leistungsstärkere Schüler*innen, die er individuell herauszufordern versucht. Unter das pädagogische Selbstverständnis, allen Schüler*innen optimale Lernbedingungen zu ermöglichen, kann auch die fallweise Ablehnung der gemeinsamen Beschulung eines scheinbar autistischen Jungen verortet werden. So entsprechen die inadäquaten Bedingungen an der Grundschule nicht seinem Verständnis von Inklusion, sondern führen aus der Perspektive von Herrn Jansen vielmehr zu Diskriminierung des Jungens (vgl. 3.6.1 Konstruktion der Schüler*innen- und Elternklientel; 3.6.3 Auseinandersetzung mit Spannungsfeldern der pädagogischen Arbeit).

Insgesamt spiegelt sich in den Bezugnahmen und Darstellungen zur Unterstützung und Förderung möglichst aller Schüler*innen das persönliche Engagement und die hohe Eigeninitiative von Herrn Jansen wider. Das pädagogische Handeln scheint hierbei die gesamte Schule zu betreffen. Etwa verdeutlicht er, dass das gemeinsame Unterrichten von Schüler*innen mit zum Lern- und Entwicklungsprozess eines jeden Lehrers bzw. einer jeden Lehrerin gehört. Im Zuge dessen nutzt er alle Optionen schulinterner und schulexterner Kooperationen und gestaltet selbst die Zusammenarbeit mit anderen Professionen. Überdies formuliert er im Interview Forderungen an andere Beteiligte - auch gegenüber der Schulleitung - und leistet Überzeugungsarbeit, wenn es der Unterstützung schwieriger Kinder dient. Seine eigene Position zugunsten einer Anpassung an die Mehrheitsmeinung der Elternschaft aufzugeben, stellt für Herrn Jansen offenbar keine Option dar.

\subsubsection{Zuschreibung von Verantwortung für Bildungschancen}

Aus den unternommenen Rekonstruktionen wird deutlich, dass Herr Jansen grundsätzlich für die Herstellung gleicher Bildungschancen Verantwortung übernimmt und aktiv an der Entwicklung von Chancengleichheit arbeitet. Etwa tritt Herr Jansen erfolgreich für den Verbleib der vermeintlich psychisch kranken Schülerin an der Schule ein und sieht es als pädagogische „Herausforderung“ (Z. 2556) an, ihr Teilhabe im Zusammenhang von Schule und Unterricht zu ermöglichen. Am Beispiel eines wahrscheinlich autistischen Schülers markiert Herr Jansen aber auch, dass unangemessene Rahmenbedingungen aus seiner Sicht nicht zu Chancengleichheit, sondern im Gegenteil zu Diskriminierung führen können (vgl. 3.6.1 Konstruktion der Schüler*innen- und Elternklientel). 
An die Frage nach der schulischen Verantwortung für die Kompensation scheinbarer familialer Probleme schließt Herr Jansen eine Argumentation zu Grenzen des pädagogischen Handelns an:

ja schon (.) das gehört nun mal dazu also das ist immer schwierig ne (.) also man muss halt noch den Cut finden immer dann- dass man auch zum Unterrichten kommt man kann da nicht hier den (.) ähm ich verbessere die Welt (.) das geht halt auch nicht ne wir müssen mit dem arbeiten was wir da haben (.) und also wer als Lehrer denkt ich kann jetzt die Welt verbessern (.) also fü-jeden Tag ein ganz ganz kleines Stückchen aber ich kann die Gesellschaft nicht ändern ich kann (.) ich kann einen ganz kleinen Teil bei mir in der Klasse beitragen aber (.) ähm ich kann ja die Gesellschaft und die Eltern nicht verändern (Fallstudie 4, Interview Herr Jansen, Z. 2489-2507)

Unter dem Vorbehalt, dass auch die Vermittlung von Unterrichtsinhalten stattfinden muss, bestätigt Herr Jansen prinzipiell die Zuständigkeit der Schule. Die Vorstellung, mit der pädagogischen Arbeit „die Welt verbessern“ (Z. 2500) zu können, schätzt Herr Jansen als unrealistisch ein. Weder die Gesellschaft noch die Eltern seien veränderbar. Aus seinem Blickwinkel müssen sich Lehrkräfte vielmehr mit den vorliegenden Gegebenheiten auseinandersetzen (,wir müssen mit dem arbeiten was wir da haben“, Z. 2499) und können somit einen ,ganz kleinen Teil“ (Z. 2505) zur Kompensation vermeintlich familialer Probleme auf Klassenebene beitragen. Hieran dokumentiert sich, dass Herr Jansen die Herstellung von gleichen Bildungschancen als eine gesamtgesellschaftliche Aufgabe begreift - Lehrkräfte resp. Schule eingeschlossen.

\subsubsection{Gefahren und Fallstricke der handlungsleitenden Orientierungen}

Herr Jansen startet seine berufliche Laufbahn in einer Phase der praktischen Einführung des Förderschwerpunktes Hören und Kommunikation in einer allgemeinbildenden Schule. Die gemeinsame Beschulung stellt aus seiner Perspektive einen lehrkraftseitigen Lern- und Entwicklungsprozess im Hinblick auf den pädagogischen Umgang mit Schüler*innen mit verschiedenen Bedürfnissen sowie der Gestaltung von Lehr-Lern-Prozessen dar. In diesem Sinn arbeitet Herr Jansen aktiv an einer schulinternen Kooperation und bezieht darüber hinaus externe Einrichtungen und Akteure in sein pädagogisches Handeln mit ein. Ausschlaggebend für die Umsetzung einer gemeinsamen Beschulung ist für ihn eine möglichst konfliktfreie Kommunikation aller an Schule Beteiligten sowie eine 
gemeinsame pädagogische Strategie im Kollegium. In den Bezugnahmen auf die Schüler*innenklientel kommt zum Ausdruck, dass Herr Jansen grundsätzlich gegen Ausgrenzung ist und möglichst allen Kindern einen gleichberechtigten Zugang zu Angeboten des Unterrichts und des Schullebens zu eröffnen versucht. Unter diese Zielvorstellung kann auch die kritische Haltung gegenüber der gemeinsamen Beschulung des offensichtlich autistischen Jungens gefasst werden: Aus Sicht von Herrn Jansen sind dem Schüler Diskriminierungserfahrungen infolge inadäquater institutioneller Strukturen an allgemeinbildenden Schulen zu ersparen.

Herr Jansen verwendet an mehreren Stellen im Interview explizit den Begriff ,Inklusion'. Es ist jedoch kritisch zu hinterfragen, welches Verständnis von Inklusion den Darstellungen von Herrn Jansen zugrunde liegt. So bleibt zum einen unklar, welche Schüler*innengruppen Herr Jansen im Rahmen seines Inklusionsverständnisses adressiert. Im Mittelpunkt seiner Darstellungen stehen Kinder mit diagnostiziertem sonderpädagogischen Förderbedarf sowie Kinder mit Verhaltensauffälligkeiten. Weitere Aspekte, die bei Schüler*innen zu unterschiedlichen Lernvoraussetzungen und Entwicklungsbedingungen in der Schule sowie zu einem erhöhten Risiko für eine schulische Ungleichbehandlung führen können, wie zum Beispiel die ethnische, kulturelle und soziale Herkunft, aber auch Interessen, Motivation und Leistungsfähigkeit werden kaum thematisiert. Insbesondere vor dem Hintergrund, dass ein überdurchschnittlich hoher Anteil an Schüler*innen mit Migrationshintergrund an der Schule vertreten ist, ist bemerkenswert, dass Herr Jansen keinen Bezug auf Vielfalt von Sprachen, biografische Erfahrungen sowie Lebensentwürfe, unterschiedliche aufenthaltsrechtliche Bedingungen, religiöse Orientierungen u. v. m. nimmt. Neben der unterbelichteten Thematisierung der Verschiedenheit der Schüler*innen fallen überdies die negative Wertung und Stereotypisierung des scheinbar psychisch kranken Mädchens (,,dass die ähm offensichtlich ein Rad ab hat das hat jeder gecheckt“, Z. 2555 f.) und des mutmaßlich autistischen Schülers (,der hat sowas von einen am Sender“, Z. 1655) auf. Die abwertende Charakterisierung der beiden Schüler*innen steht im Widerspruch zu den wesentlichen Prinzipien inklusiver Pädagogik: Akzeptanz des Andersseins und Wertschätzung von Vielfalt. Die Bezugnahmen auf das anscheinend psychisch kranke Mädchen und den autistischen Jungen dokumentieren ferner, dass aus der Perspektive von Herrn Jansen nicht alle Kinder von vornherein selbstverständlich dazugehören und die Verschiedenheit der Schüler*innen als Normalität begriffen wird. Vielmehr differenziert Herr Jansen zwischen unterschiedlichen Schüler*innengruppen, die entweder in allgemeinbildenden Schulen ,integrierbar ${ }^{*}$ sind und teilnehmen dürfen (wie z. B. das psychisch kranke Mädchen), oder die in allgemeinbildenden Schulen (noch) nicht, integrierbar' sind und sonderbeschult werden müssen (wie z. B. der autistische Junge). 
Open Access Dieses Kapitel wird unter der Creative Commons Namensnennung 4.0 International Lizenz (http://creativecommons.org/licenses/by/4.0/deed.de) veröffentlicht, welche die Nutzung, Vervielfältigung, Bearbeitung, Verbreitung und Wiedergabe in jeglichem Medium und Format erlaubt, sofern Sie den/die ursprünglichen Autor(en) und die Quelle ordnungsgemäß nennen, einen Link zur Creative Commons Lizenz beifügen und angeben, ob Änderungen vorgenommen wurden.

Die in diesem Kapitel enthaltenen Bilder und sonstiges Drittmaterial unterliegen ebenfalls der genannten Creative Commons Lizenz, sofern sich aus der Abbildungslegende nichts anderes ergibt. Sofern das betreffende Material nicht unter der genannten Creative Commons Lizenz steht und die betreffende Handlung nicht nach gesetzlichen Vorschriften erlaubt ist, ist für die oben aufgeführten Weiterverwendungen des Materials die Einwilligung des jeweiligen Rechteinhabers einzuholen.

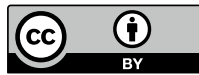

